\title{
Septiembre 2018
}

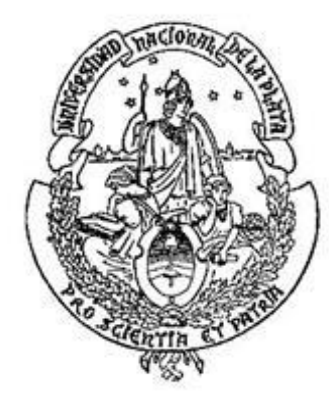

Universidad Nacional de LA PLATA

Facultad de Odontología

Carrera de Especialización en Ortodoncia

\section{Determinación de \\ la clase dentaria a nivel del primer molar en pacientes con deglución atípica}

AUTOR

Walter Acebal

DIRECTOR

Dra. Marta Rimoldi

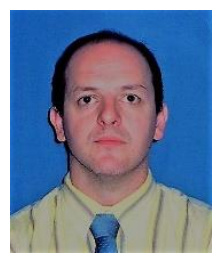


Universidad Nacional de La Plata

Facultad de Odontología

Carrera de Especialización en Ortodoncia

Tesis de Magíster

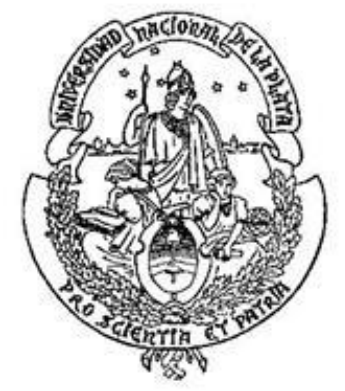

Universidad Nacional de LA Plata

FAcultad de Odontología

Carrera de Especialización en Ortodoncia

Tesis de Magíster 
“DETERMINACIÓN DE LA CLASE DENTARIA A NIVEL DEL PRIMER MOLAR EN PACIENTES CON DEGLUCIÓN ATÍPICA" 


\section{AGRADECIMIENTOS}

A mi mujer Fernanda, a mis hijas Juana y Amparo, a mi amiga Sole.

A la Facultad de Odontologia de La Plata, a la Dra Marta Rimoldi, a todos los profesores de la carrera.

Gracias!! 


\section{RESUMEN}

Introducción.La deglución atípica precisa de intervenciones tanto ortodóncicas como logopédicas para poder corregir lo estructural, funcional y posibles dificultades del lenguaje. Es preciso conocer ciertas variables clínicas con las cuales tal afectación se relaciona, sobre todo la clase o relación molar del paciente.

Objetivo general.Establecer si existe relaciónentre deglución disfuncional yla clase molar.

Metodología.Se realizó un estudio Ex post facto, no experimental, descriptivo y correlacional, transversal, cuantitativo y retrospectivo. Se conformó una muestra no probabilística de 100 pacientes con deglución atípica, niños y adolescentes, de la ciudad de Santa Rosa, provincia de La Pampa, Argentina, durante el año 2017. Se realizaron exámenes clínicosanatomofuncionalesendo y exobucales orientados a determinar el tipo de interposición y la clase molar. Los análisis fueron descriptivos e inferenciales relacionando la deglución atípica con datos demográficos, el examen funcional y la clase molar, mediante herramientas no paramétricas en el SPSS versión 24.0 para Windows.

Resultados.La deglución atípica es independiente de la edad de los pacientes dentro del rango de 6-15 años y de la etapa de desarrollo del paciente. Es más 
prevalente en pacientes de género femenino, en la relación aproximada de 1,5:1 con respecto al género masculino. Es prácticamente en su totalidad del tipo con interposición lingual, siendo la relación de aproximadamente 7:1 con respecto al resto de las variantes. Es estadística y significativamente de Clase II molar, siendo la relación de aproximadamente 2:1 con respecto a las clases I y III conjuntamente. Es más prevalente en adolescentes femeninas, en una relación aproximada de 2:1 en comparación con los adolescentes masculinos. Según el examen funcional, es independiente de la edad categorizada, la etapa de desarrollo y el género del paciente. Según las clases/ relaciones molares, es independiente de la edad categorizada, la etapa de desarrollo y el género del paciente; salvo en el caso de la Clase II molar, siendo ligeramente más prevalente en pacientes femeninos que en masculinos (relación aproximada de 1,5:1). Encuentra asociación significativa con la interposición lingual y la Clase II molar, en tanto una relación aproximada de 1,5:1 dentro del conjunto de interposiciones linguales y con respecto a las clases I y III molares en conjunto.

Conclusiones. Considerando los fundamentos epidemiológicos de adolescentes femeninas, interposición lingual y Clase II molar deberían conformarse estrategias de evaluación y tratamiento integral de la deglución atípica, ya que podría conllevar complicaciones patológicas como la neumonía aspirativa, desnutrición, deshidratación y obstrucción de la vía aérea.

Palabras clave: Deglución atípica, Datos demográficos, Examen funcional, Clase molar. 


\section{ABREVIATURAS}

ATM Articulación temporomandibular

CAT Compromiso articular temporomandibular

EMG Electromiografía

EMGS Electromiografía de superficie

OMS Organización Mundial de la Salud

RM Resonancia magnética

RN Recién nacido

SBA Síndrome de boca ardiente

SDTM Síndrome de disfunción temporomandibular 


\section{ÍNDICE DE CONTENIDOS}

AgradeCIMIENTOS IV

Resumen V

Abreviaturas VII

ÍNDICE DE TABLAS XIII

ÍNDICE DE FIGURAS XVII

1. INTRODUCCIÓN 1

1.1. Introducción 1

1.2. Estado del arte y fundamentación de la investigación 4

2. MARCO TEÓRICO 11

2.1. La boca del recién nacido 11

2.1.1. La importancia de la función desde el momento del nacimiento 12

2.1.2. Deglución infantil normal 13

2.1.3. Deglución madura normal 14 
2.3.1.1. Relación molar

2.3.2. Anomalías en sentido vertical 32

2.3.3. Anomalías en sentido transversal 34

2.4. Articulación temporomandibular 35

2.4.1. Componentes 37

2.4.1.1. Superficies articulares 37

2.4.1.2. Disco interarticular 38

2.4.1.3. Sistema ligamentoso 38

2.4.1.4. Sinoviales 40

2.4.2. Irrigación sanguínea 40

2.4.3. Movimientos de la articulación temporomandibular 42

2.4.4. Compromiso articular temporomandibular 44 
3.2.1. Objetivo general

3.2.2. Objetivos específicos

4.1. Tipo y diseño de investigación 49

4.2. Variables analizadas 52

4.3. Población, unidad de análisis, muestra y criterios de selección 53

4.4. Recolección de datos 54

4.5. Análisis de los datos 56

5. Resultados 58

5.1. Análisis descriptivos 58

5.1.1. Edad 58

5.1.2. Sexo 62

5.1.3. Examen funcional de la deglución atípica 63

5.1.4. Clase/ relación molar 65

5.2. Análisis inferenciales 66 
5.2.2.1. Todas las interposiciones 84

5.2.2.2. Interposición lingual 86

5.2.2.3. Interposición labial 91

5.2.2.4. Interposición lingual y labial 96

5.2.3. Clase/ relación molar y factores demográficos 102

5.2.3.1. Todas las clases/ relaciones molares 102

5.2.3.2. Clase/ relación I 103

5.2.3.3. Clase/ relación II 109

5.2.3.4. Clase/ relación III 115

5.2.4. Examen funcional y clase/ relación molar 121

5.2.4.1. Interposición lingual 122

5.2.4.2. Interposición labial 124

5.2.4.3. Interposición lingual y labial 125

5.2.4.4. Clase/ relación I 126

5.2.4.5. Clase/ relación II 127 
7. CONCLUSIONES 134

Bibliografía 138

ANEXos DOCUMENTALES 144

A. Formulario del consentimiento informado 144

B. Ficha clínica 145

C. Matriz de datos 147 


\section{ÍNDICE DE TABLAS}

Tabla 1. Tipo y función de las variables analizadas en el estudio. 52

Tabla 2. Criterios de selección de los participantes del estudio. 54

Tabla 3. Estadísticos descriptivos y prueba $U$ de Mann-Whitney para la edad como variable continua según el sexo. 67

Tabla 4. ANOVA de Kruskal-Wallis y $U$ de Mann-Whitney para las interposiciones de la deglución atípica según las categorías etarias, el desarrollo del paciente y el género $(n=100)$. 84

Tabla 5. Recuentos, porcentajes y chi-cuadrado para la deglución atípica con interposición lingual respecto de las categorías etarias $(n=88)$. 86

Tabla 6. Recuentos, porcentajes y chi-cuadrado para la deglución atípica con interposición lingual respecto de las categorías de desarrollo de los pacientes $(n=88)$. 88

Tabla 7. Recuentos, porcentajes y chi-cuadrado para la deglución atípica con interposición lingual respecto del género de los pacientes $(n=88)$. 90

Tabla 8. Recuentos y porcentajes para la deglución atípica con interposición labial respecto de las categorías etarias $(n=4)$. 92 
Tabla 9. Recuentos y porcentajes para la deglución atípica con interposición labial respecto de las categorías de desarrollo de los pacientes $(n=4)$. 94

Tabla 10. Recuentos y porcentajes para la deglución atípica con interposición labial respecto del género de los pacientes $(n=4)$. 94

Tabla 11. Recuentos y porcentajes para la deglución atípica con interposición lingual y labial respecto de las categorías etarias $(n=8)$. 96

Tabla 12. Recuentos y porcentajes para la deglución atípica con interposición lingual y labial respecto de las categorías de desarrollo de los pacientes $(n=8)$. 98

Tabla 13. Recuentos y porcentajes para la deglución atípica con interposición lingual y labial respecto del género de los pacientes $(n=8)$. 100

Tabla 14. ANOVA de Kruskal-Wallis y $U$ de Mann-Whitney para las clases/ relaciones molares de la deglución atípica según las categorías etarias, el desarrollo del paciente y el género $(n=100)$. 102

Tabla 15. Recuentos y porcentajes para la deglución atípica con Clase I molar respecto de las categorías etarias $(n=27)$. 104

Tabla 16. Recuentos, porcentajes y chi-cuadrado para la deglución atípica con Clase I molar respecto de las categorías de desarrollo de los pacientes $(n=27)$. 106

Tabla 17. Recuentos, porcentajes y chi-cuadrado para la deglución atípica con Clase I molar respecto del género de los pacientes $(n=27)$. 108 
Tabla 18. Recuentos, porcentajes y prueba de chi-cuadrado para la deglución atípica con Clase II molar respecto de las categorías etarias $(n=66)$. 110

Tabla 19. Recuentos, porcentajes y chi-cuadrado para la deglución atípica con Clase II molar respecto de las categorías de desarrollo de los pacientes $(n=66)$.

Tabla 20. Recuentos, porcentajes y chi-cuadrado para la deglución atípica con Clase II molar respecto del género de los pacientes $(n=66)$. 114

Tabla 21. Recuentos y porcentajes para la deglución atípica con Clase III molar respecto de las categorías etarias $(n=7)$. 116

Tabla 22. Recuentos y porcentajes para la deglución atípica con Clase III molar respecto de las categorías de desarrollo de los pacientes $(n=7)$. 118

Tabla 23. Recuentos y porcentajes para la deglución atípica con Clase III molar respecto del género de los pacientes $(n=7)$. 120

Tabla 24. Recuentos, porcentajes y chi-cuadrado para la deglución atípica con interposición lingual respecto de las clases molares $(n=88)$. 122

Tabla 25. Recuentos y porcentajes para la deglución atípica con interposición labial respecto de las clases molares $(n=4)$. 125

Tabla 26. Recuentos y porcentajes para la deglución atípica con interposición lingual y labial respecto de las clases molares $(n=8)$. 126 
Tabla 27. Recuentos y porcentajes para la deglución atípica con Clase I molar respecto del tipo de interposición $(n=27)$.

Tabla 28. Recuentos, porcentajes y chi-cuadrado para la deglución atípica con Clase II molar respecto del tipo de interposición $(n=66)$. 128

Tabla 29. Recuentos y porcentajes para la deglución atípica con Clase IIII molar respecto del tipo de interposición $(n=7)$. 130

Tabla 30. Matriz de datos. 147 


\section{ÍNDICE DE FIGURAS}

Figura 1. Deglución atípica con interposición lingual. 18

Figura 2. Deglución atípica con interposición labial. 19

Figura 3. Anomalía en sentido sagital Clase I. 22

Figura 4. Anomalía en sentido sagital Clase II $1^{\circ}$ división. 24

Figura 5. Anomalía en sentido sagital Clase II $2^{\circ}$ división. 25

Figura 6. Anomalía en sentido sagital Clase III. 26

Figura 7. Anomalía en sentido vertical, mordida cruzada. 33

Figura 8. Anomalía en sentido vertical, mordida abierta. 34

Figura 9. Anomalía en sentido transversal, mordida cruzada anterior. 35

Figura 10. Componentes de la ATM. 36

Figura 11. Arteria carótida y sus ramificaciones en relación con el cuello y la mandíbula. 41

Figura 12. Porcentajes asociados a las categorías etariasde los pacientes en la muestra total $(n=100)$. 59 
Figura 13. Porcentajes asociados a las categorías de niñez y adolescencia de los pacientes en la muestra total $(n=100)$.

Figura 14. Porcentajes asociados al sexo/ género de los pacientes en la muestra total $(n=100)$. 62

Figura 15. Porcentajes asociados al tipo de deglución atípica de los pacientes en la muestra total $(n=100)$. 64

Figura 16. Porcentajes asociados a la clase/ relación molar de los pacientes en la muestra total $(n=100)$. 65

Figura 17. Porcentajes asociados al sexo/ género de los pacientes de 6 años de edad $(n=10)$. 68

Figura 18. Porcentajes asociados al sexo/género de los pacientes de 7 años de edad $(n=14)$. 69

Figura 19. Porcentajes asociados al sexo/género de los pacientes de 8 años de edad $(n=15)$. 71

Figura 20. Porcentajes asociados al sexo/género de los pacientes de 9 años de edad $(n=14)$. 72

Figura 21. Porcentajes asociados al sexo/ género de los pacientes de 10 años de edad $(n=6)$. 73

Figura 22. Porcentajes asociados al sexo/ género de los pacientes de 11 años de edad $(n=9)$. 75 
Figura 23. Porcentajes asociados al sexo/ género de los pacientes de 12 años de edad $(n=8)$. 76

Figura 24. Porcentajes asociados al sexo/ género de los pacientes de 13 años de edad $(n=10)$. 77

Figura 25. Porcentajes asociados al sexo/ género de los pacientes de 14 años de edad $(n=10)$. 79

Figura 26. Porcentajes asociados al sexo/ género de los pacientes de 15 años de edad $(n=4)$. 80

Figura 27. Porcentajes asociados al sexo/ género de los pacientes niños/as $(n=53)$. 82

Figura 28. Porcentajes asociados al sexo/ género de los pacientes adolescentes $(n=47)$. 83

Figura 29. Porcentajes asociados a los pacientes con interposición lingual según las categorías etarias $(n=88)$. 87

Figura 30. Porcentajes asociados a los pacientes con interposición lingual según las categorías de desarrollo $(n=88)$. 89

Figura 31. Porcentajes asociados a los pacientes con interposición lingual según su género $(n=88)$. 91

Figura 32. Porcentajes asociados a los pacientes con interposición labial según las categorías etarias $(n=4)$. 93 
Figura 33. Porcentajes asociados a los pacientes con interposición labial según su género $(n=4)$. 95

Figura 34. Porcentajes asociados a los pacientes con interposición lingual y labial según las categorías etarias $(n=8)$. 97

Figura 35. Porcentajes asociados a los pacientes con interposición lingual y labial según las categorías de desarrollo $(n=8)$. 99

Figura 36. Porcentajes asociados a los pacientes con interposición lingual y labial según su género $(n=8)$. 101

Figura 37. Porcentajes asociados a los pacientes con Clase I molar según las categorías etarias $(n=27)$. 105

Figura 38. Porcentajes asociados a los pacientes con Clase I molar según las categorías de desarrollo $(n=27)$. 107

Figura 39. Porcentajes asociados a los pacientes con Clase I molar según su género $(n=27)$. 109

Figura 40. Porcentajes asociados a los pacientes con Clase II molar según las categorías etarias $(n=66)$. 111

Figura 41. Porcentajes asociados a los pacientes con Clase II molar según las categorías de desarrollo $(n=66)$. 113

Figura 42. Porcentajes asociados a los pacientes con Clase II molar según su género $(n=66)$. 115 
Figura 43. Porcentajes asociados a los pacientes con Clase III molar según las categorías etarias $(n=7)$.

Figura 44. Porcentajes asociados a los pacientes con Clase III molar según las categorías de desarrollo $(n=7)$. 119

Figura 45. Porcentajes asociados a los pacientes con Clase III molar según su género $(n=7)$. 121

Figura 46. Porcentajes asociados a los pacientes con interposición lingual según las clases molares $(n=88)$. 124

Figura 47. Porcentajes asociados a los pacientes con Clase II molar según el tipo de interposición ( $n=66)$. 129 


\section{INTRODUCCIÓN}

\subsection{Introducción}

Todo órgano constituye una unidad cuya configuración biológica no puede ser interpretada en forma separada de su función.A su vez, los órganos forman parte de un todo, de un individuo y, al ponerse en funcionamiento, se establecen entre ellos múltiples relaciones dinámicas. La salud dependerá entonces del interjuego armonioso y coordinado de los sistemas funcionales (1).

La funcionalidad oral implica la interacción de dichas estructuras, las que se tornan interdependientes, de modo tal que la alteración en una de ellas trae aparejada alteraciones en las demás (2).

De acuerdo con esto existe estrecha relación entre la fonoaudiología y la odontología a través de dos factores (3):

- De carácter anatómico: la boca es a la vez el órgano de la masticación, deglución y fonación.

- De carácter funcional: los dientes crecen en medio de grupos musculares y su equilibrio contribuye al balance dentario. 
Esta unidad anatómicamente integrada y fisiológicamente coordinada es el sistema estomatognático formado por los dientes y las estructuras que les sirven de soporte: maxilares superior e inferior, articulación temporomandibular (ATM) y músculos insertados en ambos maxilares (2).

En el momento del nacimiento se hallan presentes dos funciones: respiración y deglución, estando esta última asegurada a través de la succión. Sobre estas dos funciones primarias congénitas se van a establecer otras que ya requieren de la erupción dentaria y de una mayor movilidad de toda la musculatura bucal: la masticación y posteriormente el lenguaje, que son funciones adquiridas $(1,3)$.

La dinámica muscular adquiere en el sistema estomatognático una singular importancia, ya que incide en la conformación de las arcadas dentarias. Esta dinámica muscular está dada por la actividad lingual que es excéntrica y la actividad peribucal (labios y mejillas) que es concéntrica (4).

Es en este punto donde los odontólogos comienzan a considerar que la dinámica muscular es importante para lograr mantener el equilibrio dentario y que en muchos casos se constituye en causa o factor agravante de maloclusiones $(5,6)$.

Se debe considerar que hay ciertos hábitos que ayudan a una pobre función muscular: succionadores de dedos, labios, sabanas, lápices, etc., y respiradores bucales; todos hábitos que pueden ocasionar un cambio en la forma y deglución atípica $(3,5)$. 
El equilibrio muscular es uno de los elementos que contribuyen al establecimiento del balance dentario y fundamentalmente es una premisa a observar para garantizar la estabilidad de los trabajos ortodóncicos evitando así recidivas (5).

La deglución atípica, como un trastorno propio del sistema estomatognático e influido directamente por las maloclusiones, precisa de intervenciones tanto ortodóncicas como logopédicas, para poder corregir no solo lo estructural y funcional de la salud bucal, sino las potenciales dificultades del lenguaje. No obstante, para ello, para lograr un tratamiento efectivo, es preciso conocer, al menos, ciertas variables clínicas con las cuales tal afectación se relaciona, sobre todo la clase o relación molar del paciente, dado que esta última se corresponde principalmente con la intervención ortodóncica (7).

Por ello en el presente estudio se abordaron epidemiológicamente casos de niños y adolescentes con deglución atípica, analizando las relaciones de tal afectación con variables tanto demográficas como funcionales y de clase molar. 


\subsection{Estado del arte y fundamentación de la investigación}

En este subapartado, el desarrollo del estado del arte se consideró dentro del de la justificación del estudio. Así, siguiendo los preceptos de HernándezSampieri, Fernández-Collado y Baptista Lucio (8), en principio, respecto de la conveniencia del estudio, el mismo se justifica en tanto la necesidad de lograr modos de intervención efectivos ante la deglución atípica, para lo cual se plantea lo ineludible de relevar y desarrollar estudios epidemiológicos que permitan reconocer las relaciones significativas entre dicha alternación y otras propias del individuo en general y de su sistema estomatognático.

En este sentido, se realizó un breve relevamiento de investigaciones directamente asociadas con la problemática, pretendiendo con ello aportar a la justificación de la conveniencia del estudio. Para ello se consultaron bases de datos como PubMed/ Medline, Dialnet y ScienceDirect.

En un primer estudio, López Soto, López Soto, Osorio-Forero y Restrepo (9) desarrollaron un estudio de casos y controles orientado a relacionar la actividad y la fuerza muscular con la relación molar, el género y el rango etario en niños y adolescentes de 7-12 años de edad con deglución atípica.

En cuanto a lo metodológico, sobre un total de 172 escolares (88 casos y 88 controles) se realizaron estudios de electromiografía (EMG) de superficie (EMGS) (músculos orbicular, mentoniano y masenteros), de fuerzas 
compresiva del orbicular de los labios, la contráctil del masetero derecho e izquierdo, y la extensora del músculo lingual; asimismo, la fuerza de resistencia del orbicular de los labios mediante mioescanografía y dinamometría.

A continuación se puntualizan los principales resultados hallados:

- Significativamente mayores amplitudes de registro de la EMGS (músculos mentoniano y maseteros) en los casos, en comparación con los controles.

- Tanto el género femenino con el masculino en los casos se asoció con una menor fuerza contráctil de los músculos maseteros y extensora del músculo lingual, en comparación con los controles.

- En los niños, los casos y controles difieren en lo relacionado con la fuerza compresiva del músculo orbicular.

- En los adolescentes, los casos presentaron una reducción significativa de todas las fuerzas musculares.

De esta manera, los autores concluyeron acerca que los casos (presencia de deglución atípica) se relacionan significativamente, en términos de frecuencia, con relación molar clases II y III en ambos lados. Por su parte, si bien existen diferencias en la actividad muscular y en la fuerza de los músculos maseteros respecto del sexo entre los casos y controles, tales diferencias se acentúan a medida que se incrementa la edad.

Monaco, Cattaneo, Spadaro, MarchettiyBarone (10) desarrollaron un estudio no experimental, transversal y retrospectivo orientado a evaluar la 
prevalencia de la coincidencia kinesiográfica entre la posición más craneal durante la deglución de la mandíbula y la posición oclusal habitual, y evaluar la distribución del diagnóstico clínico en función de los patrones kinesiográficos de deglución.

En cuanto a lo metodológico, sobre un total de 201 pacientes ortodóncicos, protésicos, con alteraciones de la ATM y controles, se realizaron registros kinesiográficos mediante el uso de $\mathrm{K} 7 \mathrm{I}$ y posicionando un sensor magnético de marco integral con la cabeza y el campo sensorial balanceado sobre un magneto artificial adherido a la mucosa que cubre las raíces y los incisivos mandibulares inferiores. Se comparó la posición oclusal kinesiográfica con aquella kinesiográfica más craneal de la mandíbula durante la deglución.

Como principales resultados se hallaron los siguientes:

- Se halló discrepancia entre la posición más craneal y la oclusal durante la deglución en 99 pacientes, ello correspondiéndose con una incidencia de 49,3\% para la deglución atípica.

- En el resto de los pacientes la posición más craneal coincidió con la oclusal durante la deglución.

De esta manera, los autores concluyeron, primero, que la kinesiografía computarizada es de gran utilidad para analizar la deglución, detectando fiablemente patrones de movimiento; segundo, que la deglución atípica parece presentarse menos atípica y que, si bien pudo correlacionarse con la maloclusión (principalmente Clase II), se halló una correlación inversa con la 
necesidad de tratamiento protésico y una no tan elevada incidencia de la alteración en pacientes con defectos de la ATM.

Störmer yPancherz (11) desarrollaron un estudio de casos y controles orientado a evaluar los datos de EMG de los músculos perioral y masticatorias en pacientes ortodóncicos con deglución atípica.

Metodológicamente, se incluyó un total de 35 pacientes (20 con patrón de deglución atípico, de los cuales 10 se incluyeron luego de un tratamiento ortodóncico, y 15 con patrón deglución normal). Sobre ellos se registró la actividad de EMG de los labios superior e inferior en la región del modiolo y mentalis, de los músculos mesetero y temporal durante la deglución de saliva y de agua luego de masticar maní, así como durante la mordida máxima en posición intercuspídea.

Los principales hallazgos se puntualizan a continuación:

- Los pacientes con patrón de deglución atípico presentaron, durante la deglución, mayor actividad de EMG de los músculos perioral, pero menor actividad EMG de los músculos masticatorios, todo ello en comparación con los controles.

- Por su parte, durante la mordida máxima en posición intercuspídea, ambos grupos de pacientes presentaron mayor actividad de EMG de los músculos masetero y temporal, pero menor actividad de los músculos periorales. 
- Además, no se observó normalización del patrón de deglución de EMG durante el tratamiento ortodóncico, lo cual implicaría cierre de la mordida abierta.

De esta manera, los autores concluyeron acerca de patrones de movimiento de EMG diferentes en pacientes con deglución atípica y normal, los primeros correspondiéndose en frecuencia con maloclusiones, sobre todo Clase II molar.

Monaco, Cattaneo, Spadaro yGiannoni (12) desarrollaron un estudio no experimental, transversal y retrospectivo orientado a evaluar los patrones de actividad de los músculos elevadores mandibulares (masetero y temporal anterior), los submentonianos y del cuello (esternocleidomastoideo) en personas saludables durante la deglución espontánea de saliva y relacionar las actividades musculares con el movimiento mandibular.

Los autores partieron del reconocimiento que la fisiología de la deglución se caracteriza por una activación compleja y coordinada de diversos músculos estomatognáticos, faríngeos y laríngeos. Estudios de EMGy cinemática previos han abordado el patrón faríngeo y laríngeo de la deglución para analizar las diferencias entre pacientes normales y difágicos. Por su parte, dentro del campo dental, la activación muscular durante la deglución se crea causada por maloclusiones, principalmente de Clase II.

Metodológicamente, se incluyó un total de 111 individuos sobre los cuales se midió la deglución espontánea de saliva mediante EMGS y kinesiografía computarizada del movimiento mandibular. 
Como principales resultados se hallaron los siguientes:

- De los 111 individuos, $57(51,4 \%)$ presentó deglución sin contacto oclusal, mientras que el resto $(48,6 \%)$, con contacto oclusal.

- Durante la deglución, los músculos esternocleidomastoideos presentaron una leve pero constante activación.

- No se hallaron diferencias entre ambos grupos de individuos en lo referido a los registros de EMGS de los músculos submentonianos y esternocleidomastoideos.

- Se hallaron diferencias significativas desde la EMGS para los músculos temporal anterior y masetero.

- La duración de la deglución fue significativamente mayor en los individuos sin contacto oclusal.

- $\mathrm{Ni}$ el género ni la edad de los individuos se correlacionó significativamente con la activación electromiográfica.

En este sentido, los autores concluyeron acerca de la inexistencia de un patrón único, simple, normal o típico de la deglución espontánea de saliva. Además, que el polígrafo se presenta como una herramienta valiosa, simple, no invasiva y fiable para analizar la fisiología de la deglución.

Prosiguiendo con la justificación del estudio, respecto de su relevancia social, los beneficios directos del estudio se asocian con lo heurístico o académico en sí; es decir, siendo un estudio epidemiológico, se espera aporte datos de tal índole a fines de que puedan ser utilizados en el futuro para 
diseñar mejor abordajes diagnósticos y terapéuticos de la deglución atípica y las maloclusiones.

Respecto de las implicaciones prácticas del estudio, las mismas se justifican en tanto la necesidad de conocer en mayor medida las relaciones entre la deglución atípica, el tipo de interposición y la clase/ relación molar asociadas, así como las asociaciones con factores demográficos de los pacientes.

Finalmente, respecto del valor teórico, el mismo se justifica a partir de lo siguientes puntualizado:

- Si bien el estudio se realiza dentro de un contexto temporal y territorial específico, los resultados hallados bien pueden generalizarse a principios más amplios, siendo que se fundamentan en preceptos de la fisiología de la deglución.

- Los resultados obtenidos serán de utilidad para apoyar los conceptos fisiológicos ya desarrollados sobre la deglución atípica, así como conocer en mayor medida el comportamiento de las variables medidas.

- El estudio se orienta también a sugerir líneas de intervención y de investigación futura sobre la deglución atípica. 


\section{MARCO TEÓRICO}

\subsection{La boca del recién nacido}

En el recién nacido (RN) la alimentación es exclusivamente líquida, es por eso que la boca tiene características particulares, con exquisita sensibilidad.El maxilar superior se encuentra formado por paladar duro y paladar blando, donde el primero se encuentra recubierto por mucoperiostio de consistencia muy firme apareciendo en el rafe medio los surcos transversales y las rugas palatinas. El paladar blando se observa de un color más rojo que el duro.El proceso alveolar es delgado en la porción anterior y aplanado en la parte posterior $(1,2)$.

Los procesos alveolares están cubiertos por abultamientos gingivales que luego se segmentaran para indicar la localización de los dientes.En este momento se está en presencia del rodete gingival (2).

La mandíbula del RN se encuentra en una posición muy retruida con respecto al maxilar superior.Suele haber una diferencia de 6-12 mm entre ambos, la cual se reduce en pocos días. 
En ambos rodetes superior e inferior en la región de incisivos existe un cordón fibroso de Robin y Margitot que va desapareciendo dando lugar a la erupción de los dientes.

La posición de la lengua en el RN es baja, apoyando está en el piso de la boca.Los labios son de forma triangular. El superior presenta en la parte media el llamado apoyo para la succión (2).

\subsubsection{La importancia de la función desde el momento del nacimiento}

Sucede que es importante el acto de la amamantamiento ya que el bebe respira mientras succiona del seno materno la leche.Durante esta succión es necesario morder, avanzar y retruir la mandíbula por lo que se estimula neuromuscularmente, y se va adquiriendo el desarrollo y tono muscular necesarios para ser utilizados a la llegada de la primera dentición. El movimiento protrusivo y retrusivo excita al mismo tiempo las partes posteriores de los meniscos y parte superior de la ATM, y se obtiene como respuesta el crecimiento portero anterior de las ramas mandibulares $\mathrm{y}$, simultáneamente, la modelación del ángulo mandibular. Si la dentición decidua o de leche empieza a atrofiarse dejando de funcionar equilibradamente, por impedimentos, mal posiciones, caries, falta de tono muscular, masticación atípica con movimientos únicamente de apertura y cierre, alimentación blanda, etc., el cambio a la segunda dentición se hará en estas condiciones y se establecerá un plano oclusal patológico con erupciones dentarias que impedirán los movimientos de 
lateralidad mandibular y por ese motivo no será excitada la ATM por falta de un buen recorrido en estos movimientos $(1,2)$.

También es importante mencionar que en los casos en que la alimentación civilizada no estimula el acto mecánico de trituración que debe proporcionar la energía suficiente para que se desarrolle la cara y la mandíbula, estas quedan en retraso y es por eso que se insiste en que la falta de función es la causa habitual de las malposiciones dentarias (13).

La deglución es una acción motora automática y rápida, de los componentes de la cavidad bucal, faringe, laringe y del aparato gastrointestinal. El objetivo es el transporte del bolo alimenticio y también la limpieza del tracto respiratorio $(14,15)$.

Es primordial diferenciar entre deglución infantil normal y deglución madura normal.

\subsubsection{Deglución infantil normal}

La lengua descansa entre las almohadillas gingivales y la mandíbula es estabilizada por obvias contracciones de los músculos faciales. El buccinador tiene mucha actividad en este momento. Ladeglución infantil se ve en el neonato y gradualmente va desapareciendo con la erupción de los dientes anteriores en la dentición primaria. El cese de esta y la aparición de la 
deglución madura, no son fenómenos simples y ocasionales, sino que se van entremezclando con la dentición primaria y los comienzos de la dentición mixta. La disminución de la actividad del buccinador, y principalmente la aparición de contracciones de los elevadores mandibulares, son indicios de este cambio gradual $(16,17)$.

\subsubsection{Deglución madura normal}

Está caracterizada por la muy poca actividad de labios y carrillos, y la contracción de los elevadores mandibulares que llevan a los dientes a oclusión. La cantidad de actividad labial depende de la capacidad de la lengua de efectuar un sellado valvular completo contra los dientes y procesos alveolares $(16,17)$.

Mediante la deglución, la boca, la garganta y el esófago se mantienen limpios. La fase bucal es voluntaria, mientras que la faríngea es involuntaria y los movimientos se realizan en décimas de segundo (18).

El hábito deglutorio normal se caracteriza por estar la punta de la lengua presionada contra las rugas palatinas detrás de los dientes superiores anteriores; la parte media sube para encontrar el paladar duro y la parte posterior forma un ángulo de $45^{\circ}$ paralelo a la pared faríngea. Los dientes están juntos y los labios cerrados.

Se mencionan tres etapas del acto deglutorio, aunque pueden considerarse cuatro $(14,18)$ : 
1. La primera es la preparatoria: cuando se prepara el alimento mordiéndolo y masticándolo, para que el mismo pueda ser transformado en un bolo homogéneo.

2. Etapa oral: inmediatamente antes de que empiece el acto de la deglución, la lengua está en posición de descanso pasivo, con la punta en contacto con los incisivos inferiores, el maxilar inferior está en posición de descanso fisiológico con los arcos dentarios separados y los labios en contacto uno con el otro pero sin ninguna acción; el conducto respiratorio se encuentra abierto a través de las fosas nasales.

Cuando comienza la deglución los dientes se ponen en contacto oclusal y el bolo alimenticio queda sostenido en el dorso de la lengua por breves instantes, la punta de la lengua se coloca en contacto con el borde alveolar superior en la mucosa palatina cerca de la cara palatina de los incisivos. El dorso de la lengua adquiere una forma de cuchara sosteniendo el bolo alimenticio, y elevándose en forma de arco para encontrar el paladar blando, el cual desciende al mismo tiempo para contactar con la lengua. Este cierre es conocido como válvula palatolingual, tiene el papel de impedir que el bolo entre prematuramente en la faringe. Posteriormente el bolo alimenticio es impelido hacia atrás por un movimiento de dirección posterior de los músculos de la lengua, que se oprime contra el paladar en su parte anterior. La lengua y el velo del paladar desarrollan una presión conjunta que conduce el bolo hasta el istmo de las fauces.

3. Etapa faríngea: una vez que el bolo alcanza el istmo de las fauces se desencadena la etapa faríngea de modo reflejo. El paladar blando se 
cierra, evitando el pasaje del bolo para la nasofaringe. El alimento no podrá subir, ni volver a la boca, porque el dorso de la lengua está impidiendo su pasaje para la cavidad bucal. Por lo tanto, el alimento tendrá que bajar. En ese instante la faringe se elevará, facilitando este bloqueo que será concomitante a la abertura del músculo cricofaríngeo, para que el alimento pueda entrar en el esófago.

4. Etapa faríngea: es involuntaria, durante entre entre 6-8 s. Se relaciona con el alcance del estómago por parte del bolo alimenticio, permitidas por las ondas peristálticas y la apertura del esfínter esofágico inferior.

\subsection{Deglución atípica}

Según del diccionario atípico es lo que se aleja de lo normal de lo típico. Deglución atípica corresponde a movimientos inadecuados de la lengua y/o de otras estructuras que participan del acto de deglutir, durante la fase oral de la deglución, sin que haya ninguna alteración de forma en la cavidad oral (14).

Si persiste el patrón de deglución de los primeros meses de vida, la lengua se apoyara entre ambos grupos incisivos, originando generalmente una mordida abierta anterior y protrusión de estos dientes, creando una disfunción muscular en la deglución porque la actividad no será de los maseteros y temporales sino de la musculatura perioral. 
La punta de la lengua puede ser activada en contra o entre los dientes superiores o inferiores, y también la lengua se puede mover posterior o bilateralmente contra o entre los molares.Así esta no se limita a un mero empuje lingual sino que también puede producir problemas oclusales posteriores por deglución atípica unilateral o bilateral y puede observarse que aparte de la deglución con interposición lingual existe otra muy importante que es con interposición labial (18).

La deglución atípica puede clasificarse en tres tipos $(14,18)$ :

- Con interposición lingual:aquí la lengua se interpone entre los arcos dentales impidiendo la oclusión anterior de los mismos. Puede darse en el sector anterior, o en los sectores laterales. Además se observan contracciones del cinturón labioyugal, mientras los músculos de la mandíbula no actúan. Ello se representa en la siguiente figura (19). 
Figura 1. Deglución atípica con interposición lingual.

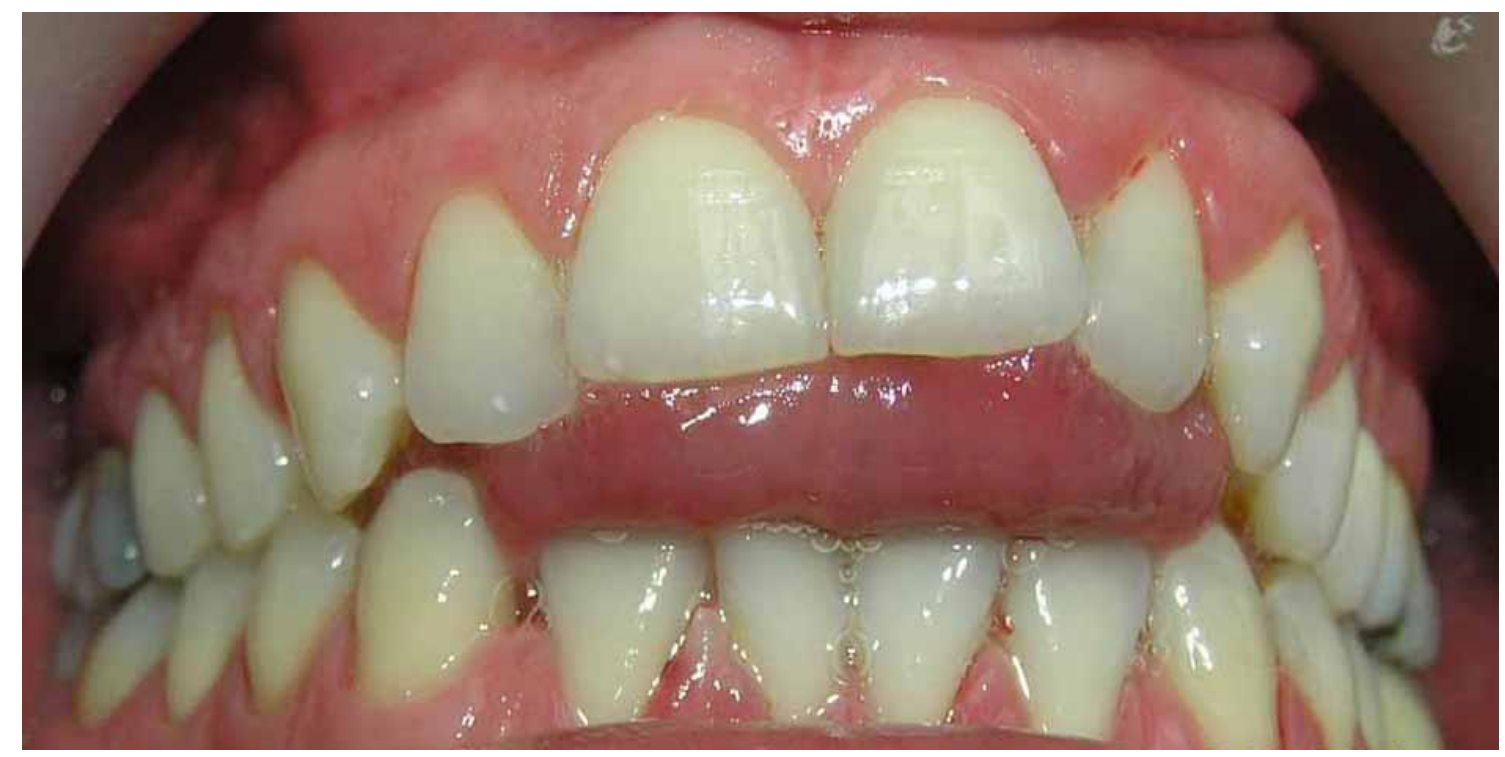

Fuente: Queiroz IM. 1999.

- Con interposición labial:se da la interposición del labio inferior entre los dientes frontales superiores, en el momento de tragar. Se presenta en los casos de overjet. Para sellar la cavidad bucal en la zona anterior, el labio inferior y borla de la barba, se contraen fuertemente contra los incisivos inferiores. La lengua no necesariamente se protruye, según se presenta en la siguiente figura. 
Figura 2. Deglución atípica con interposición labial.

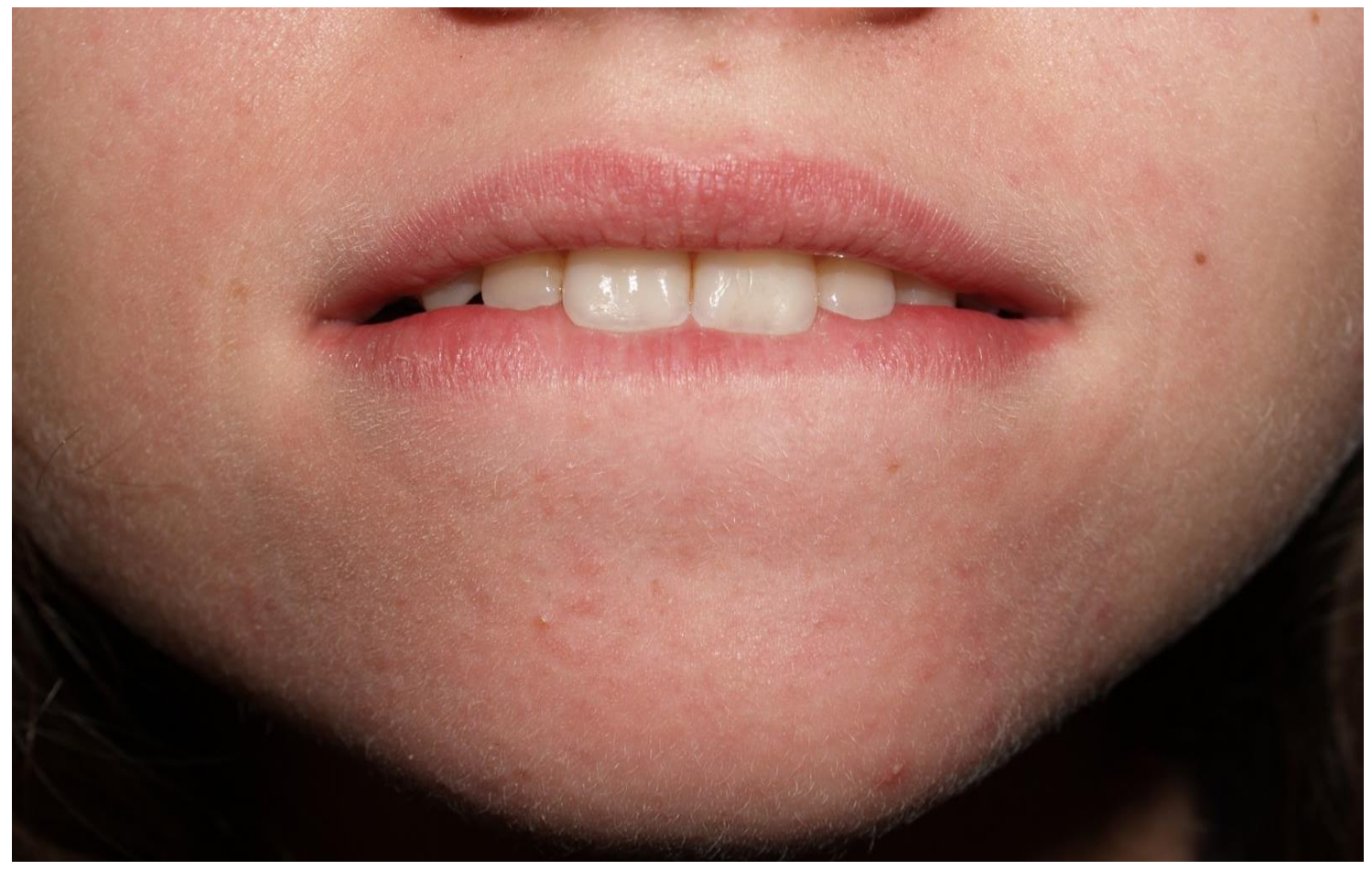

Fuente: Queiroz IM. 1999.

- Con interposición labial y lingual:son aquellos casos en los que se ven las dos divisiones anteriores simultáneamente.

Otros autores agregan a esta clasificación, otros tipos de deglución (14):

- Con presencia de musculatura periorbicular.

- Sin contracción del masetero.

- Con ruidos.

- Con residuos.

Por otra parte, Moyers, habla de (16): 
- Deglución con empuje lingual simple: este tipo muestra contracciones de los labios, del músculo mentoniano y los elevadores mandibulares; los dientes están en oclusión mientras la lengua protruye entre los dientes.

- Deglución con empuje lingual Complejo: se define como el empuje lingual con una deglución con dientes separados.

- Deglución infantil persistente: persistencia predominante del reflejo de deglución infantil, después de la llegada de los dientes permanentes. Se observan contracciones muy fuertes de los labios y la musculatura facial, hasta como una mueca masiva. Estos casos no son muy habituales.

\subsection{Anomalías dentarias}

El término anomalía puede ser limitado e inadecuado, pero es válido para el clínico que intenta realizar un diagnóstico diferencial de los pacientes que va a tratar. Anomalía es la desviación respecto a la normalidad individual. Cada individuo es distinto, con un patrón morfogenético normal para él, pero puede presentar diferencias en cuanto a la posición, volumen y forma de las partes integrales del aparato masticatorio. Estas diferencias son las que se denominan anomalías, término que así entendido facilita su aplicación en el diagnóstico al destacar lo anormal de lo normal. La maloclusión refiere a lo patológico caracterizado por una relación anormal entre los dientes en el mismo arco y con los del arco antagonista (19). 


\subsubsection{Anomalías en sentido sagital}

\subsubsection{Relación molar}

Angle (20) realizó una clasificación teniendo en cuenta que el primer molar superior era un diente que permanecía inmóvil; es decir, que el diente nunca variaba su posición y Angle creía que esa era la posición correcta en todos los casos.

Angle divide tres clases (20):

- Clase l:es donde la cúspide mesiovestibular del primer molar superior engrana u ocluye con el surco mesiovestibular del primer molar inferior.

En esta clasificación tambiénpueden encontrar alteraciones en el sector anterior; es decir, que los dientes pueden estar en la clase pero el sector anterior puede estar apiñado,con diastemas,con giroversiones individuales,etc.

Las malposicionesmás comunes de los dientes anteriores son:

- Retrusión superior e inferior; es decir falta de desarrollo anteroposterior y transversal de los maxilares con apiñamiento dentario y caninos generalmente fuera de los arcos dentarios. 
- Retrusión superior solamente, con el maxilar inferior normal, pudiendo estar los caninos superiores retenidos o en vestíbulo intraversión, sin o con poco espacio. Es la aparente clase III por su aspecto facial y la relación bilabial.

- Protrusión superior: dientes en vestíbuloversion y con diastemas. Por su aspecto facial y/o relación labial aparentan un paciente de clase II.

- Protrusión inferior: pudiendo llegar a estar en mordida invertida anterior dentaria.

- Biprotrusión.

En la siguiente figura se esquematiza esta relación molar (21).

Figura 3. Anomalía en sentido sagital Clase I.
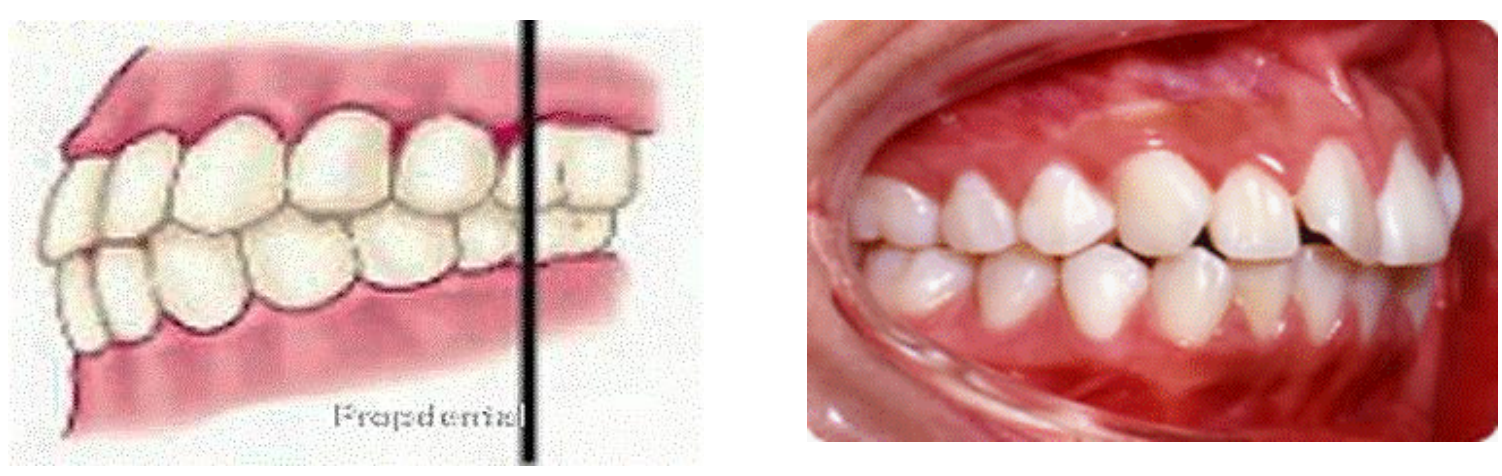

Fuente: Almandoz Calero AR. 2011. 
- Clase II: disto-oclusión.Es cuando la cúspide mesiovestibular del primer molar superior ocluye por delante del surco mesiovestibular del primer molar inferior.

El surco vestibular del primer molar inferior está en distoposición con respecto a la cúspide mesiovestibular del primer molar superior.

Es la relación distal del primer molar inferior y del arco en consecuencia respecto al superior.

Se establecen dos divisiones dentro de esta clase y a su vezsubdivisionesen cada una de ellas.

- Clase II: $1^{\circ}$ división.Es cuando los incisivos están vestibulizados. Se encuentran protruidos, con aumento del overjet. El arco superior por lo general se encuentraatrasito. Los labios separados, el superior protruido junto con los dientes.

Las piezas dentarias del arco inferior se encuentran en relación distal al menos una cúspide. Los incisivos inferiores suelen tocar la mucosa del paladar. El labio inferior queda entre ambos grupos incisivos. Pertenecen a este grupo normalmente los respiradores bucales. En la siguiente figura se esquematiza este tipo de anomalía. 
Figura 4. Anomalía en sentido sagital Clase II $1^{\circ}$ división.
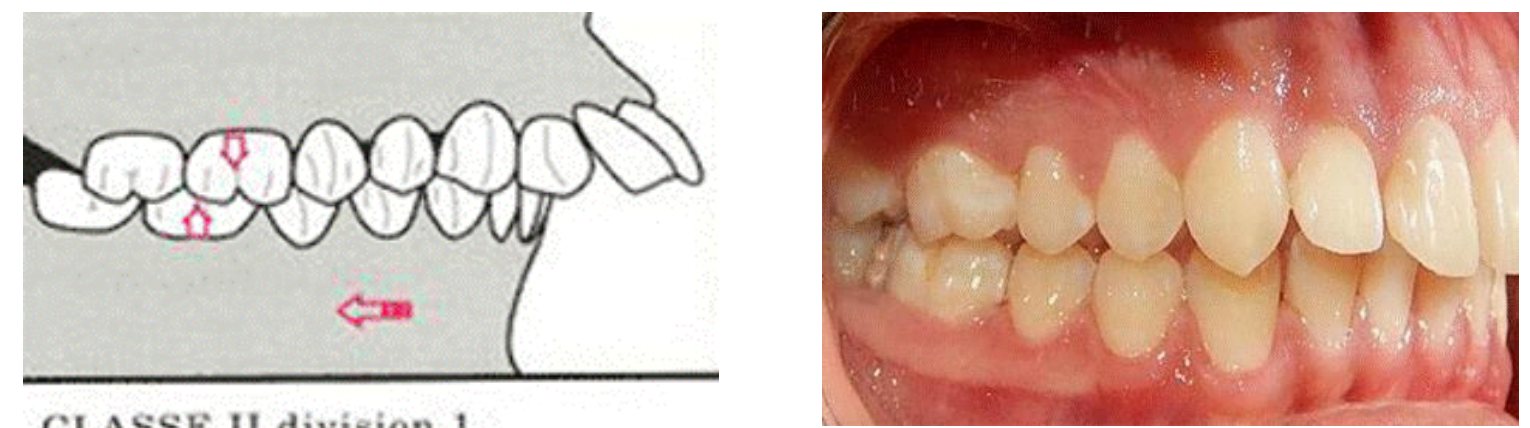

CLASSE II division 1.

Fuente: Almandoz Calero AR. 2011.

- Clase II: $2^{\circ}$ división, Deckbis.Es cuando los incisivos centrales superiores están retro-inclinados ylos laterales superiores vestibularizados.

Generalmente hay una linguoversión de los incisivos inferiores. Hay un gran aumento de la sobremordida, llegando en algunos casos a cubrir por completo a los incisivos inferiores. Eloverjet se encuentra disminuido y aumentado el overbite.

Por lo general estos pacientes no presentan alteración a nivel respiratorio.

A nivel labial se ve un surco nasolabial y un surco labiomentoniano aumentado, esto por la disminución de la dimensión vertical.

La subdivisión se da cuando hay una distorrelaciónunilateral(derecha o izquierda) y una clase I del otro lado. 
Figura 5. Anomalía en sentido sagital Clase II $2^{\circ}$ división.

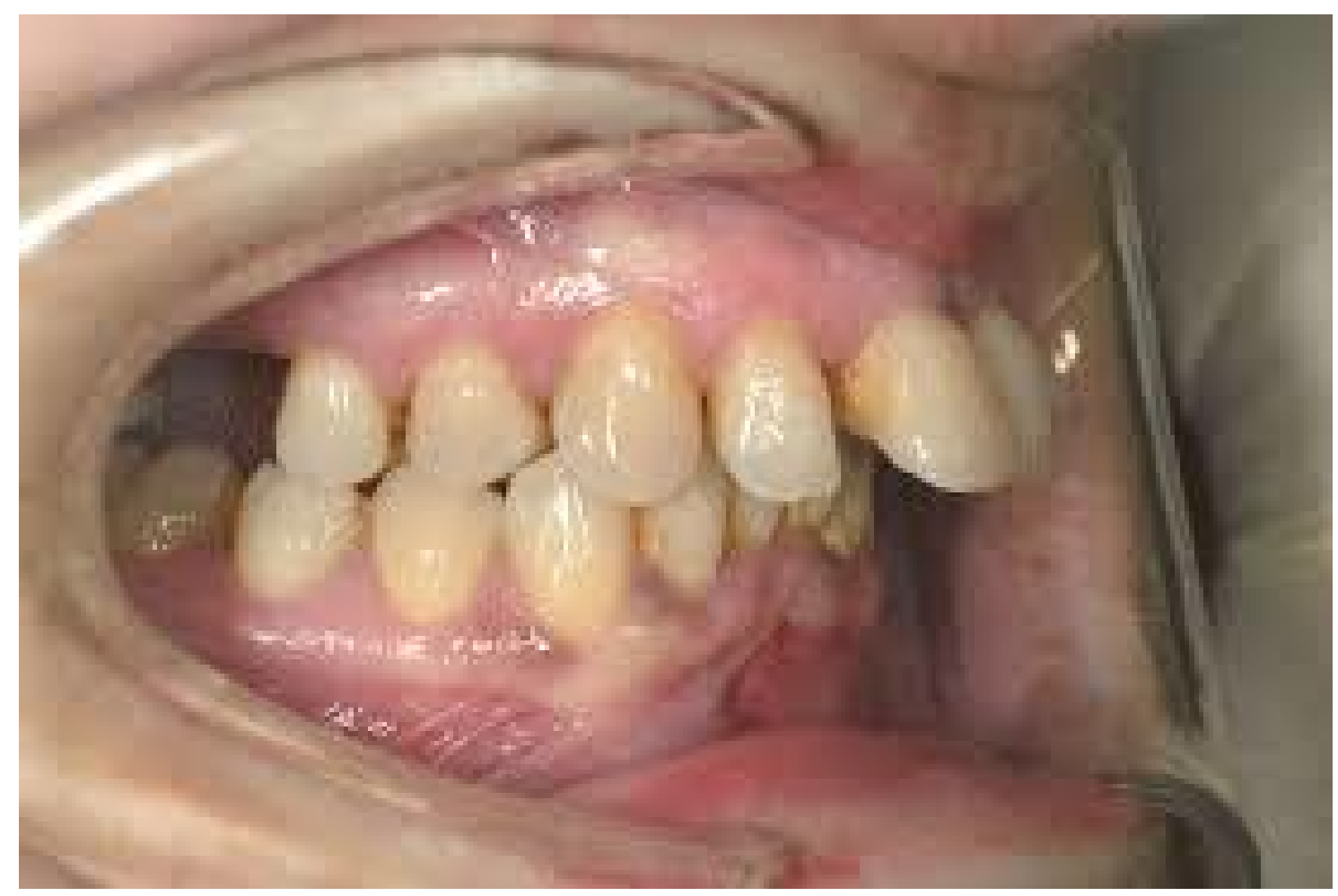

Fuente: Almandoz Calero AR. 2011.

Según la magnitud de la anomalía, la clase II puede ser completa (la cúspide mesiovestibular ocluye en el espacio interdental entre el primer molar inferior y es segundo premolar) o incompleta (existiendo una relación cúspide a cúspide en el sentido sagital).

- Clase III: mesioclusión. Es cuando la cúspide del primer molar superior articula por distal del surco mesiovestibular del primer molar inferior (2123). Es la relación mesial de los molares inferiores y, por lo tanto, de todo el arco inferior. 
Figura 6. Anomalía en sentido sagital Clase III.
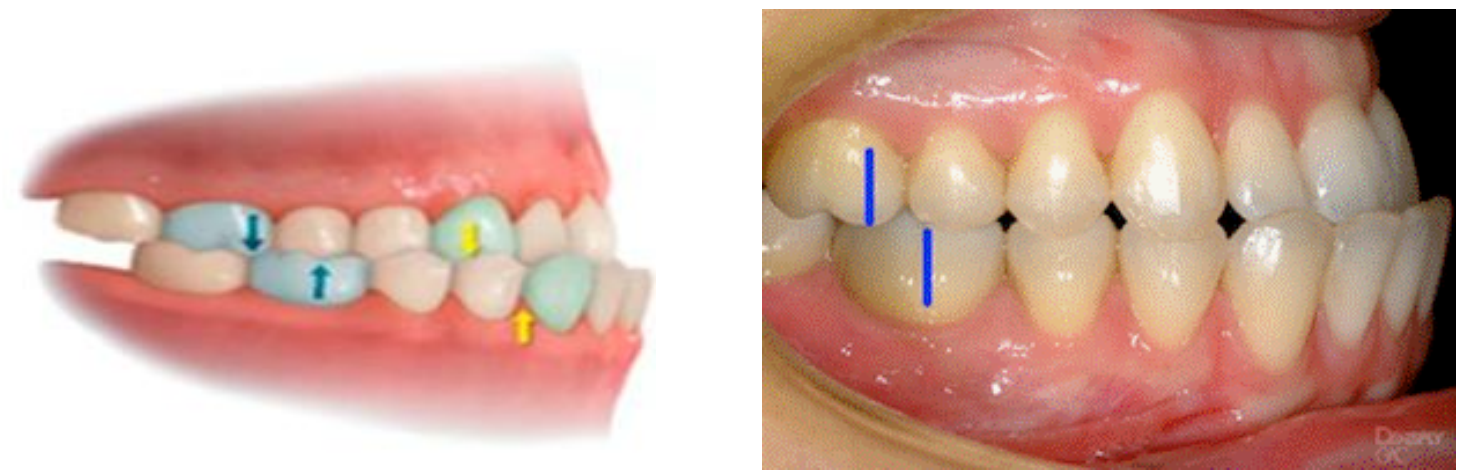

Fuente: Almandoz Calero AR. 2011.

La subdivisión se da cuando es unilateral.

Angle pensó en otra clase molar, que es cuando existe relación mesial de un lado y distal del otro, pero dado la rareza del caso la desestimó.

Las malposiciones individuales Angle las designa basándose en la desviación de la línea de oclusión; utiliza el radical oclusión y los prefijos marcan el sentido del movimiento.

Cuando se desvía hacia afuera de la línea del arco: vestíbuloversion o labio oclusión. Cuando lo hace hacia adentro: linguo-oclusión. Acercándose a la línea media: mesio-oclusión. Alejándose: distooclusión. 
Si no alcanza el plano de oclusión: infra-oclusión y si lo sobrepasa: supra-oclusión.

\subsubsection{Relación canina}

Usualmente se utiliza la siguiente clasificación $(24,25)$ :

- Clase I: el canino superior se sitúa por detrás del canino inferior quedando sus cúspides a una distancia de $3 \mathrm{~mm}$.

- Clase II:esta distancia es menor o bien el canino superior se ubica por delante del canino inferior.

- Clase III: la cúspide del canino superior está a más de $3 \mathrm{~mm}$ por detrás del canino inferior.

A nivel del canino también se utiliza la llave de Atkison(26):

- Clase I: es cuando la cúspide del canino superior articula en el espacio interdentario entre el canino y el primer premolar inferior.

- Clase II: es cuando la cúspide del canino superior articula a mesial del espacio interdentario entre canino y primer premolar inferior.

- Clase III: es cuando la cúspide del canino superior articula a distal del espacio interdentario entre canino y primer premolar inferior.

Otra de las clasificaciones muy usadas es la de Lischer(27).Se basa en la clasificación de Angle, la aumenta y utiliza terminología muy clara.Divide la oclusión patológica en: 
1. Mal posición de los dientes: adopta el radical versión para todas las malposiciones dentarias y los prefijos dan el sentido del movimiento: labio-linguo-mesio-disto-supra-infra-torso y per.

2. Relaciones anormales de los arcos: basado en la clasificación de Angle.Neutro-oclusión: mesio-distal normal. Disto-oclusión: relación distal de los molaresy del arco(clase II de Angle). Mesio-oclusión: relación mesial de los molares y del arco (clase III de Angle).

3. Mal posición de los maxilares: adopta el radicalgnatismo y las divide en: macrognatismo y micrognatismo.

4. Mal posición de la mandíbula: representa el avance de toda la mandíbula: anteversión mandibular y retroversión mandibular.

Otros autores clasifican las anomalías de oclusión según los distintos planos del espacioen:sagital, transversal y vertical.

- Sagital: clasell y clase III.

- Transversal: mordida cruzada, falta de oclusión bucal, falta oclusión lingual.

- Vertical: mordida profunda, mordida abierta.

Sin embargo cabe aclarar que la relación intermaxilar de los sectores laterales se modifica, con la independencia de la relación anatómicaósea, por anomalías de posición dental del maxilar superior, de la mandíbula o de ambos (migración mesial o migración distal) (28).

Como ya se sabe que la clasificación de Angle es incompleta y errónea, algunos autores empezaron a valorar la relación de los dientes con sus bases 
óseas y la relación de las bases entre sí. Ejemplo de ello es la clasificación de Anderson que, si bien parte desde Angle, la hace más amplia y certera. Es muy utilizada hoy en día ya que considera además de la relación molar, la relación entre ambos maxilares (29):

- Clase I:Neutro-oclusión.Relación normal entre arcos, molares en clase I:

- Tipo 1: dientes superiores e inferiores apiñados, o caninos en labioversión,infralabioversión o linguoversión.

- Tipo 2: incisivos superiores protruidos o espaciados.

- Tipo 3: si uno o más dientes están cruzados en relación con los inferiores.

- Tipo 4: mordida cruzada posterior (temporal o permanente), con anteriores alineados.

- Tipo 5: si hay pérdida de espacio posterior por migración del 6 mayor de $3 \mathrm{~mm}$ protrusiónbimaxilar. Posición de avance en ambos arcospuede o no haber malposiciones individuales de los dientes y correcta forma de arcos, pero la estética esté afectada.

- Clase II:Disto-oclusión.Maxilar en posición mesial con respecto al arco mandibular y cuerpo mandibular en relación distal con respecto al maxilar superior.

- División 1: los incisivos superiores se encuentran en labioversión.

- División 2: los incisivos centrales superiores se encuentran en posición casi normal o ligera linguoversión, y los laterales se encuentra inclinados hacia mesial. 
- Clase III: Mesiorrelación.Mandíbula en relación mesial con respecto al maxilar superior:

- Tipo 1: si se observan los arcos por separados, estos se ven de manera correcta pero la oclusión es a tope.

- Tipo 2: los dientes superiores están bien alineados y los incisivos inferiores apiñados y en posición lingual con respecto a los superiores.

- Tipo 3: arco mandibular muy desarrollado y arco maxilar con poco desarrollo. Los dientes superiores a veces apiñados y en posición lingual con respecto a los inferiores. Deformación facial acentuada.

Todas estas clasificaciones tratan de definir las maloclusionesdentarias, pero con el desarrollo de las nuevas técnicas radiográficas se comenzó a clasificar a las maloclusiones, no solo desde el aspecto dentario sino también desde el punto de vista craneométrico, estableciendo primero relaciones intermaxilares independientemente de la relación molar.

De esta manera la clasificación de Angle pasó a ser un método más para el estudio de las maloclusiones y no el único, de allí que se establece como norma actual que para realizar un buen diagnóstico se debe realizar:

1. Examen clínico.

2. Estudio de modelos.

3. Examen radiográfico. 
Y de esta manera poder determinar si la anomalía es solo dentaria o dento-esqueletal.En este punto del trabajo es importante describir lo que puede observarse a nivel esqueletal (29).

- Clase I:

- Posición normal de los maxilares con respecto a base de cráneo.

- Posición de avance de ambos maxilares con respecto a base de cráneo (biprotrusión).

- Posición de retrusión de ambos maxilares con respecto a base de cráneo (birretrusión).

- Clase II:

- Maxilar en posición y mandíbularetruida.

- Maxilar protruido y mandíbula en posición normal.

- Maxilar protruido y mandíbularetruida.

- Clase III:

- Maxilar en normo posición y mandíbula protruida.

- Maxilar retruido y mandíbula en normo posición.

- Maxilar retruido y mandíbula protruida.

Se debe tener en cuenta también la guía anterior la cual debe poseer una altura funcional que permita generar una desoclusión inicial y una final de los cuadrantes posteriores; es decir, ambas alturas funcionales deben estar relacionadas.

Otra de las cosas a tener en cuenta son las curvas sagitales.La curva de Wilson hace que la boca se comporte como un sistema de curvas y contra 
curvas y facilite la desoclusión en las áreas intermedias (sectores posteriores) (30).

\subsubsection{Anomalías en sentido vertical}

- Sobremordida: es la distancia en sentido vertical entre los bordes incisales de los incisivos centrales superior e inferior. Se proyecta el borde incisal superior sobre la cara vestibular del inferior en forma paralela al plano oclusal y se mide la distancia desde esta marca al borde incisal del incisivo inferior. Se considera positivo cuando el borde incisal del superior está por debajo del inferior. La norma es $>2,5-3,0$ $\mathrm{mm}$ (25). En la siguiente figura se representa la sobremordida. 
Figura 7. Anomalía en sentido vertical, mordida cruzada.

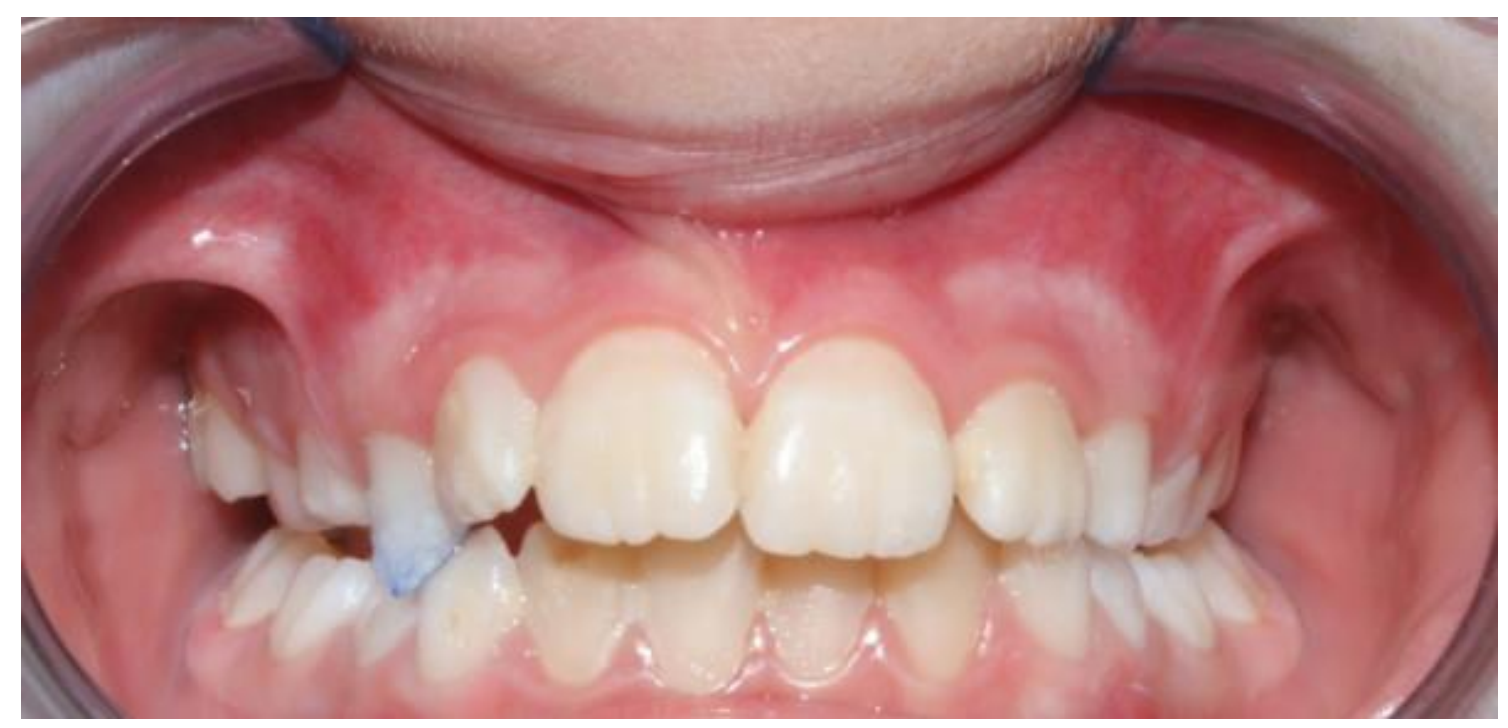

Fuente: Gregoret J. 1997.

- Mordida abierta: siguiendo con la evaluación anterior, cuando los valores son negativos, se considera este tipo (25). En la siguiente figura se representa la mordida abierta. 
Figura 8. Anomalía en sentido vertical, mordida abierta.

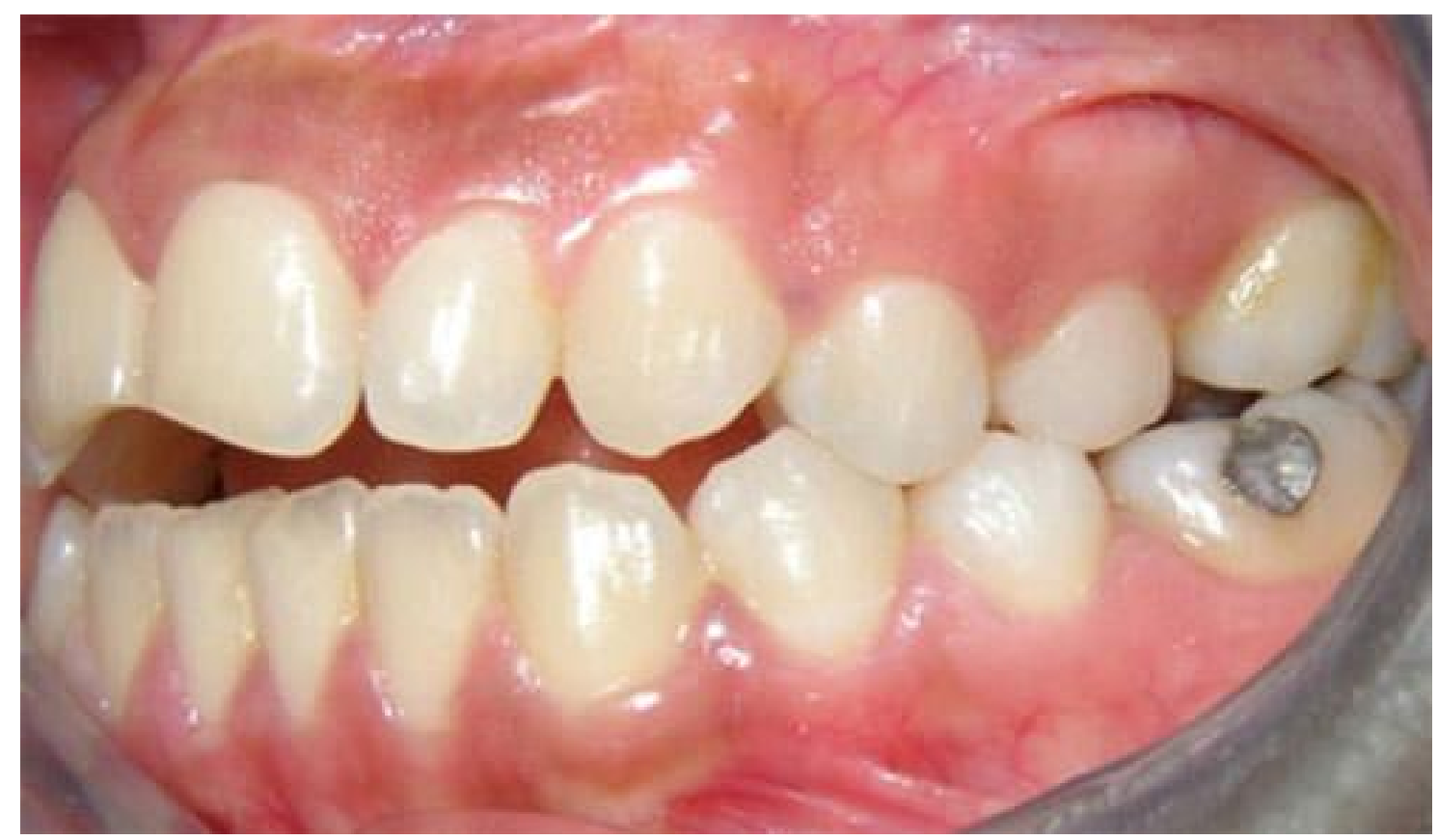

Fuente: Gregoret J. 1997.

\subsubsection{Anomalías en sentido transversal}

- Mordida cruzada: se usa para indicar una relación bucolingual (labio lingual) anormal de los dientes. La más común es la que se ve cuando hay cúspides bucales de algunos de los dientes posteriores superiores que ocluyen por lingual de las cúspides bucales de los dientes inferiores. Cuando uno o más dientes superiores están en mordida cruzada hacia la línea media, se denomina mordida cruzada lingual. Cuando las cúspides linguales de los dientes posteriores superiores ocluyen completamente por bucal de las cúspides bucales de los dientes inferiores, se denomina mordida cruzada bucal (25). 
- Mordida cruzada anterior: es cuando los incisivos superiores ocluyen por lingual de los incisivos inferiores $(25,31)$. En la siguiente figura se representa la mordida cruzada anterior.

Figura 9. Anomalía en sentido transversal, mordida cruzada anterior.

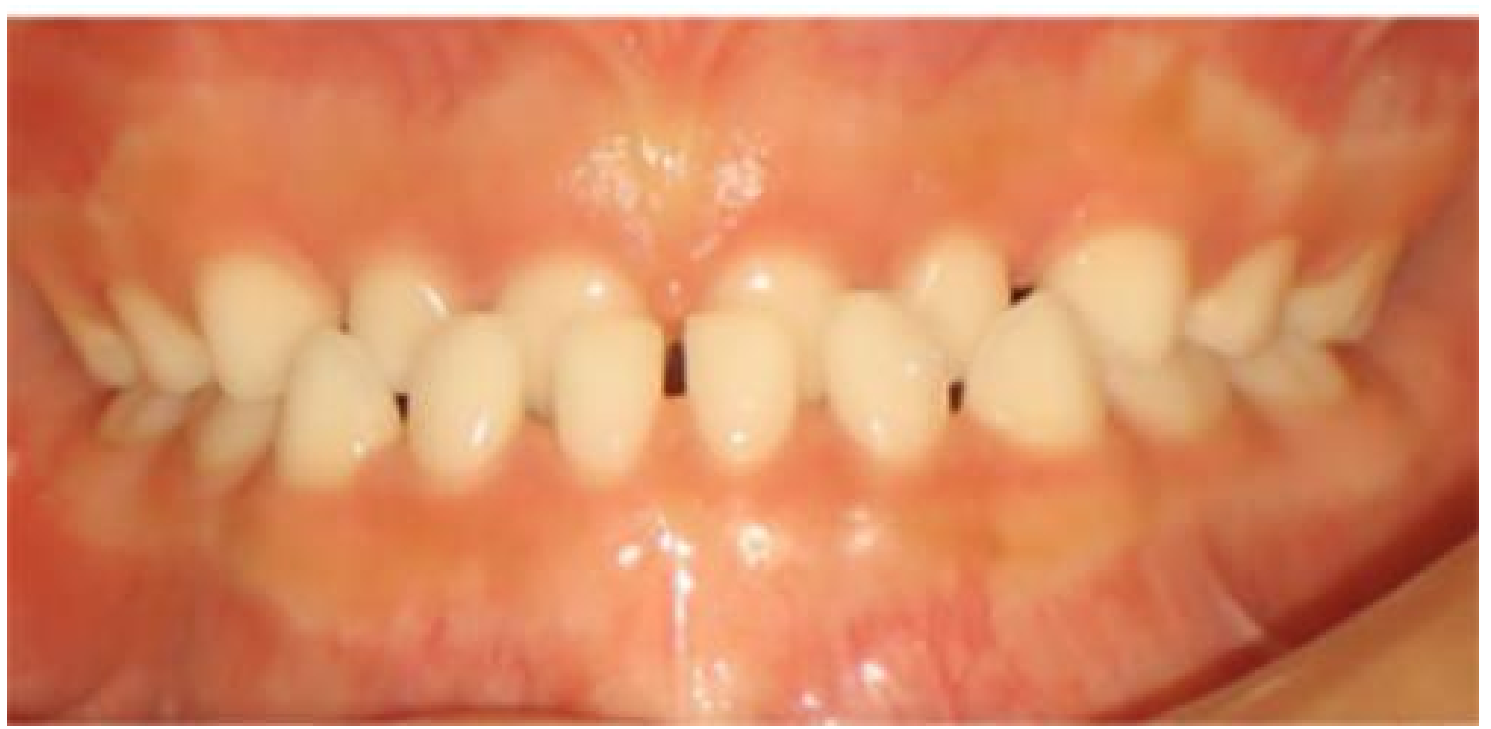

Fuente: Gregoret J. 1997.

\subsection{Articulación temporomandibular}

La ATM (también llamadacomplejo articular craneomandibular) es la articulación existente entre el hueso temporal y la mandíbula. En realidad se trata de dos articulaciones, a cada lado de la cabeza, sincronizadas. Es una de 
las pocas articulaciones móviles que hay en la cabeza, junto con la cabeza del atlanto-occipital. En la siguiente figura se esquematiza la ATM y sus componentes (32).

Figura 10. Componentes de la ATM.

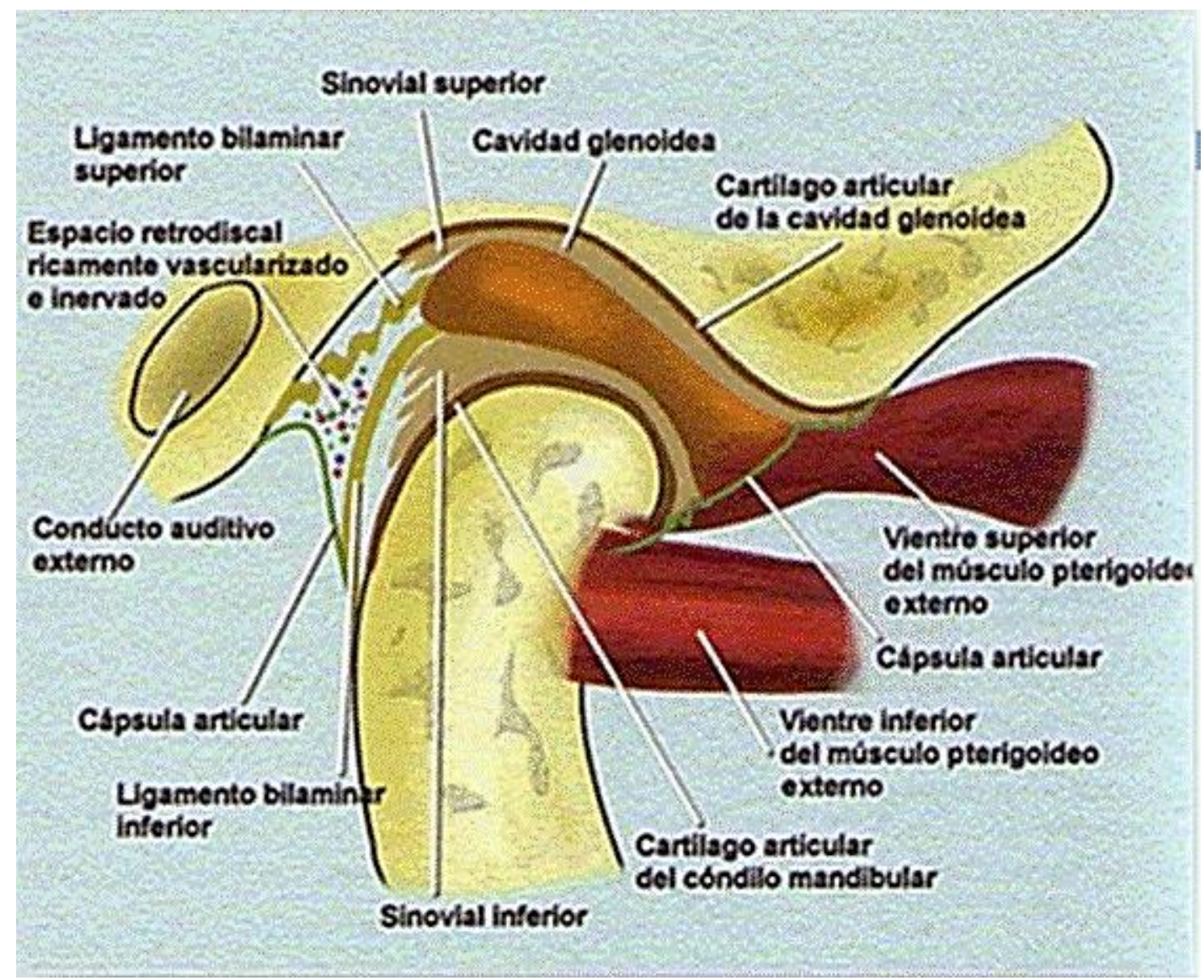

Fuente: Figún ME, Garino RR. 1992. 


\subsubsection{Componentes}

\subsubsection{Superficies articulares}

Implican parte de la fosa mandibular y el tubérculo de cada uno de los huesos temporales y la apófisis condilar de la mandíbula.Representadas por el cóndilo de la mandíbula y por la cavidad glenoidea y el cóndilo del temporal (32).

- Cóndilo mandibular: eminencia elipsoidea situada en el borde superior de la rama ascendente de la mandíbula, a la que está unida por un segmento llamado cuello del cóndilo. La superficie articular tiene dos vertientes: una anterior, convexa, que mira arriba y adelante y otra posterior, plana y vertical.

- Eltubérculo articulary lafosa mandibularrepresentan las superficies articulares del temporal, en correspondencia con la de la mandíbula. La cavidad glenoidea se encuentra dividida en dos zonas, separadas por lacisura de Glasser: una zona anterior, articular, y una zona posterior que corresponde a la pared anterior de la región timpánica del temporal (no articular). En la parte más profunda de la cavidad glenoidea la pared es muy fina siendo esa una zona con alta vulnerabilidad a fracturas. Ambas superficies articulares están cubiertas por tejido fibroso que resiste los roces. Está ausente en la parte más profunda. Amortigua las presiones y las distribuye sobre las superficies articulares. 


\subsubsection{Disco interarticular}

Entre ambas superficies articulares se emerge en la cara superior un disco articular entre el cóndilo de la mandíbula y la fosa mandibular. En la periferia se confunde con el sistema ligamentoso y la cápsula articular. Esto divide a la ATM en dos cavidades: una superior osuprameniscal, y otra inferior oinframeniscal. El menisco presenta dos caras: una, anterosuperior, que es cóncava en su parte más anterior para adaptarse al cóndilo temporal, y convexa en la parte más posterior, que se adapta a la cavidad glenoidea. Otra posteroinferior, cóncava, que cubre al cóndilo mandibular. El borde posterior del menisco es más grueso que el anterior y se divide en dos láminas elásticas, ligeramente distensibles: una se dirige hacia el hueso temporal (freno meniscal superior) y la otra al cóndilo mandibular (freno meniscal inferior). Las dos extremidades laterales (interna y externa) se doblan ligeramente hacia abajo y se fijan por medio de delgados fascículos fibrosos a ambos polos del cóndilo mandibular, lo que explica que el menisco acompañe a la mandíbula en sus desplazamientos. Se puede afirmar que menisco y cóndilo mandibular forman una unidad anatómica y funcional $(33,34)$.

\subsubsection{Sistema ligamentoso}

- Cápsula articular: revestimiento fibroso y laxo alrededor de toda la articulación. Permite una gran amplitud de movimientos. Se inserta en 
las superficies óseas de la vecindad. Está formada por dos planos de haces de fibras verticales: uno superficial, de fibras largas y gruesas, desde la base del cráneo al cuello de la mandíbula. Otro profundo, de fibras cortas, que van del temporal al menisco, y del menisco al cóndilo mandibular. La cápsula articular es delgada en casi toda su extensión, sobre todo en la parte anterior, donde se insertan algunos fascículos de lospterigoideos externos. En zonas donde las fuerzas de tracción son mayores se engruesa para formar los ligamentos de refuerzo. En la parte posterior de la ATM, a los haces fibrosos de la cápsula se añaden unos haces elásticos que nacen cerca de la cisura de Glasser y se insertan en la parte posterior del menisco (haces retro-articulares). Estos haces facilitan el desplazamiento del menisco, pero también limitan su recorrido y el del cóndilo en los movimientos de descenso y los dirigen hacia atrás cuando la mandíbula está en reposo (4).

- Ligamentos de refuerzo: tienen una función pasiva; solo limitan los movimientos. Son intrínsecos a la cápsula (son engrosamientos de la misma):

- Ligamento lateral externo: es el principal medio de unión de la ATM, reforzándola por fuera.

- Ligamento lateral interno: ocupa el lado interno de la cápsula. Es más delgado que el externo.

- Ligamento anterior y ligamento posterior: estos son simples engrosamientos mal delimitados. 
- Ligamentos accesorios: no son exactamente elementos integrantes de la ATM, pero sí contribuyen a limitar sus movimientos extremos. Son el esfenomandibular, el estilomandibular, y el pterigomandibular $(4,32)$.

\subsubsection{Sinoviales}

Son membranas de tejido conectivo laxo que tapizan la cápsula articular por su superficie interior. Es la parte más ricamente vascularizada de la articulación. Segrega el líquido sinovial, líquido viscoso que lubrica la articulación. Son dos: la membrana sinovial superior y la membrana sinovial inferior (4).

\subsubsection{Irrigación sanguínea}

Las arterias de la ATM proceden de varios orígenes $(4,32)$ :

- Arteria temporal superficial, rama de la arteria carótida externa.

- Arteria timpánica, arteria meníngea media y arteria temporal profunda media, ramas de la arteria maxilar.

- Arteria parotídea, rama de la arteria auricular posterior.

- Arteria palatina ascendente, rama de la arteria facial.

- Arteria faríngea ascendente.

En la siguiente figura se esquematiza la irrigación sanguínea de la ATM. 
Figura 11. Arteria carótida y sus ramificaciones en relación con el cuello y la mandíbula.

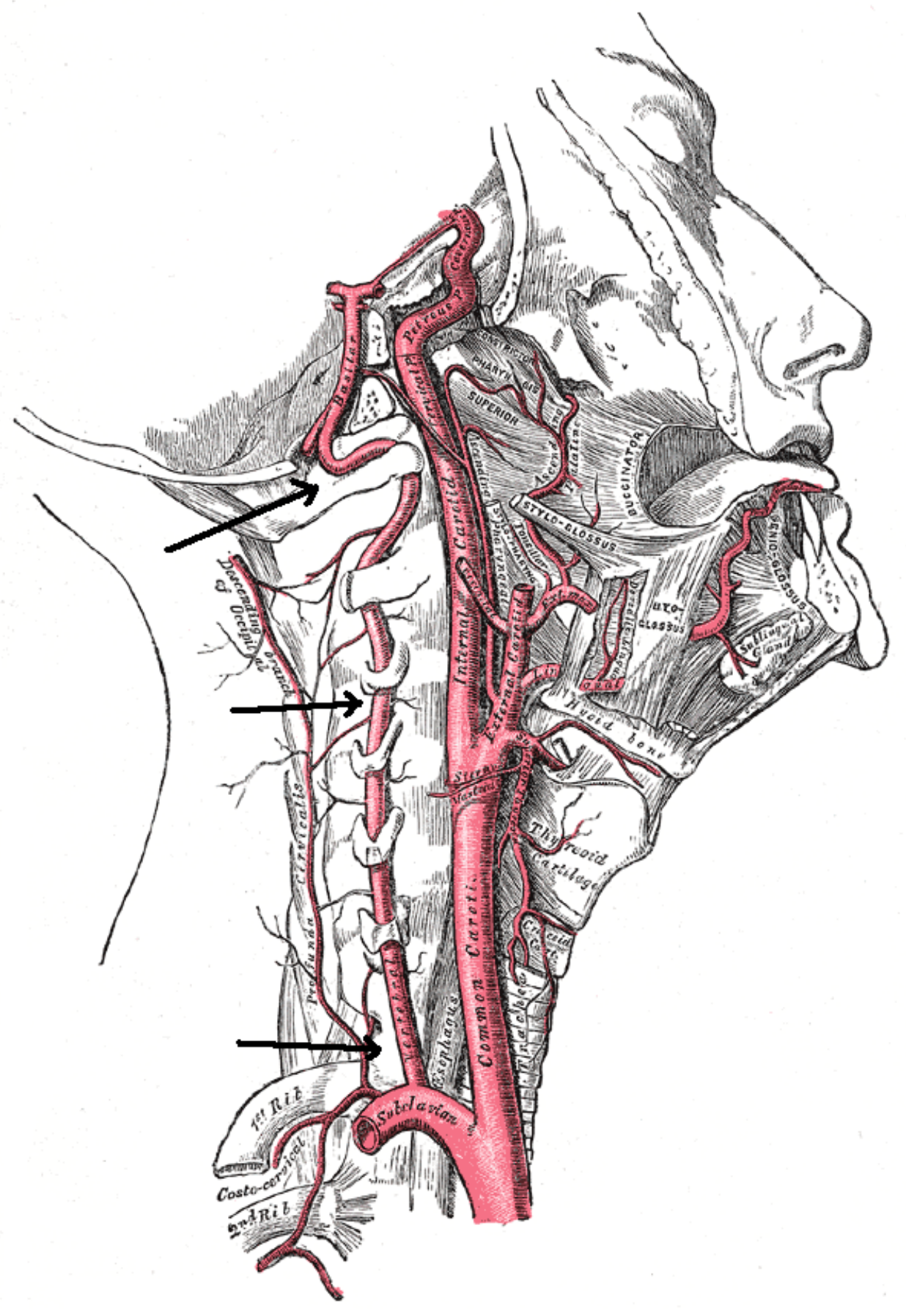

Fuente: Figún ME, Garino RR. 1992. 


\subsubsection{Movimientos de la articulación temporomandibular}

El maxilar inferior puede ejecutar tres clases de movimientos $(2,4,16)$ :

- Movimientos de descenso y elevación: se efectúan alrededor de un eje transversal que pasa por la parte media de la rama ascendente del maxilar inferior, un poco por encima del orificio del conducto dentario. Sobre este eje, entonces, el mentón y el cóndilo se desplazan simultáneamente en sentido inverso. En el movimiento de descenso el mentón se dirige hacia abajo y atrás, mientras el cóndilo se desliza de atrás adelante, deslizando hacia anterior la cabeza del proceso condilar y colocándose bajo la raíz transversa del arco cigomático. El recorrido del cóndilo es de aproximadamente un centímetro. El disco interarticular acompaña al cóndilo en su recorrido, debido a sus uniones ligamentosas y también a que el músculo pterigoideo lateral se inserta en ambas estructuras. Se diferencian dos tiempos en el movimiento de descenso: en un primer tiempo tanto el cóndilo como el disco articular abandonan la fosa mandibular del hueso temporal y se dirigen hacia más anterior; en un segundo momento el disco articular se detiene y el cóndilo, continuando su movimiento, se desliza hacía posterior. El disco articular de la ATM posee una posición de reposo oblicua hacia posterior desde el tubérculo articular, se horizontaliza a medida que la mandíbula se va abriendo, participando acciones de bisagra y deslizamiento cuando se está hiperextendiendo. 
El movimiento de elevación se efectúa por el mismo mecanismo pero en sentido opuesto.

- Movimientos de proyección hacia delante y hacia atrás (de protusión y retrusión): estos movimientos son bastante limitados en el ser humano, pero de gran importancia para los roedores. Se efectúan en el plano horizontal. La protusión es un movimiento por el cual el maxilar inferior se dirige hacia delante, pero conservando el contacto con el maxilar superior. Ambos cóndilos abandonan la cavidad glenoidea y se colocan bajo la raíz transversa. El arco dentario inferior se sitúa así unos 4-5 mm por delante del arco dentario superior. La retrusión es el movimiento por el que el maxilar inferior, deslizándose en sentido inverso, vuelve al punto de partida.

- Movimientos de lateralidad o diducción: son movimientos por los cuales el mentón se inclina alternativamente a derecha e izquierda. Tiene por objeto deslizar los molares inferiores sobre los superiores y desmenuzar los alimentos por efecto de esa fricción. El movimiento se produce cuando uno de los dos cóndilos se desplaza hacia delante colocándose bajo la raíz transversa correspondiente, mientras el otro cóndilo permanece fijo, actuando como eje de giro. Con esto el mentón se desplaza al lado contrario al del cóndilo desplazado. Estos son realizados por el temporal y contralateralmente por el pterigoideo externo y el masetero. 


\subsubsection{Compromiso articular temporomandibular}

Refiere a un conjunto de síntomas y signos principalmente sensitivos, dolor de cabeza (cefalea) y vegetativos, inestabilidad (mareos, vértigos), ocasionados por el impacto o choque de la mandíbula contra el maxilar superior durante sus movimientos funcionales quedando disminuidos 0 limitados. En el aparato masticatorio la articulación comprometida es la ATM; el menoscabo funcional se refiere a la masticación y fonación; la causa del compromiso articular temporomandibular (CAT) es extra o intraarticular y el CAT puede ser uni o bilateral. El CAT es la causa de las migrañas, de las cefaleas tipo migrañosas y del síndrome de boca ardiente (SBA). Pueden puntualizarse las siguientes generalidades $(2,4,16,22)$ :

- La patología de la ATM presenta una elevada prevalencia $(20-40 \%$ de la población).

- Existen muchas clasificaciones pero básicamente se puede dividirlas en dos: las puramente musculares o miofasciales y las intrínsecas de la propia articulación.

- El síndrome más frecuente es el intrínseco de la propia articulación, síndrome de disfunción temporomandibular(SDTM).

- Un factor predisponente muy importante es el estrés.

- En la historia clínica debe darse una importancia especial al síntoma que motiva la consulta. Los síntomas fundamentales son: dolor, chasquido y limitación a la apertura bucal. 
- El manejo de la patología de la ATM debe ser gestionado de forma multidisciplinar.

- Se debe derivar al odontólogo de atención primaria a todo paciente que presente historial de dolor, chasquidos, bloqueos y/o desgastes importantes de los dientes.

- La prueba complementaria habitual es la ortopantomografía y la de elección, la resonancia magnética (RM).

- El tratamiento conservador es eficaz en el $90 \%$ de los casos.

Se calcula que entre un $40-75 \%$ de la población presenta o ha presentado algún signo de disfunción de la ATM. Encuestas realizadas dan una presencia de ruidos en la ATM en un $50 \%$ de la población. No obstante, la mayoría no consultan o buscan atención médica porque los signos o síntomas no les afectan la calidad de vida diaria (24).

Los que buscan asistencia presentan como síntoma principal el dolor orofacial. De hecho el origen principal del dolor orofacial es la presencia de una disfunción de la ATM.

Afecta más a mujeres que a hombres, en una proporción 3:1 hasta 9:1. En cuanto a la edad, es más frecuente entre los 15 y 45 años. La incidencia es mínima en la edad infantil.Como factores de riesgo se encuentran el apretamiento o rechinamiento dentario, las prótesis que no encajan bien, el estrés y la artritis (24). 
Existen otras patologías también muy frecuentes, como el bruxismo y el síndrome miofascial, que aunque no se pueden considerar como patologías propias de la ATM, sí pueden derivar en ella y presentan como factores asociados el estrés y espasmo muscular $(24,26)$.

Existen múltiples clasificaciones de la patología de la ATM.Teniendo en cuenta las múltiples clasificaciones existentes y basándose en criterios prácticos, los problemas temporomandibularesse pueden clasificar en $(2,4,16$, $22,24,26,32)$ :

- Desórdenes musculares o miopatías temporomandibulares: los cuadros más frecuentes son el síndrome miofascial y el bruxismo.

- Desórdenes articulares o artropatías temporomandibulares: son los cuadros intrínsecos de la propia ATM (luxaciones, desplazamientos discales, bloqueos, etc.). 


\section{HIPÓTESIS Y OBJETIVOS}

\subsection{Hipótesis}

Se estableció la siguiente hipótesis de trabajo de carácter correlacional y explicativo:

"La deglución atípica incide en la clase molar".

\subsection{Objetivos}

\subsubsection{Objetivo general}

Establecer si existe relaciónentre deglución disfuncional yla clase molar.

\subsubsection{Objetivos específicos}

- Evaluar epidemiológicamente las características demográficas, funcionales y clase molar de pacientes niños y adolescentes con deglución atípica. 
- Evaluar asociaciones significativas entre la deglución atípica y características demográficas de los pacientes.

- Evaluar asociaciones significativas entre la deglución atípica y los tipos de interposiciones.

- Evaluar asociaciones significativas entre la deglución atípica y la clase molar.

- Evaluar asociaciones significativas entre el tipo de interposición y la clase molar en pacientes con deglución atípica.

- Aportar datos epidemiológicos hacia el logro de la detección temprana del déficit funcional a fin de evitar mayores complicaciones. 


\section{MATERIALES Y MÉTODOS}

\subsection{Tipo y diseño de investigación}

En cuanto al tipo de investigación, a continuación se puntualizan las características de la misma (8):

- Finalidad básica: dado que el estudio se orientó a dar respuesta al interrogante de investigación y satisfacer los objetivos asociados, referentes, desde lo general, a establecer si existe relación entre deglución disfuncional y la clase molar.

- Profundidad descriptiva y correlacional: descriptiva, en tanto la presentación de estadísticos descriptivos asociados a cada variable; correlacional, en tanto la búsqueda de asociaciones significativas entre la deglución disfuncional yla clase molar.

- Amplitud microsociológica: debido a que las fases descriptiva y correlacional del estudio se fundamentaron en un grupo pequeño y muy específico de individuos, cuyas características diferenciales refirieron a que sonpacientes con deglución atípica de 8-15 añosde la ciudad de Santa Rosa, provincia de La Pampa, Argentina, durante el año 2017. 
- Fuentes primarias: ya que, pese a fundamentarse el estudio en un gran espectro de documentos de consulta (como ser libros de texto, artículos de revista, conferencias y congresos, tesis de grado, posgrado y doctorales, y referencias electrónicas, tanto de primera mano como de tipo recopilación), se realizó un trabajo de campo que aporta datos científicos originalesen su generación, sistematización y análisis.

- Carácter cuantitativo: al abordar datos científicos de naturaleza cuantitativa, en muchas variables, codificación mediante. Los mismos fueron sometidos a análisis estadístico, incluyeron datos referentes características generales, exámenes funcionales y de la clase molar.

- Concepción nomotética: ya que si bien los resultados del estudio se circunscriben a un contexto temporal y territorial específico, los mismos pueden generalizarse a otras circunstancias, en tanto refieran a pacientes niños y adolescentes con deglución atípica. Esto se justifica por el hecho que las condiciones anatómicas y clínicas propias de la patología trascienden las limitaciones culturales y demográficas que sí podrían ser limitantes en otro tipo de estudios, como ser de carácter sociológico.

- Orientada a la corroboración: dado que, a partir del trabajo de campo, se deriva directamente la evaluación del estado de corroboración de la hipótesis de trabajo planteada.

- Retrospectiva: dado que se plantea, primero, la medición (presencia) de la variable dependiente (deglución atípica) y la búsqueda de correlaciones con las independientes (entre ellas, la clase molar). 
- Alcance de los resultados analítico y de intervención: analítico, en tanto el análisis de correlaciones entre las variables permitirán plantear lineamientos de interpretación de las mismas; de intervención, en tanto tal análisis correlacional podría derivar en instancias de intervención odontológica, sobre todo de índole preventiva sobre la deglución atípica.

Por su parte, respecto del diseño de investigación, valen las siguientes características (8):

- Ex post facto: en tanto se parte del reconocimiento que las variables medidas ya han ocurrido.

- Transversal: dado que las mediciones de las variables se efectuaron una vez sobre cada unidad de análisis.

- Interpretativo: en tanto el relevamiento e interpretación de datos de naturaleza no opiniática.

- Sociocrítico: dado que el estudio se orienta, en principio, a describir el estado sobre la problemática abordada, mediciones y análisis de variables mediante. 


\subsection{Variables analizadas}

En función al interrogante de investigación, los objetivos y la hipótesis de trabajo, se plantean las siguientes variables, descritas en la tabla según su tipo y función que cumplen en el presente trabajo.

Tabla 1. Tipo y función de las variables analizadas en el estudio.

\begin{tabular}{lll}
\hline Variable & Tipo & Función \\
\hline Deglución atípica & Cuantitativa & Dependiente \\
\hline Aspectos funcionales & Cuantitativa & Independiente \\
\hline Clase molar & Cuantitativa & Independiente \\
\hline Características demográficas & Cuantitativa & Independiente \\
\hline
\end{tabular}

Fuente: Elaboración propia. 


\subsection{Población, unidad de análisis, muestra y criterios de selección}

La población o universo del estudio estuvo conformada por la totalidad de pacientes con deglución atípica, niños y adolescentes, de la ciudad de Santa Rosa, provincia de La Pampa, Argentina, durante el año 2017.

La unidad de análisis estuvo representada por cada uno de los pacientes, aunque a nivel empírico, la unidad de análisis se trabajó de manera grupal.

Por su parte, se conformó una muestra no probabilística, intencional e incidental (8) de 100 pacientes, justificando tal modalidad en tanto la ausencia de estadísticas referentes a la incidencia de tal patología en el contexto territorial de la ciudad de Santa Rosa, provincia de La Pampa.

No obstante, la muestra se confeccionó mediante la satisfacción de los criterios de selección presentados en la siguiente tabla. 
Tabla 2. Criterios de selección de los participantes del estudio.

\begin{tabular}{lll}
\hline Criterios de inclusión & \multicolumn{1}{l}{ Criterios de exclusión } \\
\hline - Ser niño o adolescente con & - No deseo de participar en el \\
diagnóstico de deglución atípica, de & estudio. \\
cualquier característica funcional. & - No satisfacción del consentimiento \\
- Ser paciente con tal patología & informado escrito por parte de los \\
residente en la ciudad de Santa & padres/tutores. \\
Rosa, provincia de La Pampa. & - Presentación de complicaciones \\
- Ser paciente tratado en cualquier & asociadas a la determinación de la \\
centro médico durante el año 2017. & clase molar en sentido sagital. \\
- Ser paciente de 8-15 años de edad. & \\
- Ser paciente de cualquier sexo.
\end{tabular}

Fuente: Elaboración propia.

\subsection{Recolección de datos}

En relación con los procedimientos de recolección de datos, primero se acudió a los centros médicos odontológicos de la ciudad de Santa Rosa Capital con el fin de relevar potenciales pacientes participantes del estudio, previa presentación de las características teleológicas y metodológicas del estudio a las autoridades de dichas instituciones. 
En los casos en los que se encontró al menos un caso, se procedió a entregar un formulario de consentimiento informado destinado a los padres/ tutores de los niños o adolescentes, vía institución. Dicho formulario se dispone en el Anexo A.

Una vez obtenidos dichos consentimientos informados escritos, se procedió a realizar un examen clínico anatomofuncionalendo y exobucal, con todos los elementos de bioseguridad, entre los cuales se puntualizan los siguientes:

- Guantes.

- Barbijos.

- Baja lenguas.

- Anteojos.

- Juegos clínicos.

El examen comentado constó de dos tipos de procedimientos, el funcional y el de clase molar. Respecto del primero, se ubica al paciente en una silla delante del odontólogo y se le pide que piense en algo que haya vivido en las vacaciones o en el último fin de semana, para poder evaluar la deglución espontánea de saliva. Así, se observa si posee deglución atípica con interposición labial, interposición lingual o interposición labial y lingual (22).

Por su parte, respecto del examen de clase molar, el mismo se realizó en sentido sagital, teniendo en cuenta la clasificación de relación molar de Angle (20), pero aunando todas las subclases II en una Clase II totalitaria. 
Los datos así obtenidos fueron registrados en una ficha clínica que constó de trespartes:

- Datos generales:datos personales solicitados a los padres o tutores del niño/a o adolescente.

- Datos del examen funcional: determinación de deglución atípica con interposición labial, interposición lingual o interposición labial y lingual.

- Datos del examen de la clase/ relación molar: determinación de la relación molar según Clase I, II o III.

El formulario de tal ficha clínica se anexa modelo de historia clínica.

\subsection{Análisis de los datos}

El análisis de los datos se desarrolló siguiendo una doble estrategia, una descriptiva y otra inferencial. Respecto de la primera, se presentaron estadísticos descriptivos para todas las variables medidas en el estudio, utilizando frecuencias absolutas y porcentajes asociados para las variables nominales, y media, intervalo de confianza al 95\% (IC 95\%), desviación típica (Dt), mediana, mínimo y máximo para las variables continuas.

Respecto de la estrategia inferencial, y teniendo en cuenta los objetivos y la naturaleza de las variables (presencia del tipo de interposición y de la relación molar), se utilizaron herramientas no paramétricas, ANOVA de 
Kruskal-Wallis y $\mathrm{U}$ de Mann-Whitney, según se trate de emparejar más de 2 o 2 factores, respectivamente. También se utilizó la prueba de chi-cuadrado para analizar la existencia de diferencias estadísticamente significativas entre categorías medidas dentro de una misma variable (35).

La matriz de datos y los análisis estadísticos fueron desarrollados utilizando el programa SPSS versión 24.0 para Windows, aceptando un nivel de significancia de $p<0,05$ en los análisis inferenciales. 


\section{Resultados}

Todos los resultados de esta sección se efectuaron en función de la matriz de datos dispuesta en el Anexo C.

\subsection{Análisis descriptivos}

\subsubsection{Edad}

Al considerar la edad como variable cuantitativa y continua, para la muestra total se halló una media de 9,89 años (IC 95\%=9,34-10,44 años), Dt=2,752 años, mínimo=6 años y máximo=15 años.

Por su parte, considerando el rango de 6-15 años para la muestra total, cada edad particular fue utilizada como valor nominal, categoría etaria, en tanto la necesidad de discriminar los valores de la variable dependiente según esta independiente.

De esta manera, se halló un mayor recuento para los pacientes con 8 años de edad $(n=15)$, inmediatamente seguidos por aquellos de 7 y 9 años (ambos con 14 casos cada uno), 6, 13 y 14 años (todos con 10 casos cada 
uno), 11 años $(n=9), 12$ años $(n=8), 10$ años $(n=6)$ y, finalmente, 15 años $(n=4)$, según se representa en la siguiente figura.

Figura 12. Porcentajes asociados a las categorías etariasde los pacientes en la muestra total $(n=100)$.
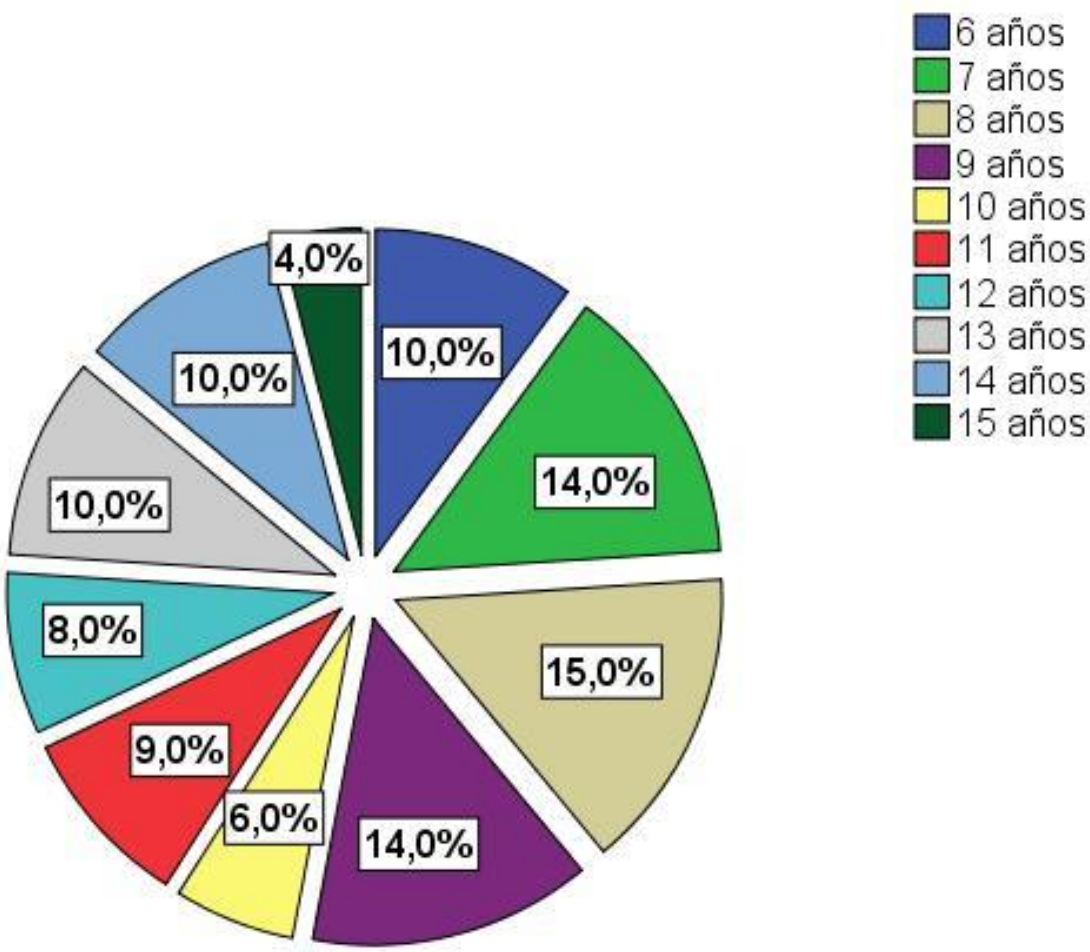

Fuente: Elaboración propia.

Desde la prueba de chi-cuadrado, depreciando la serie de datos de pacientes con 15 años de edad (dado que el recuento $<5$ podría generar 
sesgos estadísticos al aplicar la prueba estadística) (35), no se hallaron diferencias estadísticamente significativas $(p>0,05)\left(x^{2}=6,938 ; p=0,543 ; 8 \mathrm{gl}\right)$, ello indicando equivalencia estadística entre las distintas edades de los pacientes incluidos en el estudio.

Por su parte, también se definieron categorías de edad en función de las etapas de desarrollo de los pacientes; es decir, niñez y adolescencia. Puntualmente, los pacientes de 6-9 años se consideraron como niños/as, mientras que aquellos de 10-15 años, como adolescentes, siguiendo la definición de adolescencia de la Organización Mundial de la Salud (OMS), según la cual el período de desarrollo de la adolescencia se encuentra entre los 10 y 19 años de edad (36).

Así, si bien un mayor recuento se correspondió con la niñez $(n=53)$, el mismo fue muy similar al de la adolescencia $(n=47)$, según se aprecia en la siguiente figura. 
Figura 13. Porcentajes asociados a las categorías de niñez y adolescencia de los pacientes en la muestra total $(n=100)$.

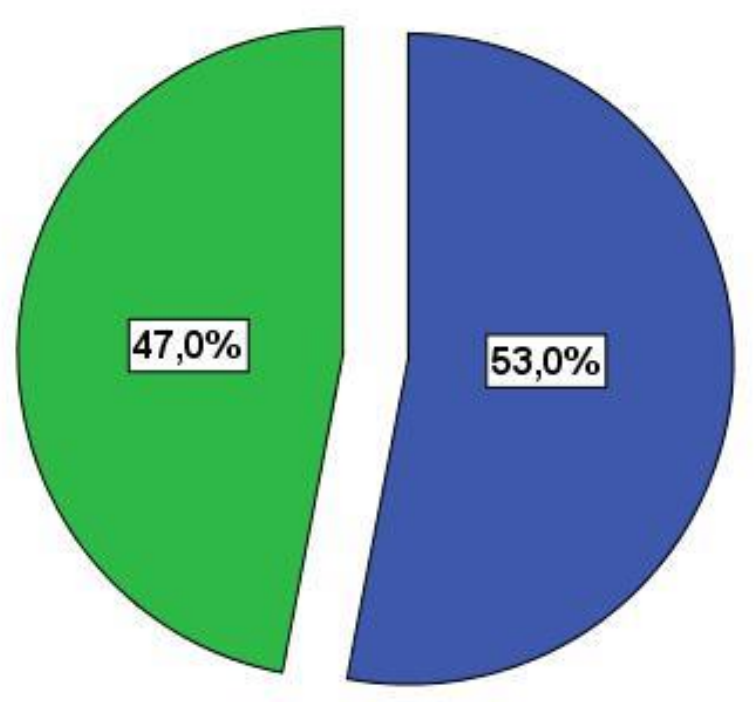

Fuente: Elaboración propia.

Considerando los anteriores valores de frecuencia, no se hallaron diferencias estadísticamente significativas $(p>0,05)$ desde la prueba de chicuadrado $\left(x^{2}=0,360 ; p=0,549 ; 1 \mathrm{gl}\right)$, hecho justificado en tanto la equivalencia estadística entre ambos períodos de desarrollo en la muestra total. 


\subsubsection{Sexo}

Respecto del género de los pacientes, se halló una mayor frecuencia de pacientes del género femenino $(n=61)$, en comparación con aquellos del género masculino $(n=39)$, según se aprecia en la siguiente figura.

Figura 14. Porcentajes asociados al sexo/ género de los pacientes en la muestra total $(n=100)$.

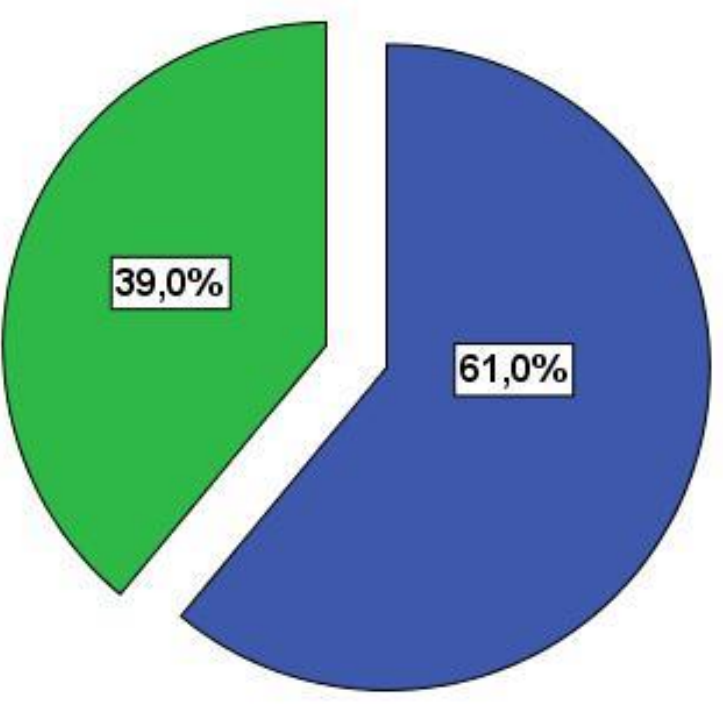

Fuente: Elaboración propia. 
Como podría estipularse, desde la prueba de chi-cuadrado se hallaron diferencias estadísticamente significativas $(p<0,05)\left(x^{2}=4,840 ; p=0,028 ; 1 \mathrm{gl}\right)$, las cuales se justificaron a partir de la mayor y significativa cantidad de pacientes del género femenino, en comparación con aquellos masculinos.

\subsubsection{Examen funcional de la deglución atípica}

Respecto del tipo de deglución atípica en función del examen funcional, prácticamente la totalidad de los pacientes presentaron la anomalía con interposición lingual $(n=88)$, luego seguido por aquellos con interposición mixta

(lingual y labial) $(n=8)$ y, finalmente, aquellos con interposición labial $(n=4)$, según se aprecia en la siguiente figura. 
Figura 15. Porcentajes asociados al tipo de deglución atípica de los pacientes en la muestra total $(n=100)$.

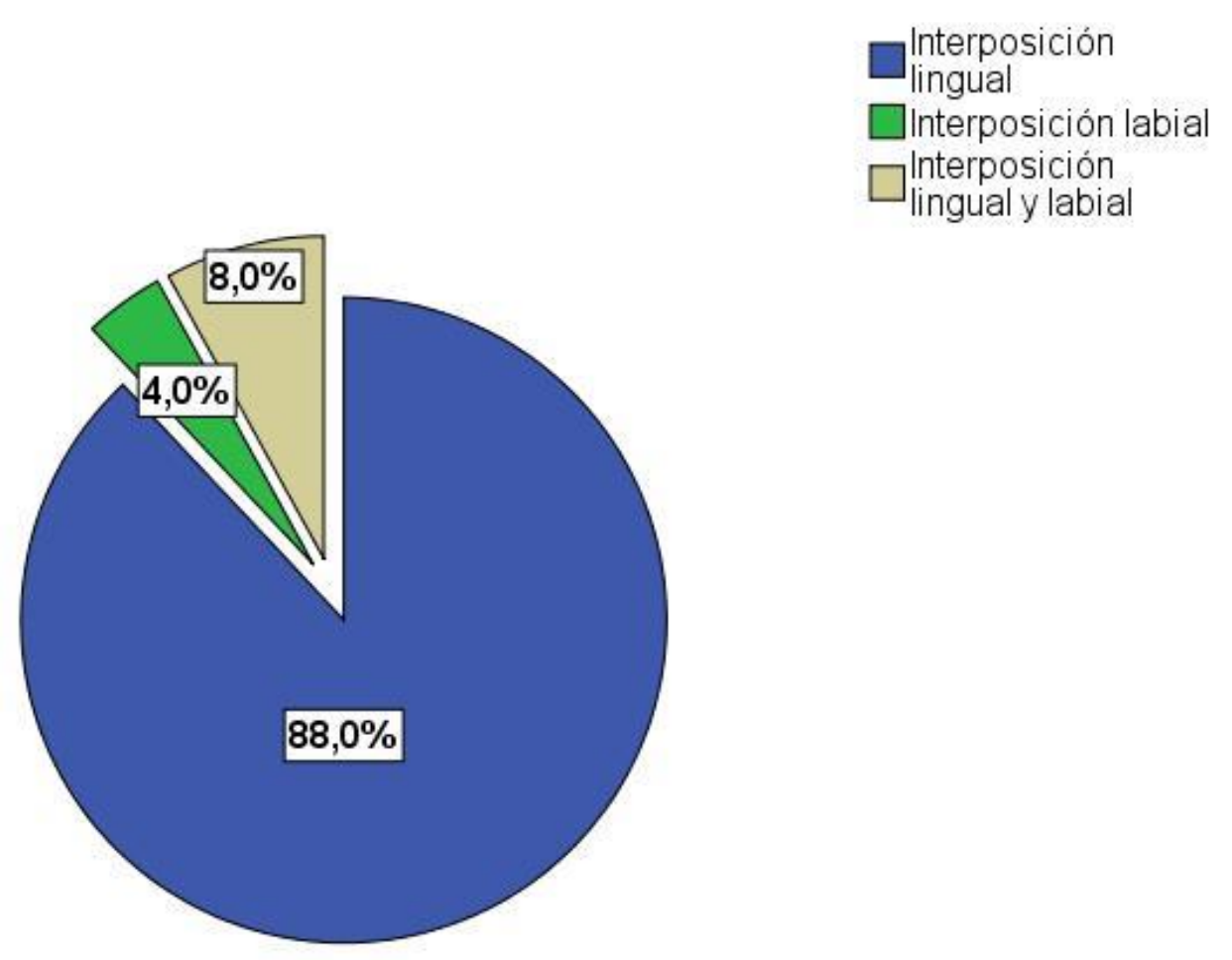

Fuente: Elaboración propia.

Al aplicar la prueba de chi-cuadrado sobre las anteriores series de datos, pero depreciando la de interposición labial por recuento $<5$, se hallaron diferencias estadísticamente significativas $(p<0,05)\left(x^{2}=66,667 ; p=0,000 ; 1 \mathrm{gl}\right)$, ello justificándose a partir de la mayor y significativa cantidad de pacientes con deglución atípica con interposición lingual. 


\subsubsection{Clase/ relación molar}

Respecto de la clase/ relación molar, un mayor recuento se correspondió con la Clase II $(n=66)$, seguido por los pacientes con Clase I $(n=27)$ y, finalmente, aquellos con Clase III $(n=7)$, según se aprecia en la siguiente figura.

Figura 16. Porcentajes asociados a la clase/ relación molar de los pacientes en la muestra total $(n=100)$.

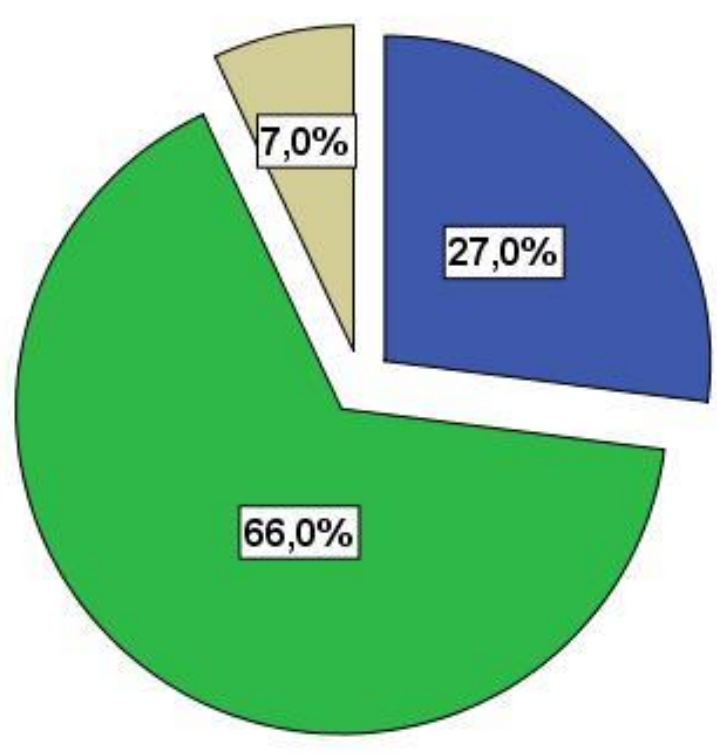

Fuente: Elaboración propia. 
Desde la prueba de chi-cuadrado, considerando los anteriores valores de frecuencia, se hallaron diferencias estadísticamente significativas $(p<0,05)$ $\left(x^{2}=54,020 ; p=0,000 ; 2 \mathrm{gl}\right)$, las cuales se justificaron en tanto la mayor $y$ significativa cantidad de pacientes con clase/ relación molar II, al comparar su recuento con el de la variante de frecuencia menor inmediata (Clase I) y hallar resultados similares $(p<0,05)\left(x^{2}=16,355 ; p=0,000 ; 1 \mathrm{gl}\right)$.

\subsection{Análisis inferenciales}

\subsubsection{Edad y sexo}

Al considerar la edad como variable continua, se obtuvieron los estadísticos descriptivos y análisis mediante la prueba $U$ de Mann-Whitney presentados en la siguiente tabla. 
Tabla 3. Estadísticos descriptivos y prueba U de Mann-Whitney para la edad como variable continua según el sexo.

\begin{tabular}{lllllll}
\hline Género & Media & Dt & Mediana & Mínimo & Máximo & U de Mann- \\
& (IC & & & & & Whitney \\
& $95 \%)$ & & & & & \\
\hline Femenino & 10,05 & 2,819 & 10,00 & 6 & 15 & $\mathrm{U}=1099,500 ;$ \\
& $(9,33-$ & & & & & $\mathrm{p}=0,522$ \\
& $10,77)$ & & & & & \\
\hline Masculino & 9,64 & 9,00 & 2,661 & 6 & 15 & \\
& $(8,78-$ & & & & & \\
& $10,50)$ & & & & & \\
\end{tabular}

Fuente: Elaboración propia.

En este sentido, no se hallaron diferencias estadísticamente significativas $(p>0,05)$ entre los géneros de los pacientes respecto de la edad como variable continua.

Por su parte, recordando la presentación de estadísticos descriptivos para edad según variable continua, nominal y categorizada según desarrollo del individuo (niñez y adolescencia), para los cruzamientos con el género también se consideraron tales alternativas. 
Así, respecto de las categorías etarias, primero en relación con los pacientes de 6 años de edad, se halló un mayor recuento de aquellos del género femenino $(n=7)$, en comparación con los del género masculino $(n=3)$, según se aprecia en la siguiente figura.

Figura 17. Porcentajes asociados al sexo/ género de los pacientes de 6 años de edad $(n=10)$.

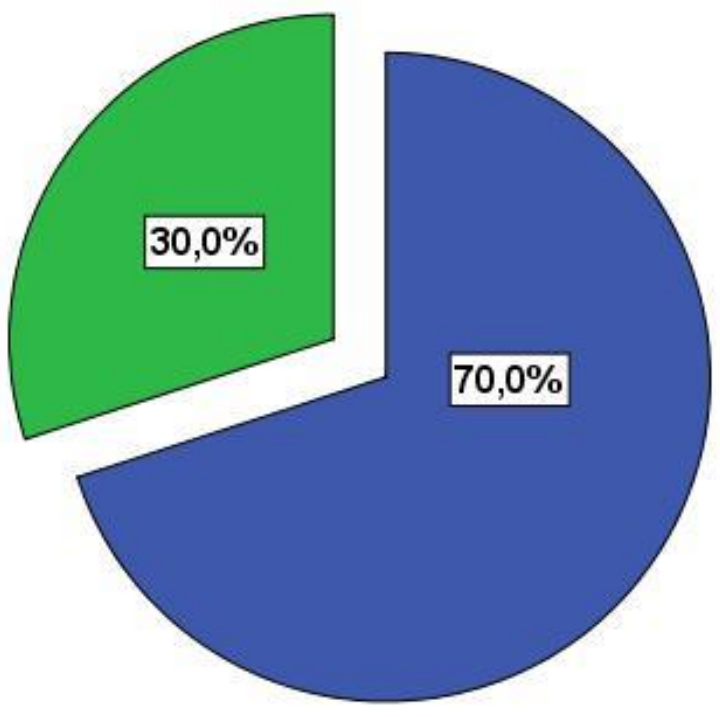

Fuente: Elaboración propia. 
En este caso, no resultó factible realizar la prueba de chi-cuadrado (dado el recuento $<5$ en la serie de datos del género masculino), pero interpretando valores similares entre los pacientes de ambos géneros; es decir, tendencia hacia la equivalencia estadística.

Respecto de los pacientes de 7 años, el recuento también fue ligeramente mayor en los pacientes de género femenino $(n=9)$, en comparación con los del género masculino $(n=5)$, según se presenta en la siguiente figura.

Figura 18. Porcentajes asociados al sexo/género de los pacientes de 7 años de edad $(n=14)$.

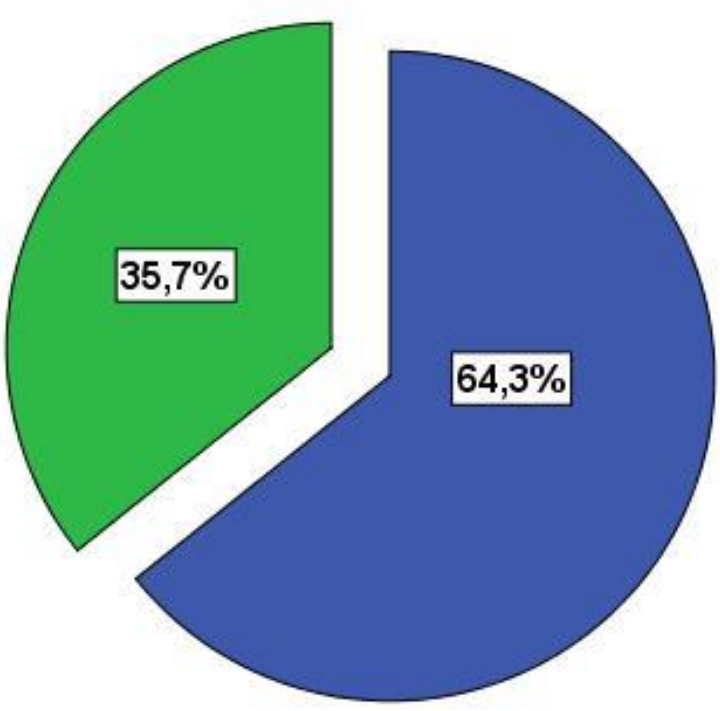


Fuente: Elaboración propia.

En relación con las anteriores frecuencias, no se hallaron diferencias estadísticamente significativas $(p>0,05)$ desde la prueba de chi-cuadrado $\left(x^{2}=1,143 ; p=0,285 ; 1 \mathrm{gl}\right)$, indicando equivalencia estadística entre las pacientes y los pacientes de 7 años de edad.

Respecto de los pacientes de 8 años de edad, un mayor recuento, al contrario que los anteriores casos, se correspondió con el género masculino $(n=10)$, en comparación con el femenino $(n=5)$, según se aprecia en la siguiente figura. 
Figura 19. Porcentajes asociados al sexo/ género de los pacientes de 8 años de edad $(n=15)$.

Femenino

Masculino

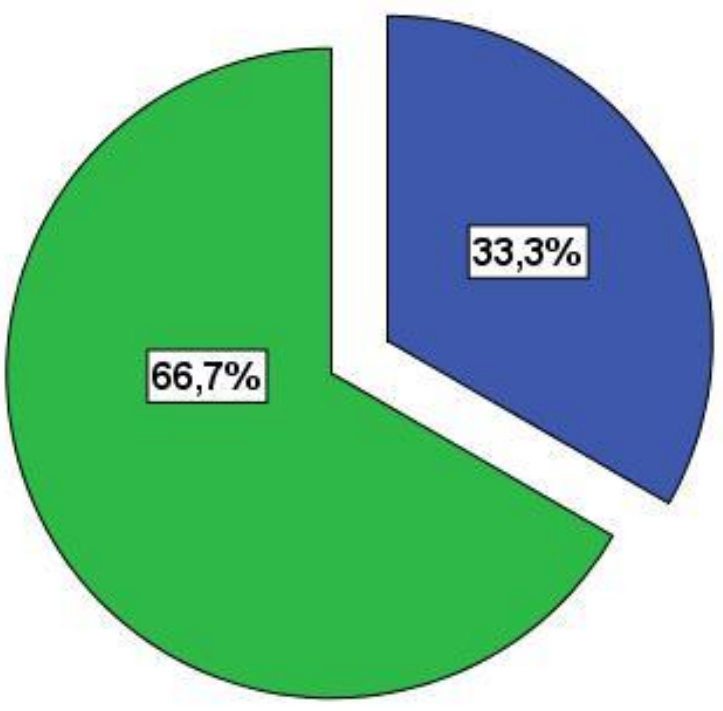

Fuente: Elaboración propia.

Al comparar los recuentos, no se hallaron diferencias estadísticamente significativas $(p>0,05)\left(x^{2}=1,667 ; p=0,197 ; 1 \mathrm{gl}\right)$, indicando equivalencia estadística entre las pacientes y los pacientes de 8 años de edad. 
Respecto de los pacientes de 9 años de edad, los recuentos fueron similares, pero siendo mayor en el género femenino $(n=8)$, en comparación con el masculino $(n=6)$, según se aprecia en la siguiente figura.

Figura 20. Porcentajes asociados al sexo/ género de los pacientes de 9 años de edad $(n=14)$.

Femenino

Masculino

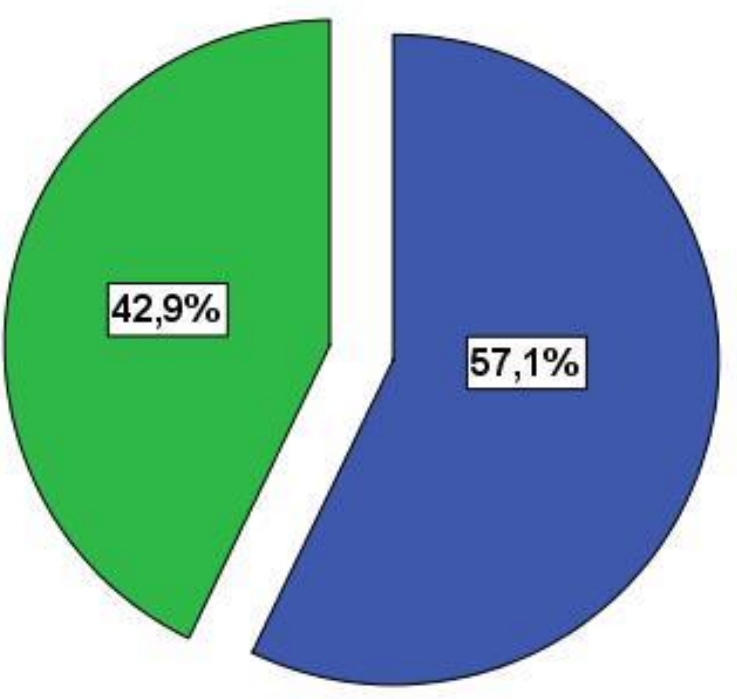

Fuente: Elaboración propia. 
Considerando los anteriores valores de frecuencias, no se hallaron diferencias estadísticamente significativas $(p>0,05)\left(x^{2}=0,286 ; p=0,593 ; 1 \mathrm{gl}\right)$, ello indicando equivalencia estadística entre las pacientes y los pacientes de 9 años de edad.

Respecto de los pacientes de 10 años de edad, los recuentos fueron similares entre las alternativas, pero mayor en el género femenino $(n=7)$ que en el masculino $(n=2)$, según se aprecia en la siguiente figura.

Figura 21. Porcentajes asociados al sexo/ género de los pacientes de 10 años de edad $(n=6)$.

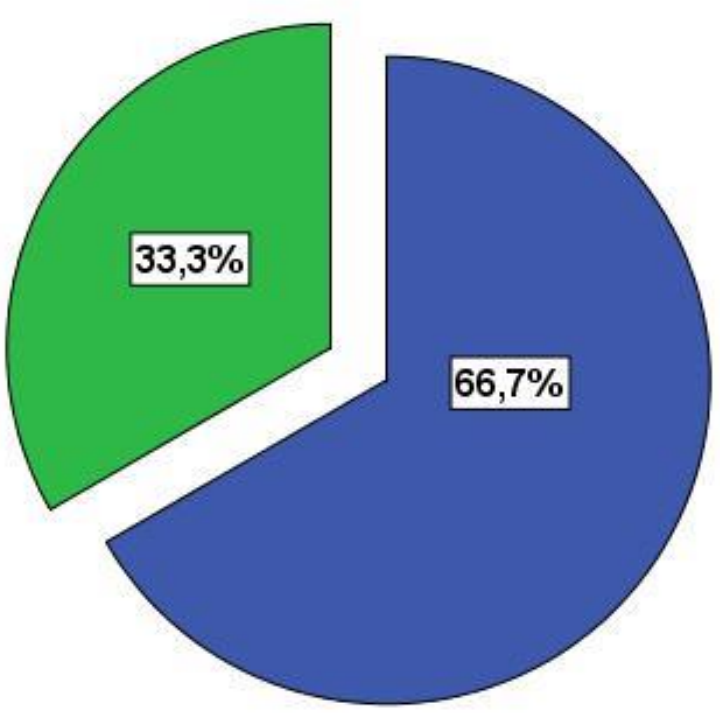


Fuente: Elaboración propia.

Hallándose que ambas series de datos poseen recuentos $<5$, no se efectuó la prueba de chi-cuadrado; sin embargo, puede interpretarse cierta equivalencia entre las pacientes y los pacientes de 10 años de edad.

Respecto de los pacientes de 11 años de edad, un mayor recuento se correspondió con aquellos de género femenino $(n=7)$, en comparación con los del género masculino $(n=2)$, según se aprecia en la siguiente figura. 
Figura 22. Porcentajes asociados al sexo/ género de los pacientes de 11 años de edad $(n=9)$.

Masculino

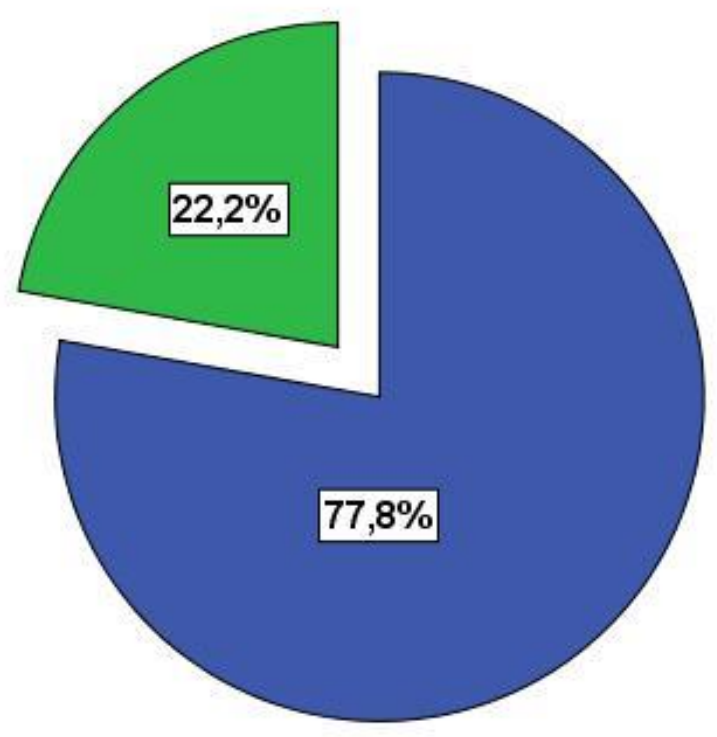

Fuente: Elaboración propia.

No resultó factible realizar la prueba de chi-cuadrado dado el recuento < 5 en la serie de datos del género masculino; sin embargo, puede interpretarse cierta equivalencia entre las pacientes y los pacientes de 11 años de edad en lo que hace a su frecuencia. 
Respecto de los pacientes de 12 años de edad, se halló un mayor recuento en los pacientes de género femenino $(n=6)$, en comparación con aquellos de género masculino $(n=2)$, según se aprecia en la siguiente figura.

Figura 23. Porcentajes asociados al sexo/ género de los pacientes de 12 años de edad $(n=8)$.

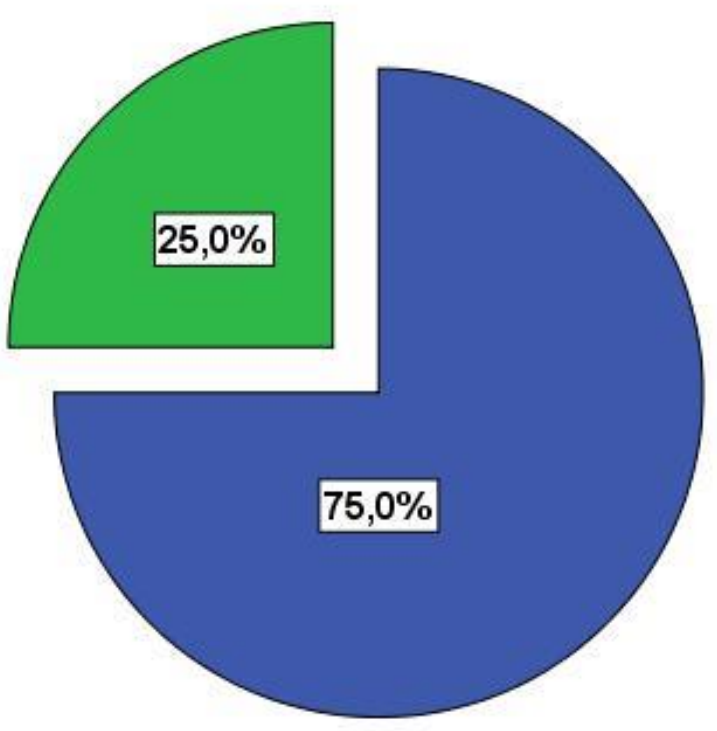

Fuente: Elaboración propia. 
Hallándose una serie de datos con recuento < 5 (género masculino), no resultó factible realizar la prueba de chi-cuadrado; sin embargo, se interpretó cierta equivalencia entre las pacientes y los pacientes de 12 años de edad en lo que hace a su frecuencia.

Respecto de los pacientes de 13 años de edad, los recuentos fueron similares, pero ligeramente mayor en el género femenino $(n=6)$, en comparación con el masculino $(n=4)$, según se aprecia en la siguiente figura.

Figura 24. Porcentajes asociados al sexo/ género de los pacientes de 13 años de edad $(n=10)$.

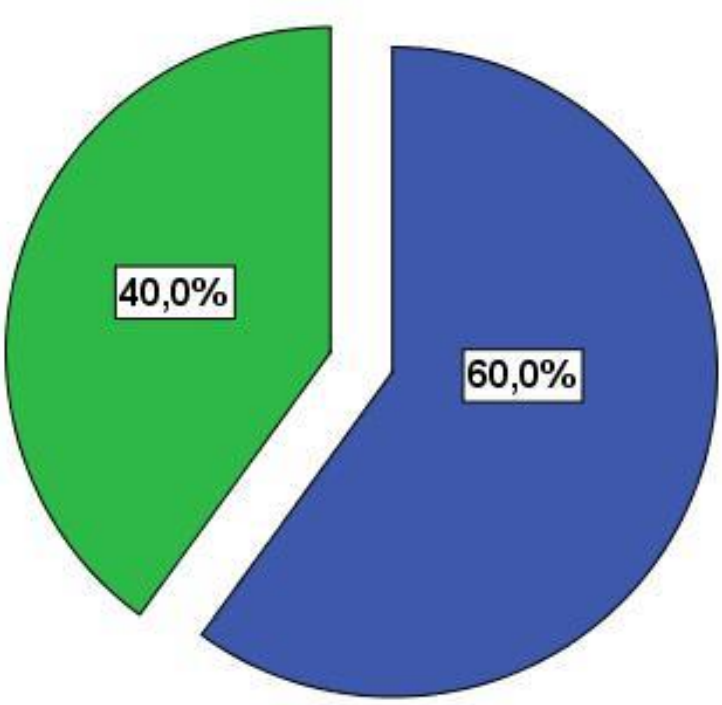


Fuente: Elaboración propia.

Nuevamente, al hallar que la serie de datos del género masculino se asoció con un recuento $<5$, no resultó factible realizar la prueba de chicuadrado, pero interpretándose cierta equivalencia entre las pacientes y los pacientes de 13 años de edad en lo que hace a su frecuencia.

Respecto de los pacientes de 14 años de edad, se halló un mayor recuento para el género femenino $(n=6)$, en comparación con el masculino $(n=4)$, según se aprecia en la siguiente figura. 
Figura 25. Porcentajes asociados al sexo/ género de los pacientes de 14 años de edad $(n=10)$.

Femenino

Masculino

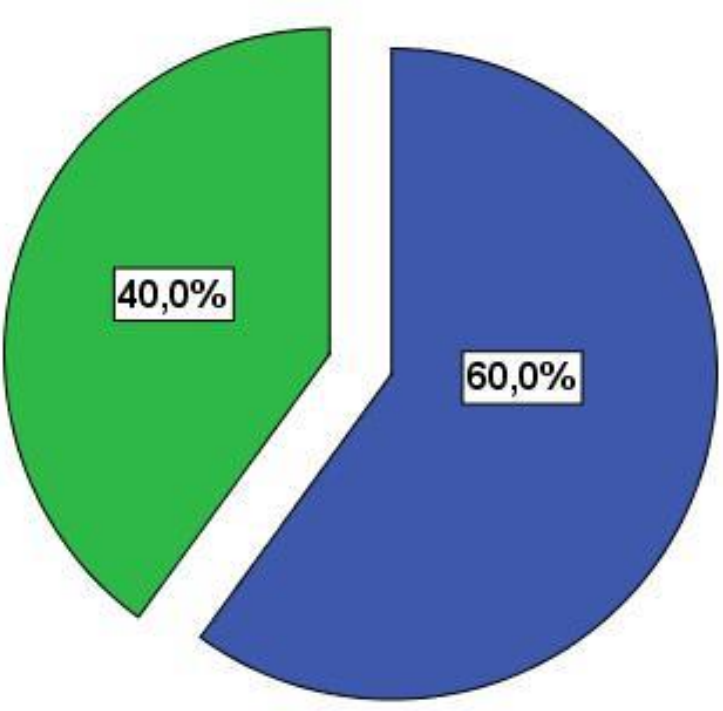

Fuente: Elaboración propia.

Asociándose la serie de datos del género masculino con un recuento < 5, no resultó confiable realizar la prueba de chi-cuadrado; sin embargo, es prudente interpretar cierta equivalencia entre las frecuencias de las pacientes y los pacientes de 14 años de edad en lo que hace a su frecuencia. 
Respecto de los pacientes de 15 años de edad, un mayor recuento se correspondió con el género femenino $(n=3)$, en comparación con el masculino $(n=1)$, según se aprecia en la siguiente figura.

Figura 26. Porcentajes asociados al sexo/ género de los pacientes de 15 años de edad $(n=4)$.

Femenino

Masculino

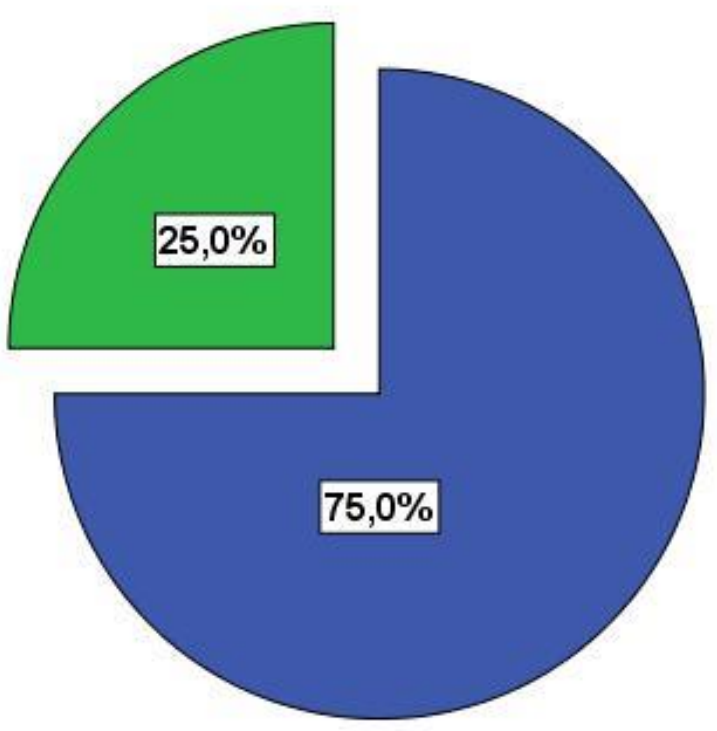

Fuente: Elaboración propia. 
Nuevamente, ambas series de datos presentaron recuentos $<5$ casos, así no siendo conveniente realizar la prueba de chi-cuadrado, pero pudiendo estipular cierta equivalencia estadística entre las frecuencias de las pacientes y los pacientes de 15 años de edad.

Por último, al considerar la etapa de desarrollo del paciente, primero respecto de la niñez, los recuentos fueron similares, pero ligeramente mayor en el género femenino $(n=29)$, en comparación con el masculino $(n=24)$, según se aprecia en la siguiente figura. 
Figura 27. Porcentajes asociados al sexo/ género de los pacientes niños/as $(n=53)$.

Femenino

Masculino

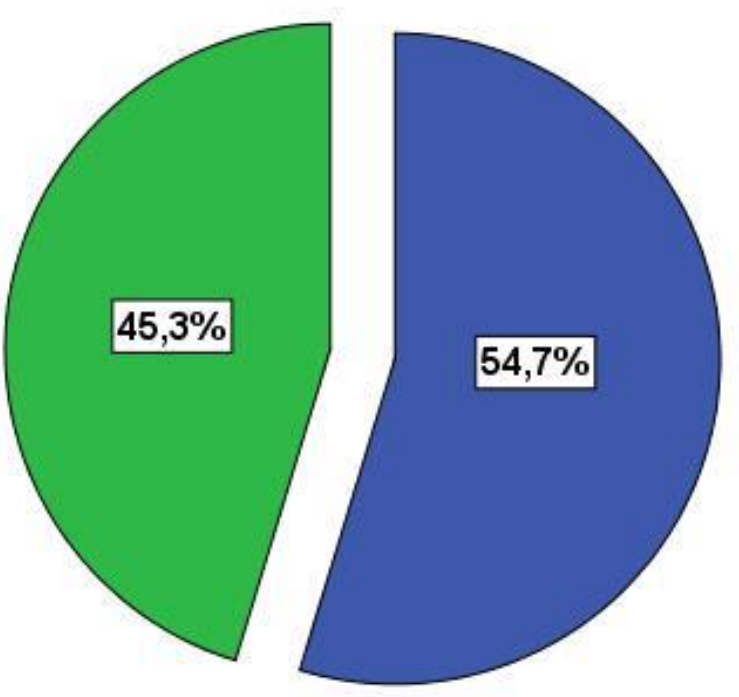

Fuente: Elaboración propia.

A partir de la prueba de chi-cuadrado no se hallaron diferencias estadísticamente significativas $(p>0,05)\left(x^{2}=0,472 ; p=0,492 ; 1 \mathrm{gl}\right)$, ello indicando equivalencia estadística entre las pacientes y los pacientes en etapa de niñez en relación con sus frecuencias. 
Por su parte, respecto de la adolescencia, también el recuento mayor se correspondió con el género femenino $(n=32)$, en comparación con el masculino $(n=15)$, según se aprecia en la siguiente figura.

Figura 28. Porcentajes asociados al sexo/ género de los pacientes adolescentes $(n=47)$.

Femenino

Masculino

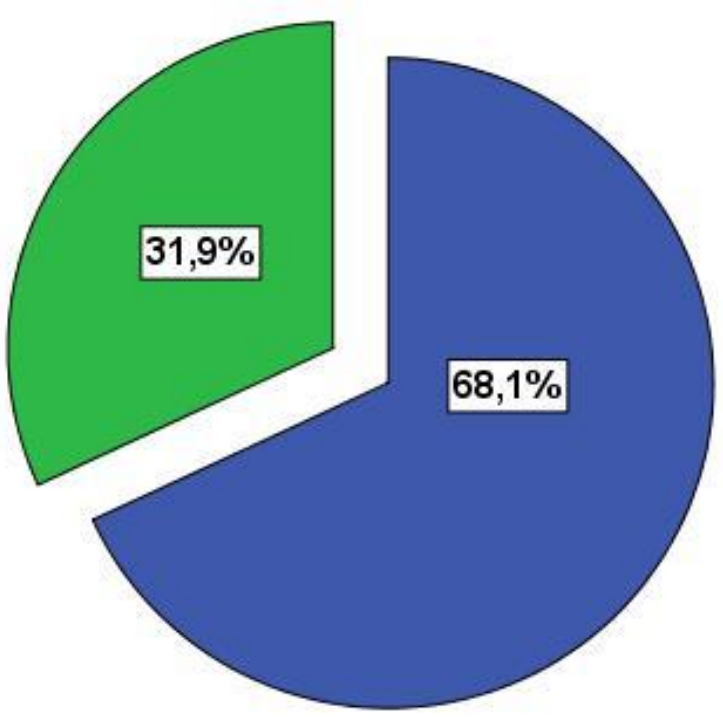

Fuente: Elaboración propia. 
Considerando los anteriores valores de frecuencia, se hallaron diferencias estadísticamente significativas $(p<0,05)$ desde la prueba de chicuadrado $\left(X^{2}=6,149 ; p=0,013 ; 1 \mathrm{gl}\right)$, ello justificándose a partir de la mayor $\mathrm{y}$ significativa cantidad de adolescentes mujeres que varones.

\subsubsection{Examen funcional y factores demográficos}

\subsubsection{Todas las interposiciones}

Primero se realizó un análisis varianza (Kruskal-Wallis o $U$ de MannWhitney) para evaluar las relaciones entre todas las interposiciones y las categorías etarias, las categorías de desarrollo del paciente y su género. Así, en la siguiente tabla se presentan los análisis inferenciales correspondientes respecto de tales factores demográficos.

Tabla 4. ANOVA de Kruskal-Wallis y $U$ de Mann-Whitney para las interposiciones de la deglución atípica según las categorías etarias, el desarrollo del paciente y el género $(n=100)$.

\begin{tabular}{llllll}
\hline Relación & Kruskal-Wallis & U de Mann- \\
& & & Whitney & \\
\hline Interposiciones/ & Categorías & $x^{2}=8,665 ;$ & $p=0,469 ;$ & - \\
\hline
\end{tabular}




\begin{tabular}{|c|c|c|}
\hline Relación & Kruskal-Wallis & $\begin{array}{l}\text { U de Mann- } \\
\text { Whitney }\end{array}$ \\
\hline etarias & $9 \mathrm{gl}$ & \\
\hline $\begin{array}{l}\text { Interposiciones/ Categorías de } \\
\text { desarrollo }\end{array}$ & - & $\begin{array}{l}U=1171,500 \\
p=0,365\end{array}$ \\
\hline Interposiciones/ Género & - & $\begin{array}{l}U=1157,500 \\
p=0,688\end{array}$ \\
\hline
\end{tabular}

Fuente: Elaboración propia.

En este sentido, ninguna de las interposiciones en pacientes con deglución atípica se relacionó estadística ni significativamente $(p>0,05)$ con la edad, la etapa de desarrollo ni el género de los mismos. Podría afirmarse que la clasificación de interposiciones es independiente de los factores demográficos de los pacientes con deglución atípica.

Sin embargo, en los siguientes subapartados se analizaron particularmente cada tipo de interposición respecto de tales factores demográficos, a modo de corroboración de lo anterior hallado. 


\subsubsection{Interposición lingual}

Respecto de la interposición lingual, en la siguiente tabla se presentan los recuentos, porcentajes y prueba de chi-cuadrado asociadosa las categorías etarias.

Tabla 5. Recuentos, porcentajes y chi-cuadrado para la deglución atípica con interposición lingual respecto de las categorías etarias $(n=88)$.

\begin{tabular}{|c|c|c|c|}
\hline $\begin{array}{l}\text { Categoría } \\
\text { (años) }\end{array}$ & etaria $n$ & $\%$ & $\mathrm{x}^{2}$ \\
\hline 6 & 8 & 9,1 & $x^{2}=10,409 ; p=0,318$ \\
\hline 7 & 11 & 12,5 & $9 \mathrm{gl}$ \\
\hline 8 & 15 & 17,0 & \\
\hline 9 & 11 & 12,5 & \\
\hline 10 & 5 & 5,7 & \\
\hline 11 & 9 & 10,2 & \\
\hline 12 & 7 & 8,0 & \\
\hline 13 & 10 & 11,4 & \\
\hline 14 & 8 & 9,1 & \\
\hline 15 & 4 & 4,5 & \\
\hline
\end{tabular}

Fuente: Elaboración propia. 
Es decir, no se hallaron diferencias estadísticamente significativas ( $p>$ $0,05)$ al considerar las categorías etarias de pacientes con interposición lingual. En la siguiente figura se representan los recuentos y porcentajes de la anterior tabla para las categorías etarias en la interposición lingual.

Figura 29. Porcentajes asociados a los pacientes con interposición lingual según las categorías etarias $(n=88)$.

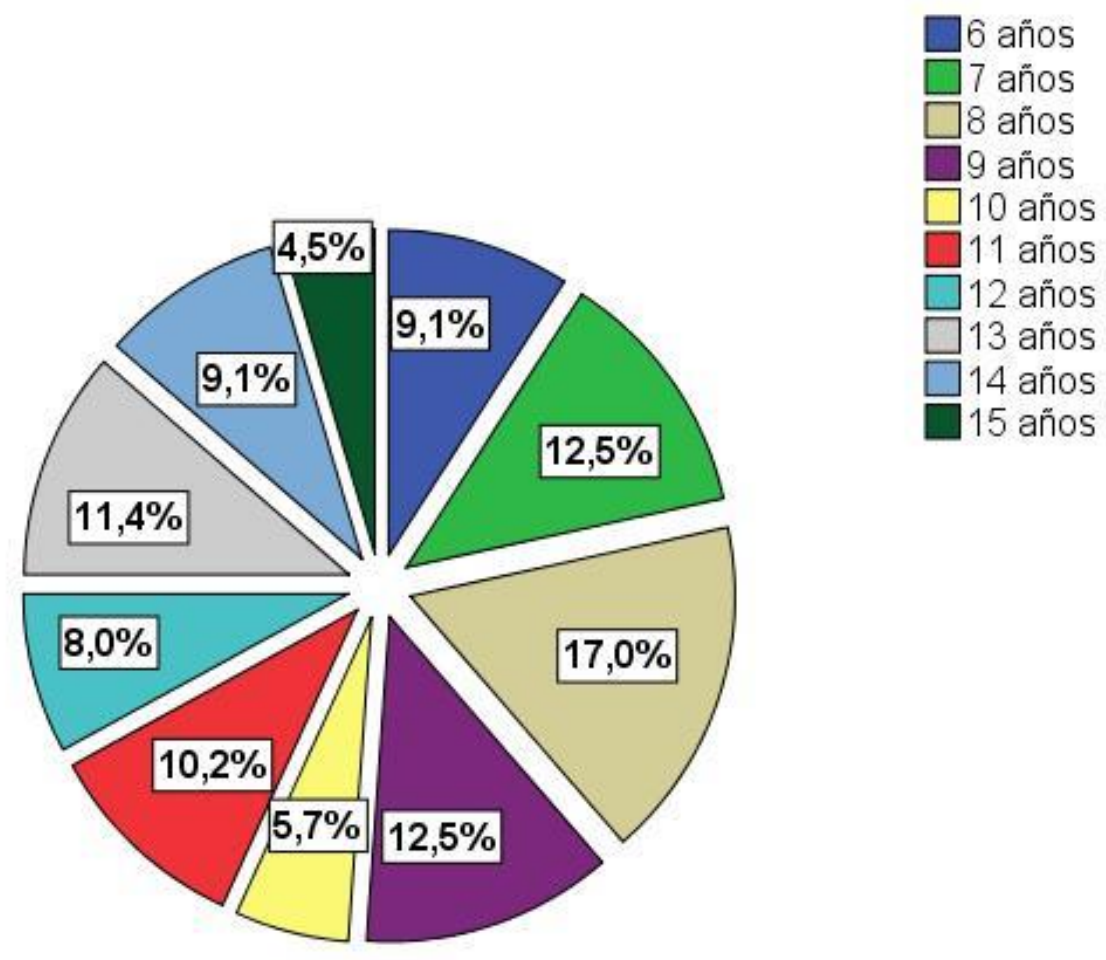

Fuente: Elaboración propia. 
Respecto de las etapas de desarrollo de los pacientes, en la siguiente tabla se presentan los recuentos, porcentajes y prueba de chi-cuadrado.

Tabla 6. Recuentos, porcentajes y chi-cuadrado para la deglución atípica con interposición lingual respecto de las categorías de desarrollo de los pacientes $(n=88)$.

\begin{tabular}{|c|c|c|c|}
\hline $\begin{array}{l}\text { Categoría } \\
\text { desarrollo }\end{array}$ & de $n$ & $\%$ & $\mathrm{x}^{2}$ \\
\hline Niñez & 45 & 51,1 & $x^{2}=0,045 ; \quad p=0,831$ \\
\hline Adolescencia & 43 & 48,9 & $1 \mathrm{gl}$ \\
\hline
\end{tabular}

Fuente: Elaboración propia.

Es decir, no se hallaron diferencias estadísticamente significativas ( $p>$ 0,05) al considerar las categorías de desarrollo de pacientes con interposición lingual. En la siguiente figura se representan los recuentos y porcentajes de la anterior tabla para las categorías de desarrollo en la interposición lingual. 
Figura 30. Porcentajes asociados a los pacientes con interposición lingual según las categorías de desarrollo $(n=88)$.

$\square$ Niñez

Adolescencia
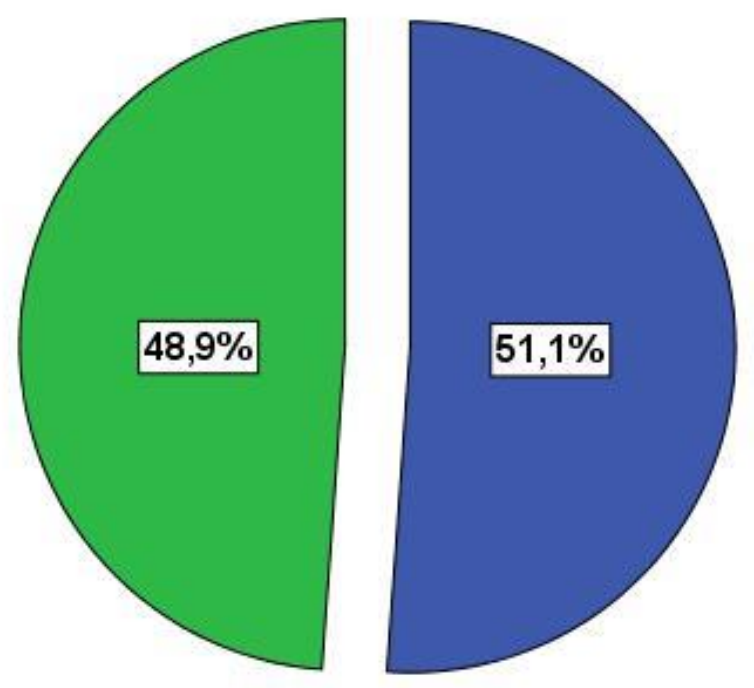

Fuente: Elaboración propia.

Respecto del género, en la siguiente tabla se presentan los recuentos, porcentajes y prueba de chi-cuadrado. 
Tabla 7. Recuentos, porcentajes y chi-cuadrado para la deglución atípica con interposición lingual respecto del género de los pacientes $(n=88)$.

\begin{tabular}{lllll}
\hline Género & $\mathbf{n}$ & $\%$ & $\mathbf{X}^{2}$ & \\
\hline Femenino & 53 & 60,2 & $\mathrm{x}^{2}=3,682 ; \quad \mathrm{p}=0,055 ;$ \\
\hline Masculino & 35 & 39,8 & $1 \mathrm{gl}$ & \\
\hline
\end{tabular}

Fuente: Elaboración propia.

Es decir, no se hallaron diferencias estadísticamente significativas ( $p>$ $0,05)$ al considerar el género de pacientes con interposición lingual. En la siguiente figura se representan los recuentos y porcentajes de la anterior tabla para el género en la interposición lingual. 
Figura 31. Porcentajes asociados a los pacientes con interposición lingual según su género $(n=88)$.

Femenino

Masculino

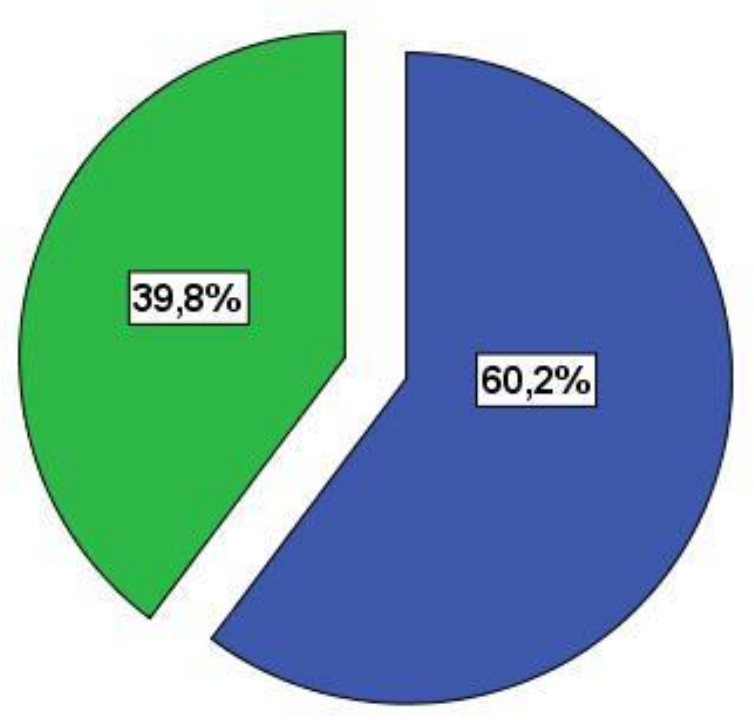

Fuente: Elaboración propia.

\subsubsection{Interposición labial}

Respecto de la interposición labial, en la siguiente tabla se presentan los recuentos y porcentajes asociados a las categorías etarias (la prueba de chicuadrado no se efectuó dados los recuentos $<5$ casos en todas las series de datos, esto siendo válido para los restantes factores demográficos). 
Tabla 8. Recuentos y porcentajes para la deglución atípica con interposición labial respecto de las categorías etarias $(n=4)$.

\begin{tabular}{lcc}
\hline Categoría etaria (años) & $\mathbf{n}$ & $\%$ \\
\hline 6 & 1 & 25,0 \\
\hline 7 & 2 & 50,0 \\
\hline 9 & 1 & 25,0 \\
\hline
\end{tabular}

Fuente: Elaboración propia.

Si bien no resultó conveniente realizar la prueba de chi-cuadrado, puede interpretarse cierta equivalencia estadística entre los recuentos hallados. En la siguiente figura se representan tales recuentos y porcentajes de la anterior tabla para las categorías etarias en la interposición labial. 
Figura 32. Porcentajes asociados a los pacientes con interposición labial según las categorías etarias $(n=4)$.

$\square 7$ años

$\square 9$ años
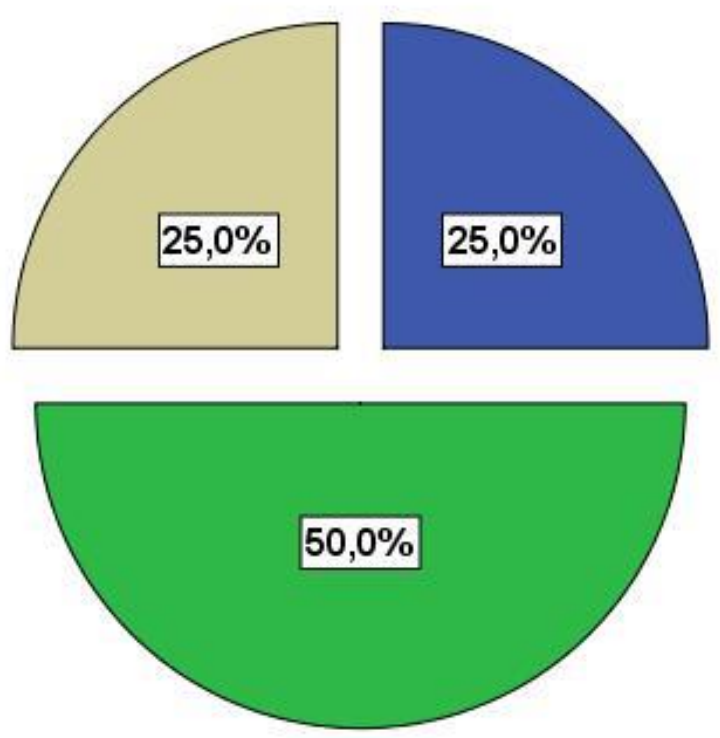

Fuente: Elaboración propia.

Respecto de las etapas de desarrollo de los pacientes, en la siguiente tabla se presentan los recuentos y porcentajes. 
Tabla 9. Recuentos y porcentajes para la deglución atípica con interposición labial respecto de las categorías de desarrollo de los pacientes $(n=4)$.

\begin{tabular}{lll}
\hline Categoría de desarrollo & $\mathbf{n}$ & $\%$ \\
\hline Niñez & 4 & 100,0 \\
\hline Adolescencia & 0 & 0,0 \\
\hline
\end{tabular}

Fuente: Elaboración propia.

En este caso, todos los pacientes con interposición labial fueron niños, no pudiendo realizar ningún análisis comparativo y, consecuentemente, siendo innecesario representan gráficamente tal resultado.

Respecto del género, en la siguiente tabla se presentan los recuentos y porcentajes.

Tabla 10. Recuentos y porcentajes para la deglución atípica con interposición labial respecto del género de los pacientes $(n=4)$.

\begin{tabular}{lll}
\hline Género & $\mathbf{n}$ & $\mathbf{\%}$ \\
\hline Femenino & 3 & 75,0 \\
\hline Masculino & 1 & 25,0 \\
\hline
\end{tabular}

Fuente: Elaboración propia. 
Nuevamente, si bien no resultó conveniente realizar la prueba de chicuadrado, puede interpretarse cierta equivalencia estadística entre los recuentos hallados. En la siguiente figura se representan tales recuentos y porcentajes de la anterior tabla para el género en la interposición labial.

Figura 33. Porcentajes asociados a los pacientes con interposición labial según su género $(n=4)$.

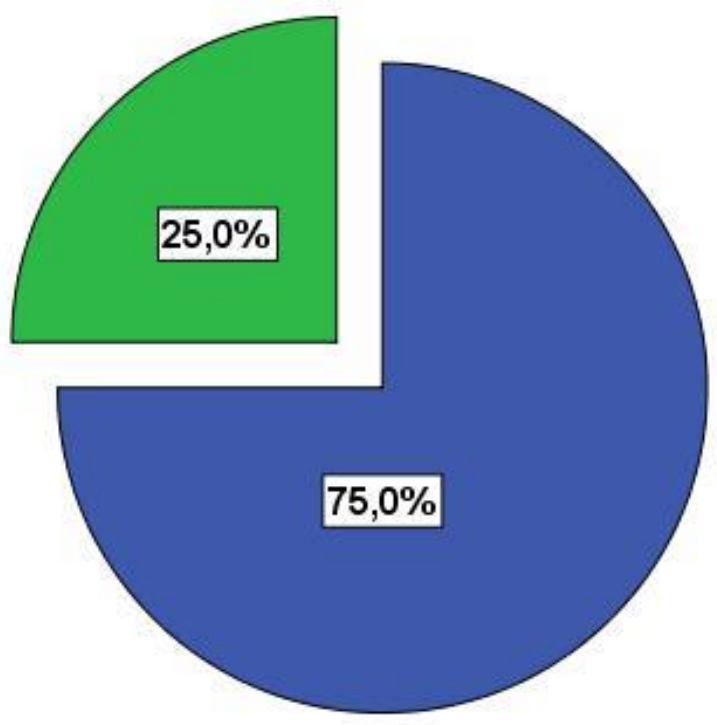

Fuente: Elaboración propia. 


\subsubsection{Interposición lingual y labial}

Respecto de la interposición lingual y labial, en la siguiente tabla se presentan los recuentos y porcentajes asociados a las categorías etarias, nuevamente no resultando conveniente realizar la prueba de chi-cuadrado dadas las series de datos con recuento $<5$, esto siendo válido para los restantes factores demográficos.

Tabla 11. Recuentos y porcentajes para la deglución atípica con interposición lingual y labial respecto de las categorías etarias $(n=8)$.

\begin{tabular}{lll}
\hline Categoría etaria (años) & $\mathbf{n}$ & $\%$ \\
\hline 6 & 1 & 12,5 \\
\hline 7 & 1 & 12,5 \\
\hline 9 & 2 & 25,0 \\
\hline 10 & 1 & 12,5 \\
\hline 12 & 1 & 12,5 \\
\hline 14 & 1 & 25,0 \\
\hline
\end{tabular}

Fuente: Elaboración propia. 
Si bien no resultó conveniente realizar la prueba de chi-cuadrado, puede interpretarse cierta equivalencia estadística entre los recuentos hallados. En la siguiente figura se representan tales recuentos y porcentajes de la anterior tabla para las categorías etarias en la interposición lingual y labial.

Figura 34. Porcentajes asociados a los pacientes con interposición lingual y labial según las categorías etarias $(n=8)$.

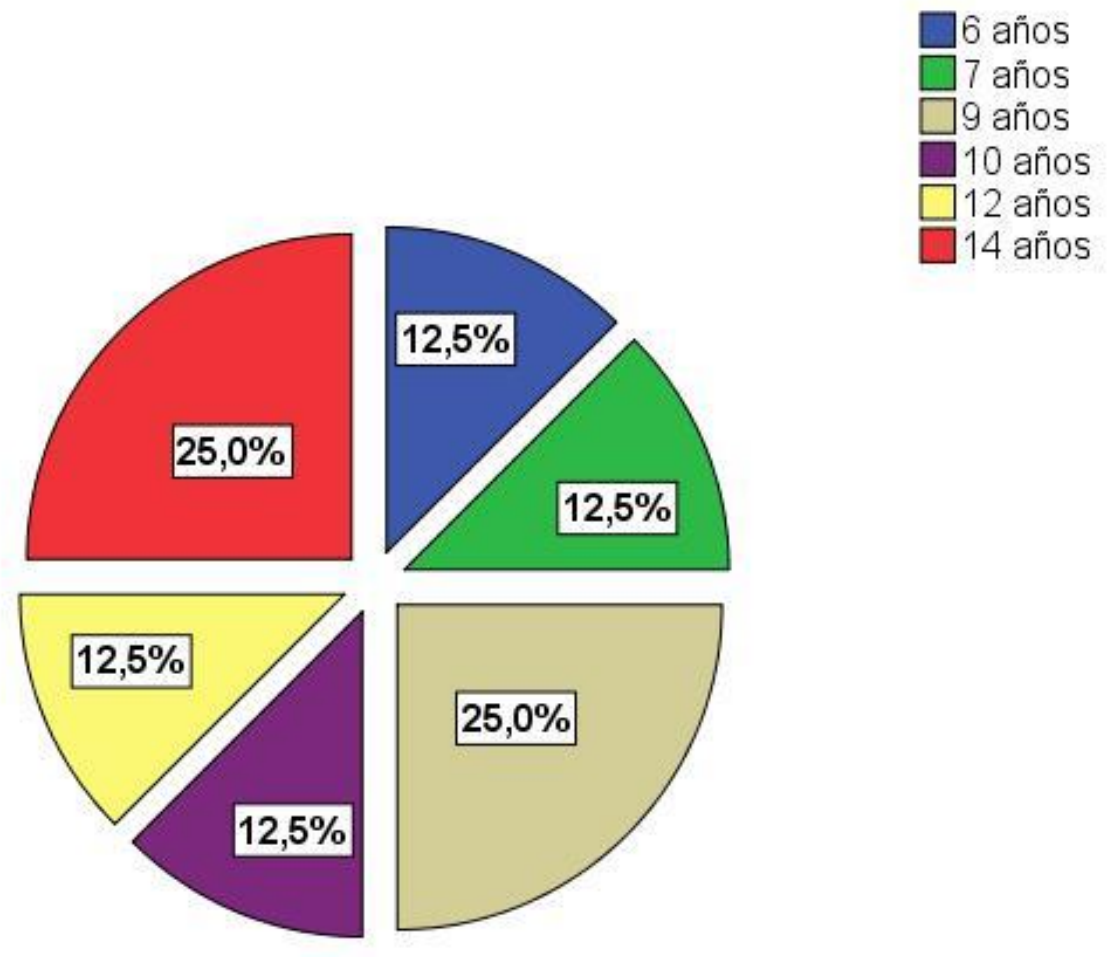

Fuente: Elaboración propia. 
Respecto de las etapas de desarrollo de los pacientes, en la siguiente tabla se presentan los recuentos y porcentajes.

Tabla 12. Recuentos y porcentajes para la deglución atípica con interposición lingual y labial respecto de las categorías de desarrollo de los pacientes $(n=8)$.

\begin{tabular}{lll}
\hline Categoría de desarrollo & $\mathrm{n}$ & $\%$
\end{tabular}

\begin{tabular}{lcc}
\hline Niñez & 4 & 50,0 \\
\hline Adolescencia & 4 & 50,0 \\
\hline
\end{tabular}

Fuente: Elaboración propia.

En este caso, si bien no resultó conveniente realizar la prueba de chicuadrado, la equivalencia estadística es totalmente justificable, dados los recuentos idénticos. En la siguiente figura se representan tales resultados. 
Figura 35. Porcentajes asociados a los pacientes con interposición lingual y labial según las categorías de desarrollo $(n=8)$.

$\square$ Niñez

Adolescencia
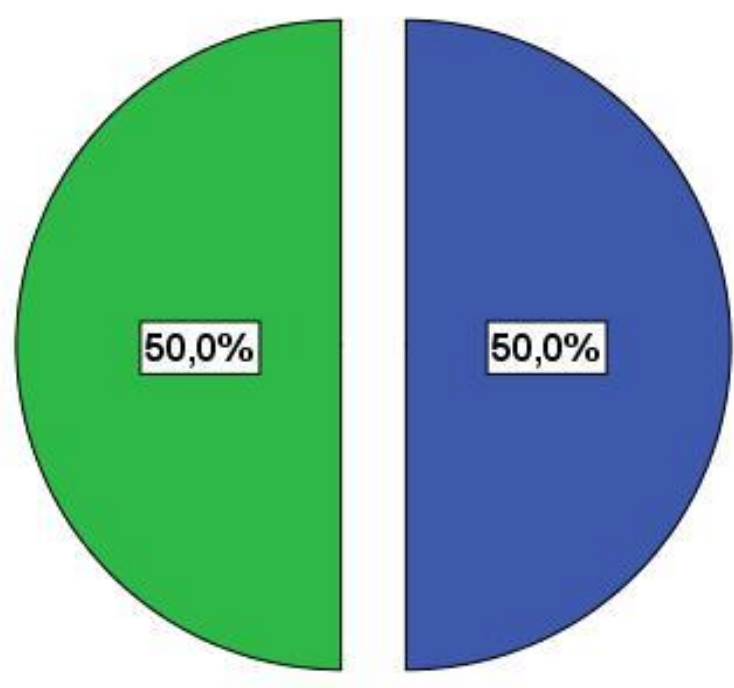

Fuente: Elaboración propia.

Respecto del género, en la siguiente tabla se presentan los recuentos y porcentajes. 
Tabla 13. Recuentos y porcentajes para la deglución atípica con interposición lingual y labial respecto del género de los pacientes $(n=8)$.

\begin{tabular}{lll}
\hline Género & $\mathbf{n}$ & $\%$ \\
\hline Femenino & 5 & 62,5 \\
\hline Masculino & 3 & 37,5 \\
\hline
\end{tabular}

Fuente: Elaboración propia.

Nuevamente, si bien no resultó conveniente realizar la prueba de chicuadrado, puede interpretarse cierta equivalencia estadística entre los recuentos hallados. En la siguiente figura se representan tales recuentos y porcentajes para el género en la interposición lingual y labial. 
Figura 36. Porcentajes asociados a los pacientes con interposición lingual y labial según su género $(n=8)$.

Femenino

Masculino

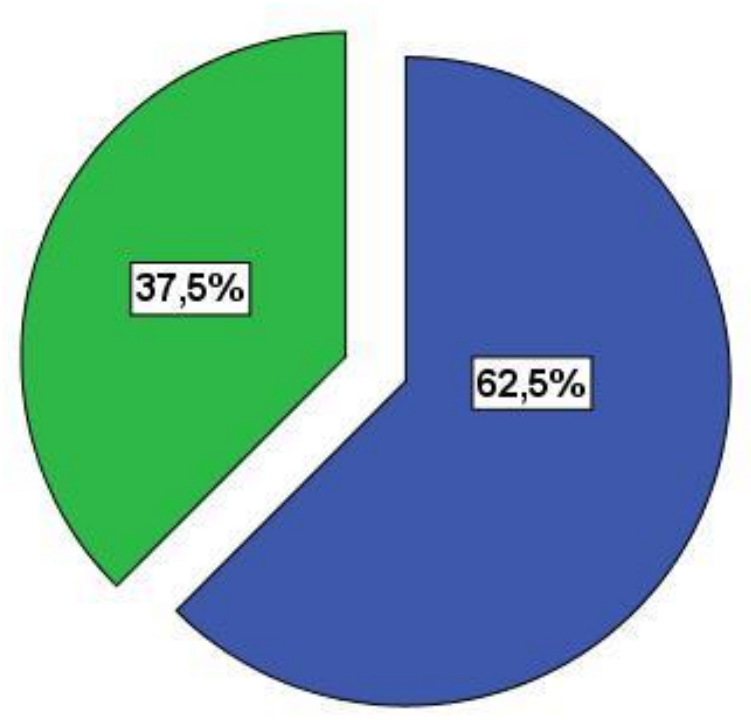

Fuente: Elaboración propia. 


\subsubsection{Clase/ relación molar y factores demográficos}

\subsubsection{Todas las clases/ relaciones molares}

Al igual que para el examen funcional, primero se realizó un análisis varianza (Kruskal-Wallis o U de Mann-Whitney) para evaluar las relaciones entre todas las clases/ relaciones molares y las categorías etarias, las categorías de desarrollo del paciente y su género. Así, en la siguiente tabla se presentan los análisis inferenciales correspondientes respecto de tales factores demográficos.

Tabla 14. ANOVA de Kruskal-Wallis y $\mathrm{U}$ de Mann-Whitney para las clases/ relaciones molares de la deglución atípica según las categorías etarias, el desarrollo del paciente y el género $(n=100)$.

\begin{tabular}{lll}
\hline Relación & Kruskal-Wallis & U de \\
& & Whitney \\
& & \\
\hline Clases molares/ & Categorías & $\mathrm{x}^{2}=18,338 ;$ \\
etarias & $\mathrm{p}=0,031^{*} ; 9 \mathrm{gl}$ & \\
\hline Clases molares/ Categorías de & - & $\mathrm{U}=1234,000 ;$ \\
desarrollo & & $\mathrm{p}=0,924$ \\
\hline Clases molares/ Género & - & $\mathrm{U}=1118,500 ;$ \\
& & $\mathrm{p}=0,547$ \\
\hline
\end{tabular}


Fuente: Elaboración propia.

Nota: * $p<0,05$.

En este sentido, solo para las categorías etarias se hallaron diferencias estadísticamente significativas $(p<0,05)$. Para el resto de las clases molares en pacientes con deglución atípica no se hallaron diferencias estadísticamente significativas respecto de las categorías de desarrollo ni el género $(p>0,05)$. Podría afirmarse que la clasificación molar es independiente de la etapa de desarrollo y el género de los pacientes con deglución atípica.

Sin embargo, en los siguientes subapartados se analizaron particularmente cada clase/ relación molar respecto de tales factores demográficos, a modo de corroboración de lo anterior hallado (y justificación de la relación significativa con las categorías etarias).

\subsubsection{Clase/ relación I}

Respecto de la Clase I, en la siguiente tabla se presentan los recuentos y porcentajes asociados a las categorías etarias, no efectuando la prueba de chi-cuadrado dados los recuentos $<5$ casos en todas las series de datos salvo dos de ellas, en las que las frecuencias fueron idénticas (5 casos). 
Tabla 15. Recuentos y porcentajes para la deglución atípica con Clase I molar respecto de las categorías etarias $(n=27)$.

\begin{tabular}{lcc}
\hline Categoría etaria (años) & $\mathbf{n}$ & $\%$ \\
\hline 6 & 5 & 18,5 \\
\hline 7 & 2 & 7,4 \\
\hline 8 & 4 & 14,8 \\
\hline 9 & 3 & 11,1 \\
\hline 10 & 2 & 7,4 \\
\hline 11 & 5 & 18,5 \\
\hline 13 & 4 & 14,8 \\
\hline 15 & 2 & 7,4 \\
\hline
\end{tabular}

Fuente: Elaboración propia.

Si bien no resultó conveniente realizar la prueba de chi-cuadrado, puede interpretarse cierta equivalencia estadística entre los recuentos hallados. En la siguiente figura se representan tales recuentos y porcentajes para las categorías etarias en la Clase I molar. 
Figura 37. Porcentajes asociados a los pacientes con Clase I molar según las categorías etarias $(n=27)$.

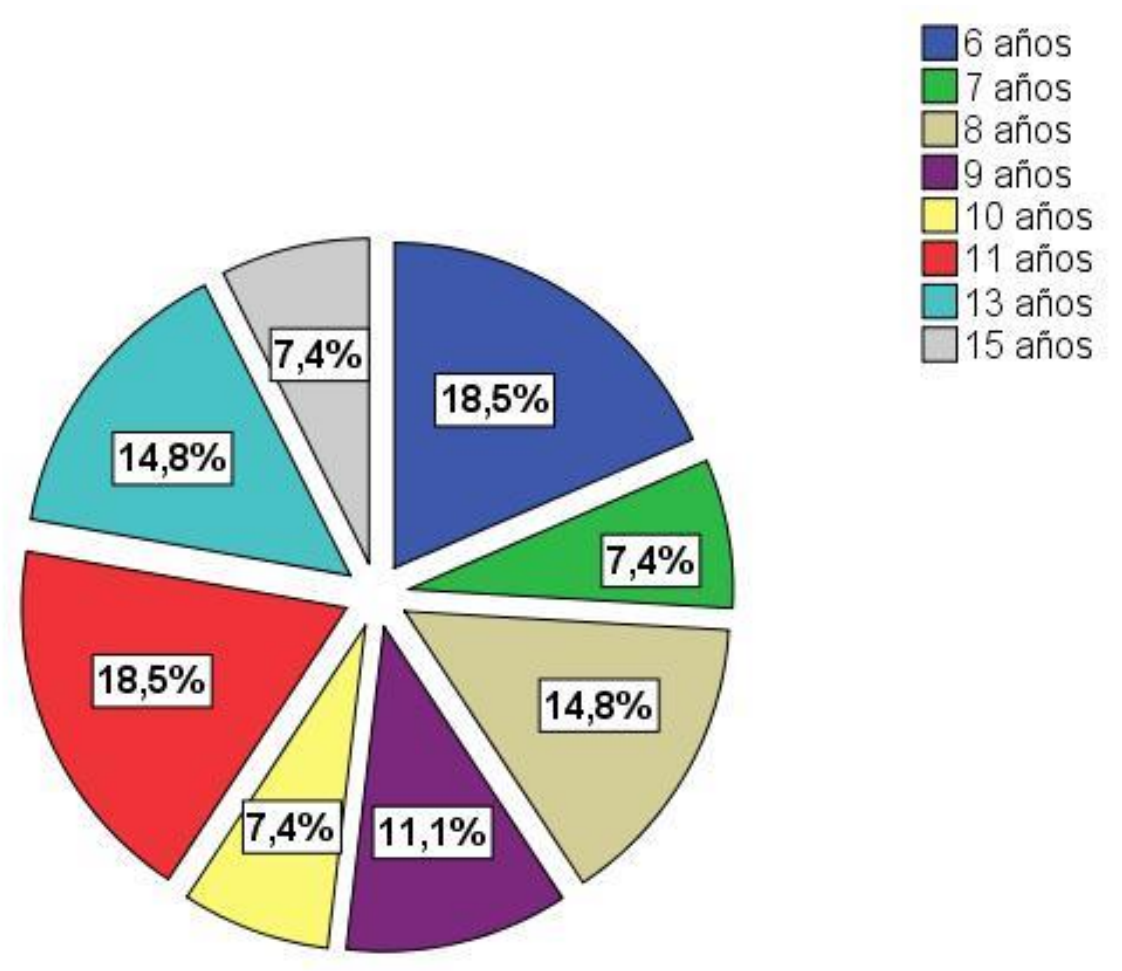

Fuente: Elaboración propia.

Respecto de las etapas de desarrollo de los pacientes, en la siguiente tabla se presentan los recuentos, porcentajes y prueba de chi-cuadrado. 
Tabla 16. Recuentos, porcentajes y chi-cuadrado para la deglución atípica con

Clase I molar respecto de las categorías de desarrollo de los pacientes $(n=27)$.

\begin{tabular}{lllll}
\hline Categoría & de & $\mathrm{n}$ & $\%$ & $\mathrm{X}^{2}$
\end{tabular}

desarrollo

\begin{tabular}{|c|c|c|c|}
\hline Niñez & 14 & 51,9 & $\mathrm{x}^{2}=0,037 ; \quad \mathrm{p}=0,847$ \\
\hline Adolescencia & 13 & 48,1 & $1 \mathrm{gl}$ \\
\hline
\end{tabular}

Fuente: Elaboración propia.

Es decir, no se hallaron diferencias estadísticamente significativas ( $p>$ $0,05)$ al considerar las categorías de desarrollo de pacientes con Clase I molar.

En la siguiente figura se representan los recuentos y porcentajes para las categorías de desarrollo en la Clase I molar. 
Figura 38. Porcentajes asociados a los pacientes con Clase I molar según las categorías de desarrollo $(n=27)$.

$\square$ Niñez

$\square$ Adolescencia

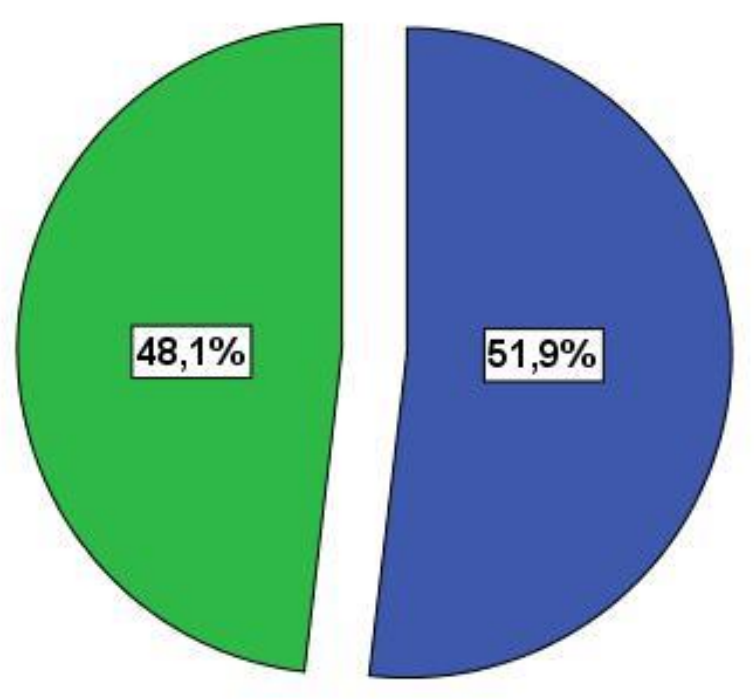

Fuente: Elaboración propia.

Respecto del género, en la siguiente tabla se presentan los recuentos, porcentajes y prueba de chi-cuadrado. 
Tabla 17. Recuentos, porcentajes y chi-cuadrado para la deglución atípica con Clase I molar respecto del género de los pacientes $(n=27)$.

\begin{tabular}{lllll}
\hline Género & $\mathbf{n}$ & $\%$ & $\mathbf{X}^{2}$ & \\
\hline Femenino & 17 & 63,0 & $\mathrm{X}^{2}=1,815 ; \quad \mathrm{p}=0,178 ;$ \\
& & & $1 \mathrm{gl}$ & \\
\hline Masculino & 10 & 37,0 & & \\
\hline
\end{tabular}

Fuente: Elaboración propia.

Es decir, no se hallaron diferencias estadísticamente significativas ( $p>$ $0,05)$ al considerar el género de pacientes con Clase I molar. En la siguiente figura se representan los recuentos y porcentajes para el género en la Clase I molar. 
Figura 39. Porcentajes asociados a los pacientes con Clase I molar según su género $(n=27)$.

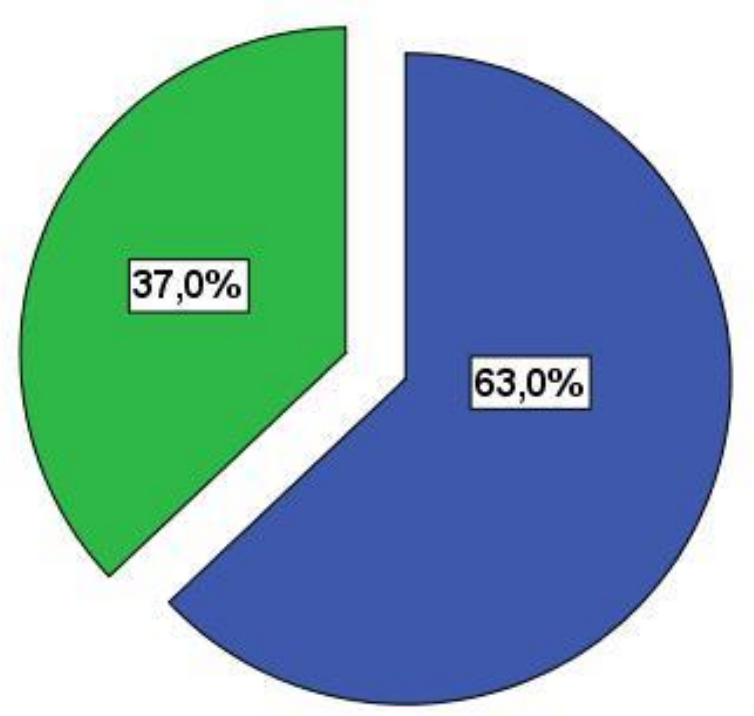

Fuente: Elaboración propia.

\subsubsection{Clase/ relación II}

Respecto de la Clase II, en la siguiente tabla se presentan los recuentos, porcentajes y prueba de chi-cuadrado asociados a las categorías etarias. 
Tabla 18. Recuentos, porcentajes y prueba de chi-cuadrado para la deglución atípica con Clase II molar respecto de las categorías etarias $(n=66)$.

\begin{tabular}{|c|c|c|c|}
\hline $\begin{array}{l}\text { Categoría etaria } \\
\text { (años) }\end{array}$ & $\mathbf{n}$ & $\%$ & $\mathrm{x}^{2}$ \\
\hline 6 & 5 & 7,6 & $x^{2}=4,281 ; \quad p=0,639$ \\
\hline 7 & 12 & 18,2 & $6 \mathrm{gl}^{*}$ \\
\hline 8 & 10 & 15,2 & \\
\hline 9 & 9 & 13,6 & \\
\hline 10 & 3 & 4,5 & \\
\hline 11 & 4 & 6,1 & \\
\hline 12 & 7 & 10,6 & \\
\hline 13 & 6 & 9,1 & \\
\hline 14 & 8 & 12,1 & \\
\hline 15 & 2 & 3,0 & \\
\hline
\end{tabular}

Fuente: Elaboración propia.

Nota: * La prueba de chi-cuadrado se efectuó depreciando las series de datos de 10, 11 y 15 años, dados los recuentos $<5$ casos.

Es decir, no se hallaron diferencias estadísticamente significativas ( $p>$ $0,05)$ al considerar las categorías etarias de pacientes con Clase II molar. En la siguiente figura se representan tales recuentos y porcentajes para las categorías etarias en la Clase II molar. 
Figura 40. Porcentajes asociados a los pacientes con Clase II molar según las categorías etarias $(n=66)$.

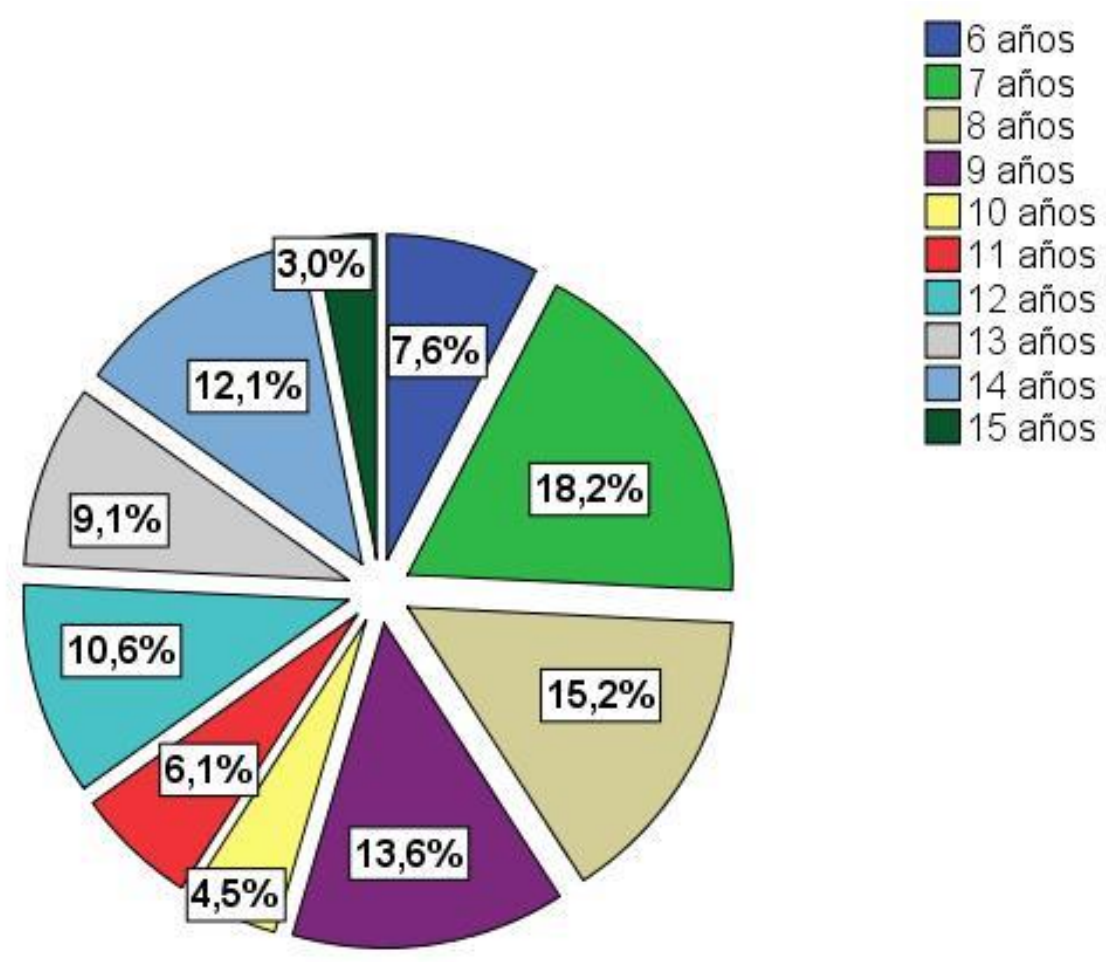

Fuente: Elaboración propia.

Respecto de las etapas de desarrollo de los pacientes, en la siguiente tabla se presentan los recuentos, porcentajes y prueba de chi-cuadrado. 
Tabla 19. Recuentos, porcentajes y chi-cuadrado para la deglución atípica con

Clase II molar respecto de las categorías de desarrollo de los pacientes $(n=66)$.

\begin{tabular}{lllll}
\hline Categoría & de & $\mathrm{n}$ & $\%$ & $\mathrm{X}^{2}$
\end{tabular}

desarrollo

\begin{tabular}{|c|c|c|c|}
\hline Niñez & 36 & 54,5 & $x^{2}=0,545 ; \quad p=0,460$ \\
\hline Adolescencia & 30 & 45,5 & $1 \mathrm{gl}$ \\
\hline
\end{tabular}

Fuente: Elaboración propia.

Es decir, no se hallaron diferencias estadísticamente significativas ( $p>$ $0,05)$ al considerar las categorías de desarrollo de pacientes con Clase II molar.

En la siguiente figura se representan los recuentos y porcentajes para las categorías de desarrollo en la Clase II molar. 
Figura 41. Porcentajes asociados a los pacientes con Clase II molar según las categorías de desarrollo $(n=66)$.

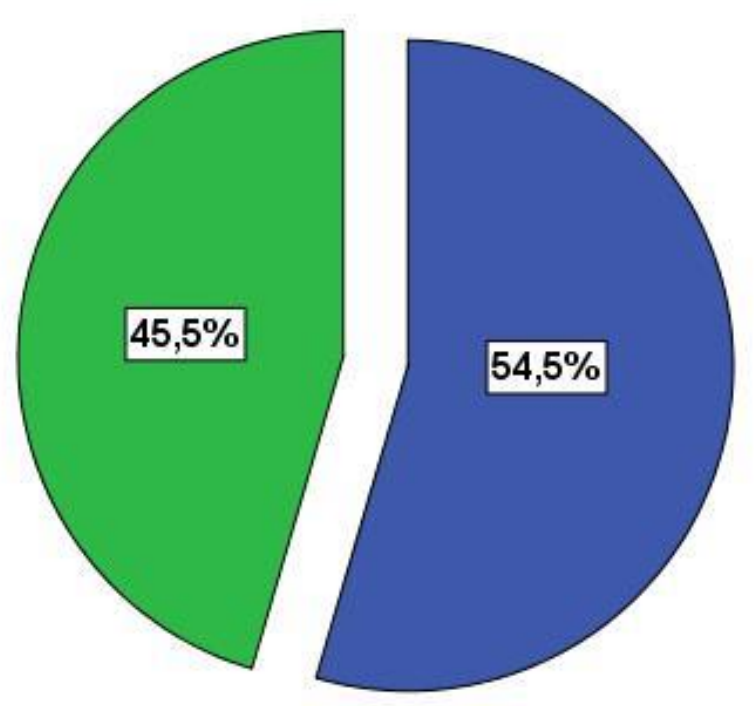

Fuente: Elaboración propia.

Respecto del género, en la siguiente tabla se presentan los recuentos, porcentajes y prueba de chi-cuadrado. 
Tabla 20. Recuentos, porcentajes y chi-cuadrado para la deglución atípica con Clase II molar respecto del género de los pacientes $(n=66)$.

\begin{tabular}{lllll}
\hline Género & $\mathbf{n}$ & $\%$ & $\mathbf{X}^{2}$ & \\
\hline Femenino & 41 & 62,1 & $\mathrm{X}^{2}=3,879 ; \quad \mathrm{p}=0,049 ;$ \\
& & & $1 \mathrm{gl}^{*}$ & \\
\hline Masculino & 25 & 37,9 & & \\
\hline
\end{tabular}

Fuente: Elaboración propia.

Nota: * $p<0,05$.

Es decir, se hallaron diferencias estadísticamente significativas $(p<$ $0,05)$, las cuales se justificaron a partir de la mayor y significativa cantidad de pacientes de género femenino, en comparación con el masculino ante la Clase II molar. En la siguiente figura se representan los recuentos y porcentajes para el género en la Clase II molar. 
Figura 42. Porcentajes asociados a los pacientes con Clase II molar según su género $(n=66)$.

\section{Femenino}

Masculino

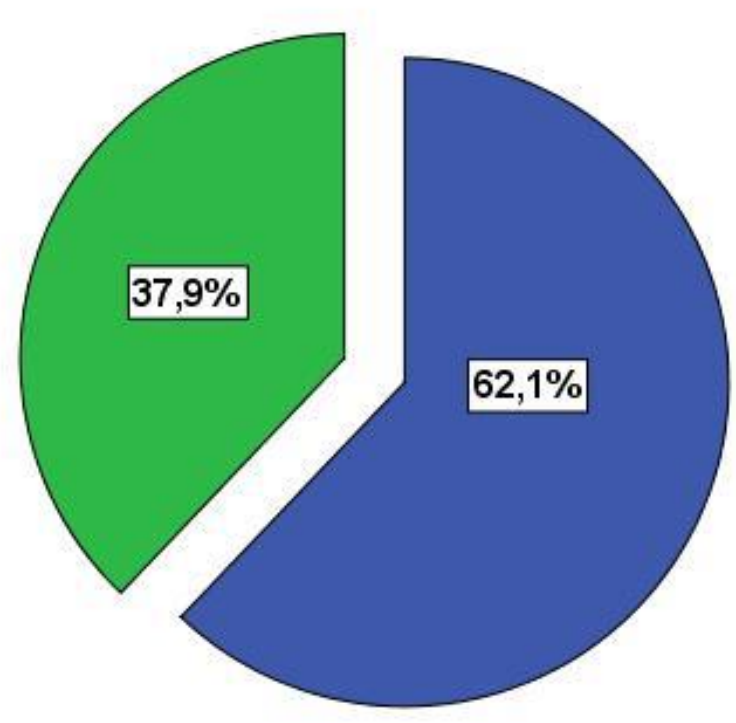

Fuente: Elaboración propia.

\subsubsection{Clase/ relación III}

Respecto de la Clase III, en la siguiente tabla se presentan los recuentos y porcentajes asociados a las categorías etarias, no resultando conveniente realizar la prueba de chi-cuadrado dadas las series de datos con recuento $<5$, esto siendo válido para los restantes factores demográficos. 
Tabla 21. Recuentos y porcentajes para la deglución atípica con Clase III molar respecto de las categorías etarias $(n=7)$.

\begin{tabular}{lcc}
\hline Categoría etaria (años) & $\mathbf{n}$ & $\mathbf{\%}$ \\
\hline 8 & 1 & 14,3 \\
\hline 9 & 2 & 28,6 \\
\hline 10 & 1 & 14,3 \\
\hline 12 & 1 & 14,3 \\
\hline 14 & 2 & 28,6 \\
\hline
\end{tabular}

Fuente: Elaboración propia.

Si bien no resultó conveniente realizar la prueba de chi-cuadrado, puede interpretarse cierta equivalencia estadística entre los recuentos hallados. En la siguiente figura se representan tales recuentos y porcentajes para las categorías etarias en la Clase III molar. 
Figura 43. Porcentajes asociados a los pacientes con Clase III molar según las categorías etarias $(n=7)$.

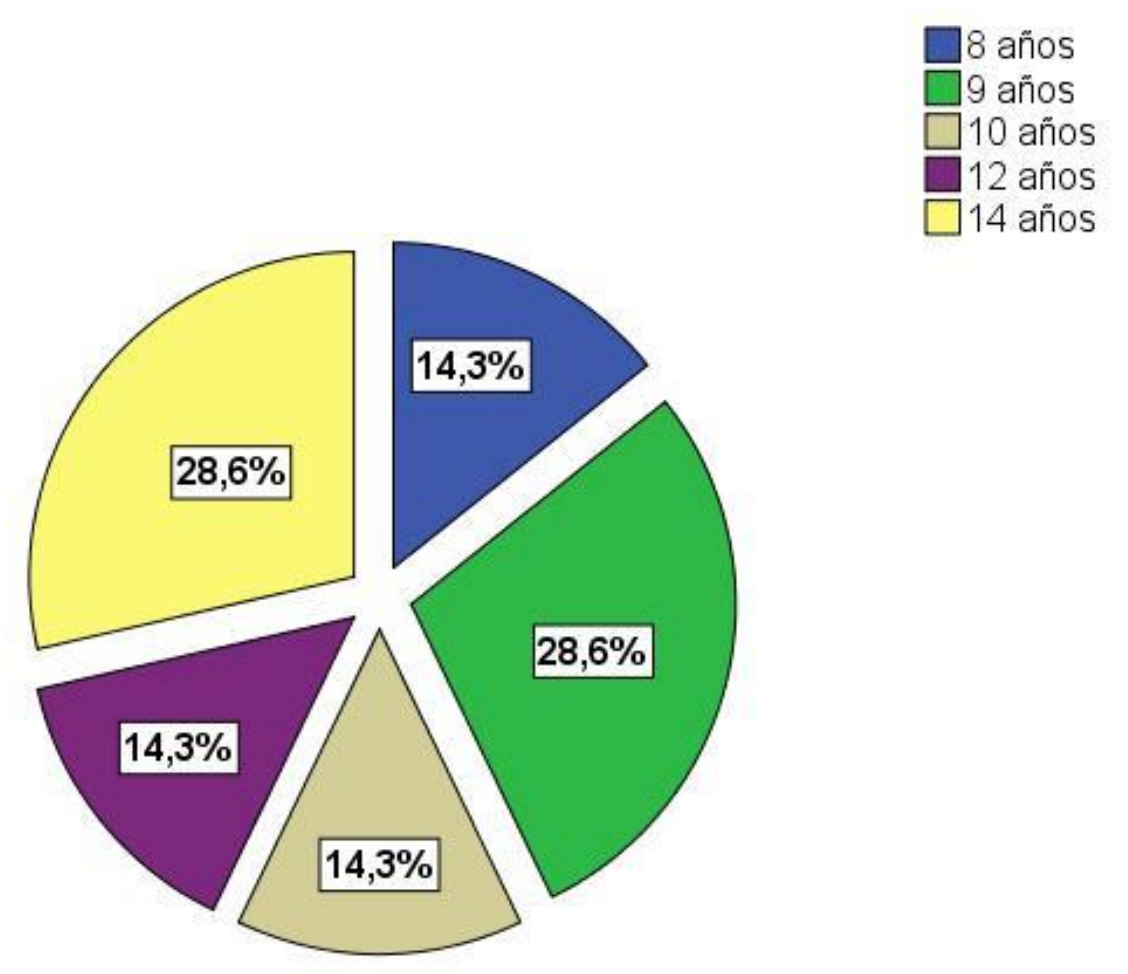

Fuente: Elaboración propia.

Respecto de las etapas de desarrollo de los pacientes, en la siguiente tabla se presentan los recuentos y porcentajes. 
Tabla 22. Recuentos y porcentajes para la deglución atípica con Clase III molar respecto de las categorías de desarrollo de los pacientes $(n=7)$.

\begin{tabular}{lcc}
\hline Categoría de desarrollo & $\mathbf{n}$ & \% \\
\hline Niñez & 3 & 42,9 \\
\hline Adolescencia & 4 & 57,1 \\
\hline
\end{tabular}

Fuente: Elaboración propia.

Nuevamente, si bien no resultó conveniente realizar la prueba de chicuadrado, puede interpretarse cierta equivalencia estadística entre los recuentos hallados. En la siguiente figura se representan tales recuentos y porcentajes para las categorías de desarrollo de los pacientes con Clase III molar. 
Figura 44. Porcentajes asociados a los pacientes con Clase III molar según las categorías de desarrollo $(n=7)$.

Niñez

Adolescencia

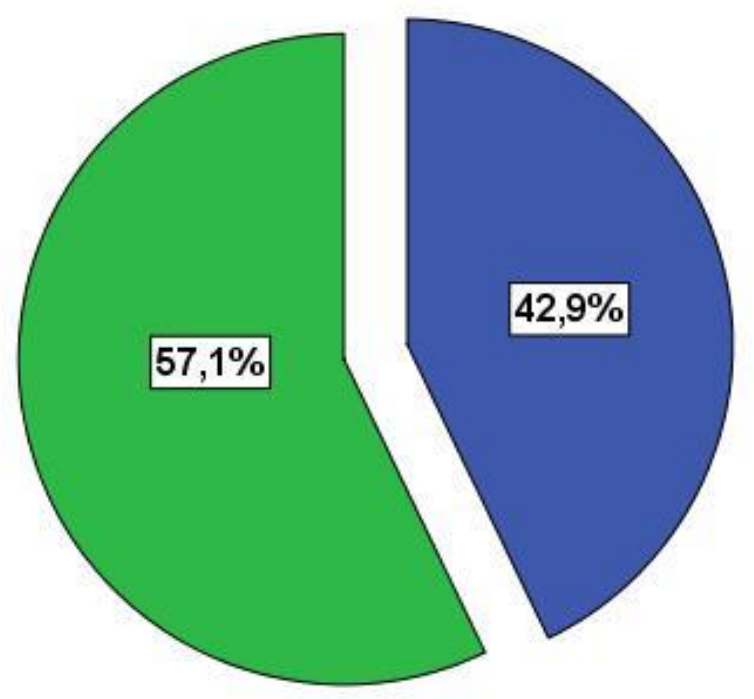

Fuente: Elaboración propia.

Respecto del género, en la siguiente tabla se presentan los recuentos y porcentajes. 
Tabla 23. Recuentos y porcentajes para la deglución atípica con Clase III molar respecto del género de los pacientes $(n=7)$.

\begin{tabular}{lcc}
\hline Género & $\mathbf{n}$ & \% \\
\hline Femenino & 3 & 42,9 \\
\hline Masculino & 4 & 57,1 \\
\hline
\end{tabular}

Fuente: Elaboración propia.

Al igual que para la etapa de desarrollo del individuo, si bien no resultó conveniente realizar la prueba de chi-cuadrado, puede interpretarse cierta equivalencia estadística entre los recuentos hallados. En la siguiente figura se representan tales recuentos y porcentajes para el género en la Clase III molar. 
Figura 45. Porcentajes asociados a los pacientes con Clase III molar según su género $(n=7)$.

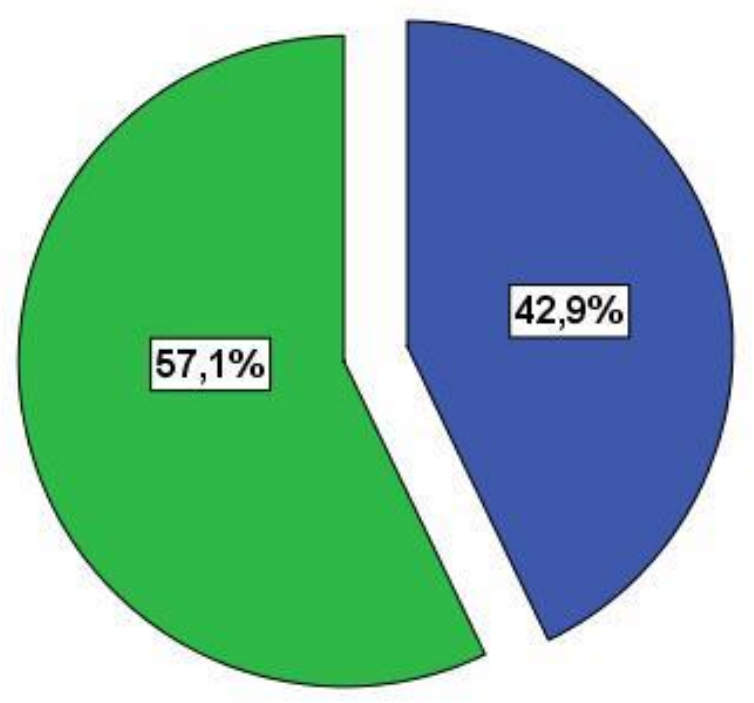

Fuente: Elaboración propia.

\subsubsection{Examen funcional y clase/ relación molar}

Desde lo general, el ANOVA de Kruskal-Wallis no arrojó relaciones estadísticamente significativas $(p>0,05)\left(x^{2}=2,339 ; p=0,310 ; 2 \mathrm{gl}\right)$, ello derivando en la interpretación de que no existen asociaciones significativas específicas entre las clases de interposiciones y las relaciones molares; en 
otras palabras, que en los pacientes con deglución atípica pueden presentarse cualquier tipo de interposición y cualquier clase molar.

Sin embargo, y según se ha desarrollado en los análisis anteriores, en los siguientes subapartados se realizaron cruzamientos particulares, tomando como variables dependientes tanto la clase molar como el tipo de interposición.

\subsubsection{Interposición lingual}

Respecto de la interposición lingual, en la siguiente tabla se presentan los recuentos, porcentajes y prueba de chi-cuadrado asociados a las clases molares.

Tabla 24. Recuentos, porcentajes y chi-cuadrado para la deglución atípica con interposición lingual respecto de las clases molares $(n=88)$.

\begin{tabular}{|c|c|c|c|}
\hline $\begin{array}{l}\text { Clasel } \\
\text { molar }\end{array}$ & relación $\mathbf{n}$ & $\%$ & $x^{2}$ \\
\hline I & 27 & 30,7 & $x^{2}=37,932 ; p=0,000$ \\
\hline II & 54 & 61,4 & $2 \mathrm{gl}^{*}$ \\
\hline III & 7 & 8,0 & \\
\hline
\end{tabular}

Fuente: Elaboración propia.

Nota: ${ }^{*} p<0,05$. 
Es decir, se hallaron diferencias estadísticamente significativas $(p<$ $0,05)$, las cuales se justificaron a partir de la mayor cantidad de pacientes con interposición lingual y Clase II molar, al hallar resultados similares cuando se comparó tal alternativa con la de frecuencia inmediata menor (Clase I molar) $\left(x^{2}=9,000 ; p=0,003 ; 1 \mathrm{gl}\right)$.

Los anteriores valores porcentuales se representan en la siguiente figura. 
Figura 46. Porcentajes asociados a los pacientes con interposición lingual según las clases molares $(n=88)$.

$\square$ Clase II

$\square$ Clase III

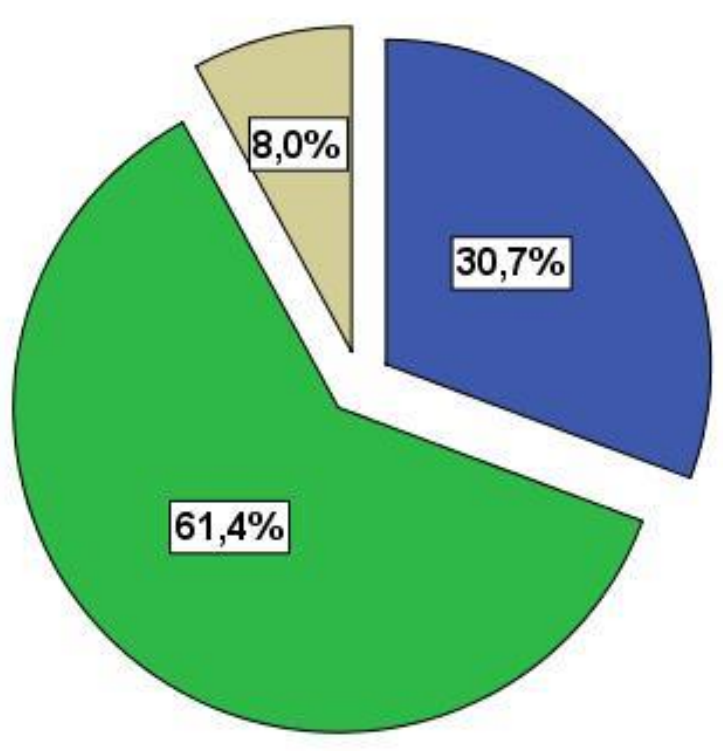

Fuente: Elaboración propia.

\subsubsection{Interposición labial}

Respecto de la interposición labial, en la siguiente tabla se presentan los recuentos y porcentajes asociados a las clases molares, no efectuando la prueba de chi-cuadrado dados los recuentos $<5$ casos en todas las series de datos. 
Tabla 25. Recuentos y porcentajes para la deglución atípica con interposición labial respecto de las clases molares $(n=4)$.

\begin{tabular}{lll}
\hline Clase/ relación molar & $\mathbf{n}$ & $\%$ \\
\hline I & 0 & 0,0 \\
\hline II & 4 & 100,0 \\
\hline III & 0 & 0,0 \\
\hline
\end{tabular}

Fuente: Elaboración propia.

Nota: * $p<0,05$.

Es decir, que todos los casos de deglución atípica con interposición lingual poseen Clase II molar. Ante esta correspondencia absoluta no resultó viable representar gráficamente los resultados.

\subsubsection{Interposición lingual y labial}

Respecto de la interposición lingual y labial, en la siguiente tabla se presentan los recuentos y porcentajes asociados a las clases molares, no efectuando la prueba de chi-cuadrado dados los recuentos $<5$ casos en todas las series de datos. 
Tabla 26. Recuentos y porcentajes para la deglución atípica con interposición lingual y labial respecto de las clases molares $(n=8)$.

\begin{tabular}{lll}
\hline Clase/ relación molar & $\mathbf{n}$ & $\%$ \\
\hline I & 0 & 0,0 \\
\hline II & 8 & 100,0 \\
\hline III & 0 & 0,0 \\
\hline
\end{tabular}

Fuente: Elaboración propia.

Nota: ${ }^{*} p<0,05$.

Es decir, que todos los casos de deglución atípica con interposición labial y lingual poseen Clase II molar. Ante esta correspondencia absoluta no resultó viable representar gráficamente los resultados.

\subsubsection{Clase/ relación I}

Respecto de la Clase I, en la siguiente tabla se presentan los recuentos y porcentajes asociados al tipo de interposición, no efectuando la prueba de chi-cuadrado dados los recuentos $<5$ casos dos de las series de datos. 
Tabla 27. Recuentos y porcentajes para la deglución atípica con Clase I molar respecto del tipo de interposición $(n=27)$.

\begin{tabular}{lll}
\hline Examen funcional & $\mathbf{n}$ & $\%$ \\
\hline Interposición lingual & 27 & 100,0 \\
\hline Interposición labial & 0 & 0,0 \\
\hline Interposición lingual y labial & 0 & 0,0 \\
\hline
\end{tabular}

Fuente: Elaboración propia.

De esta manera, no resultó factible desarrollar la prueba de chicuadrado, dado el recuento en una sola categoría. Por el mismo motivo, tampoco resultó viable representar gráficamente los resultados.

\subsubsection{Clase/ relación II}

Respecto de la Clase II, en la siguiente tabla se presentan los recuentos, porcentajes y prueba de chi-cuadrado asociados al tipo de interposición. 
Tabla 28. Recuentos, porcentajes y chi-cuadrado para la deglución atípica con

Clase II molar respecto del tipo de interposición $(n=66)$.

\begin{tabular}{|c|c|c|c|}
\hline Examen funcional & $\mathbf{n}$ & $\%$ & $x^{2}$ \\
\hline Interposición & 54 & 81,8 & $x^{2}=34,129 ; p=0,000$ \\
\hline lingual & & & $1 \mathrm{gl}^{* \dagger}$ \\
\hline Interposición labial & 4 & 6,1 & \\
\hline Interposición & 8 & 12,1 & \\
\hline lingual y labial & & & \\
\hline
\end{tabular}

Fuente: Elaboración propia.

Nota: * $p<0,05$; †La prueba de chi-cuadrado se efectuó depreciando la serie de datos de interposición labial, dado el recuento $<5$ casos.

Es decir, se hallaron diferencias estadísticamente significativas $(p<$ $0,05)$, las cuales se justificaron a partir de la mayor cantidad de pacientes con Clase II molar e interposición lingual.

Los anteriores valores porcentuales se representan en la siguiente figura. 
Figura 47. Porcentajes asociados a los pacientes con Clase II molar según el tipo de interposición $(n=66)$.

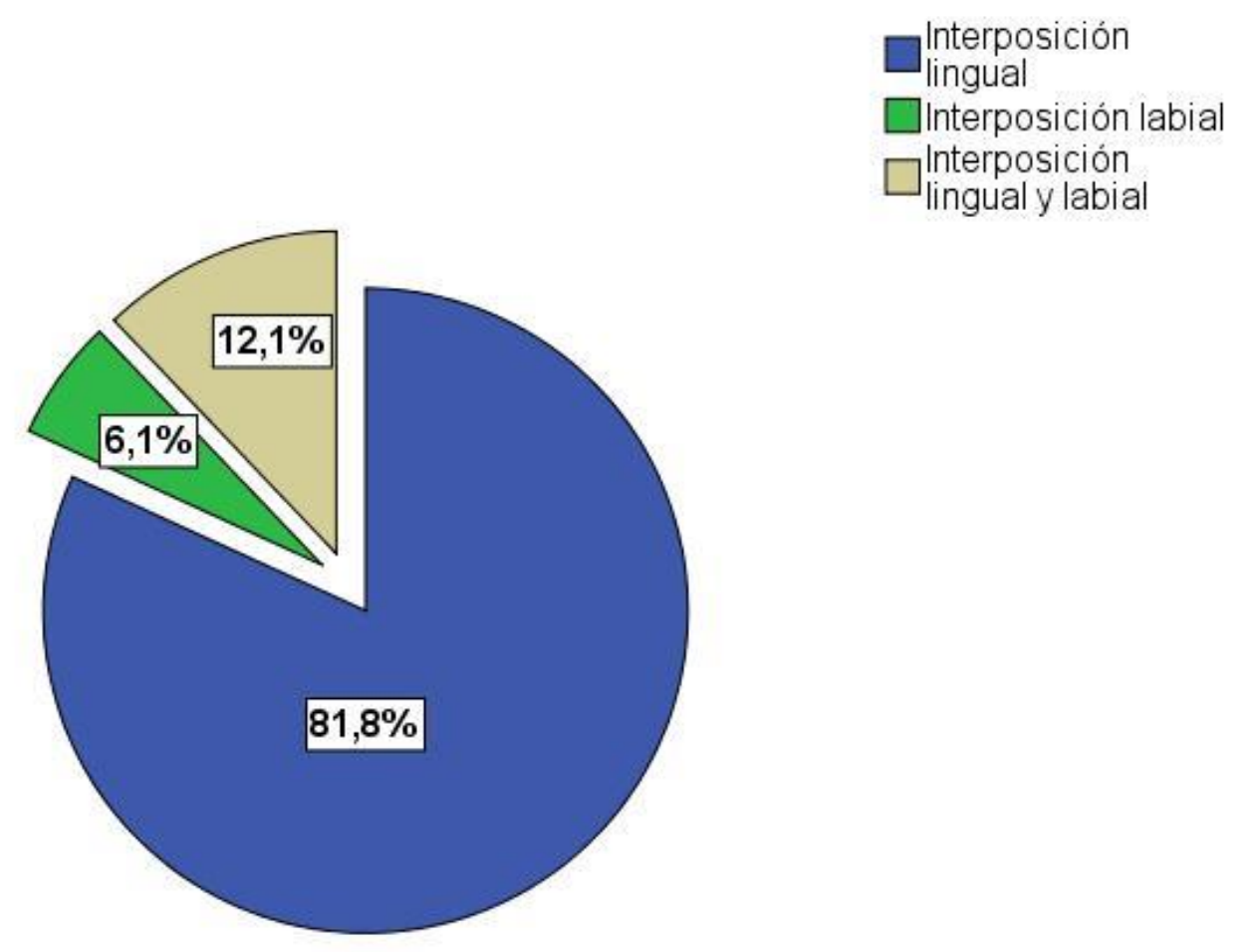

Fuente: Elaboración propia.

\subsubsection{Clase/ relación III}

Respecto de la Clase III, en la siguiente tabla se presentan los recuentos y porcentajes asociados al tipo de interposición, no efectuando la prueba de chi-cuadrado dados los recuentos $<5$ casos dos de las series de datos. 
Tabla 29. Recuentos y porcentajes para la deglución atípica con Clase IIII molar respecto del tipo de interposición $(n=7)$.

\begin{tabular}{lll}
\hline Examen funcional & $\mathbf{n}$ & $\%$ \\
\hline Interposición lingual & 7 & 100,0 \\
\hline Interposición labial & 0 & 0,0 \\
\hline Interposición lingual y labial & 0 & 0,0 \\
\hline
\end{tabular}

Fuente: Elaboración propia.

De esta manera, no resultó factible desarrollar la prueba de chicuadrado, dado el recuento en una sola categoría. Por el mismo motivo, tampoco resultó viable representar gráficamente los resultados. 


\section{DIscusióN}

Previamente al desarrollo de la discusión propiamente dicha, a continuación se puntualizan los principales hallazgos del presente estudio:

- La deglución atípica es independiente de la edad de los pacientes dentro del rango de 6-15 años.

- La deglución atípica es independiente de la etapa de desarrollo del paciente, considerando las categorías de niñez y adolescencia fundadas en la edad (36).

- La deglución atípica es más prevalente en pacientes de género femenino, en la relación aproximada de 1,5:1 con respecto al género masculino.

- La deglución atípica es prácticamente en su totalidad del tipo con interposición lingual, siendo la relación de aproximadamente 7:1 con respecto al resto de las variantes (interposición labial y lingual y labial, conjuntamente).

- La deglución atípica es estadística y significativamente de Clase II molar $(66,0 \%)$, seguida por Clase I $(27,0 \%)$. La relación con respecto a las clases I y III, conjuntamente, es de aproximadamente 2:1. 
- Si bien la deglución atípica se asoció mayormente con niñas y adolescentes femeninas, no sucedió lo mismo al considerar la edad cruzada con el género.

- La deglución atípica es más prevalente en adolescentes femeninas, en una relación aproximada de 2:1 en comparación con los adolescentes masculinos.

- La deglución atípica, según el examen funcional, es independiente de la edad categorizada, la etapa de desarrollo y el género del paciente.

- La deglución atípica, considerando las clases/ relaciones molares, es independiente de la edad categorizada, la etapa de desarrollo y el género del paciente; salvo en el caso de la Clase II molar, siendo ligeramente más prevalente en pacientes femeninos que en masculinos (relación aproximada de 1,5:1).

- La deglución atípica encuentra asociación significativa con la interposición lingual y la Clase II molar, en tanto una relación aproximada de 1,5:1 dentro del conjunto de interposiciones linguales y con respecto a las clases I y III molares en conjunto. Desde otro punto de vista, dicha asociación significativa puede expresarse en tanto una relación de 4,5:1 al considerar el conjunto de Clase II molar y comparar respecto de las interposiciones labial y lingual y labial conjuntamente.

- Todas los casos con deglución atípica de clase I y III molares poseen interposición lingual.

De esta manera, los resultados relacionados con la asociación significativa entre la deglución atípica y la Clase II molar son coincidentes con 
aquellos de los estudios relevados (9-12, 37); asimismo, con la interposición lingual $(38,39)$.

En otras palabras, la deglución atípica se asocia significativamente con la presencia de maloclusiones, las cuales derivan de diferencias en la actividad de distintos músculos; principalmente, mayor actividad de EMG de los músculos perioral, pero menor actividad EMG de los músculos masticatorios, y mayor actividad de EMG de los músculos masetero y temporal, pero menor actividad de los músculos perioralesdurante la mordida máxima en posición intercuspídea (11).

En este sentido, y con el fin primero de no solo corregir la sintomatología de la deglución atípica y lo funcional y estructural de las maloclusiones, sino de intentar evitar problemáticas de índole fonoaudiólogas (como alteraciones del habla) (39), resulta indispensable llevar a cabo estrategias de evaluación y manejo integral de la disfagia orofaríngea $(40,41)$. 


\section{Conclusiones}

Este subapartado se desarrolló considerando los justificativos de cumplimiento de los objetivos de la estudio, luego evaluando el estado de corroboración de la hipótesis de trabajo y, finalmente, realizando interpretaciones concluyentes, así como estableciendo lineamientos de investigación futura.

Así, respecto del objetivo general, que enunciaba, Establecer si existe relación entre deglución disfuncional y la clase molar, el trabajo de campo permitió identificar relaciones significativas entre las anteriores variables; precisamente, la deglución atípica se relaciona significativamente con la Clase II molar y, en menor medida, con la Clase I molar.

Por su parte, respecto del primer objetivo específico, que enunciaba, Evaluar epidemiológicamente las características demográficas, funcionales y clase molar de pacientes niños y adolescentes con deglución atípica, el mismo fue satisfecho a lo largo de todo el trabajo de campo, los justificativos particulares pudiéndose encontrar en aquellos de los siguientes objetivos específicos.

Así, respecto del segundo objetivo específico, que enunciaba, Evaluar asociaciones significativas entre la deglución atípica y características 
demográficas de los pacientes, no se hallaron correlaciones significativas con la edad particular ni el estado de desarrollo del paciente (niñez, adolescencia), pero sí con el género de los mismos, la deglución atípica siendo más prevalente en el género femenino y, más específicamente, en adolescentes de género femenino.

Respecto del tercer objetivo específico, que enunciaba, Evaluar asociaciones significativas entre la deglución atípica y los tipos de interposiciones, se halló que tal sintomatología se asocia significativamente con la interposición lingual, asociación fuerte hasta el punto que prácticamente todos los casos con deglución atípica poseen este tipo de interposición.

Respecto del cuarto objetivo específico, el cual enunciaba, Evaluar asociaciones significativas entre la deglución atípica y la clase molar, el mismo ya fue respondido al evaluar el cumplimiento del objetivo general.

Respecto del quinto objetivo específico, que enunciaba, Evaluar asociaciones significativas entre el tipo de interposición y la clase molar en pacientes con deglución atípica, se halló un correlación significativa entre la interposición lingual y la Clase II molar en los pacientes con deglución atípica, siendo también relevante que las clases I y III molar, todos los casos, se correspondieron con tal tipo de interposición.

Respecto del sexto y último objetivo específico, que enunciaba, Aportar datos epidemiológicos hacia el logro de la detección temprana del déficit funcional a fin de evitar mayores complicaciones, tales datos, factores de riesgo y comorbilidades, serían entonces: 
- Adolescentes femeninas.

- Interposición lingual.

- Clase II molar.

Con estos fundamentos epidemiológicos deberían conformarse estrategias de evaluación y tratamiento integral de la deglución atípica, como sintomatología dentro de la disfagia orofaríngea, ya que podría conllevar complicaciones patológicas como la neumonía aspirativa, desnutrición, deshidratación y obstrucción de la vía aérea.

Por ello, la detección temprana debería considerar las anteriores puntualizaciones, mientras que el tratamiento integral debería contemplar un abordaje multidisciplinario en el cual participen otorrinolaringólogos, fonoaudiólogos, nutricionistas, fisiatras, radiólogos, personal de enfermería y terapeutas ocupacionales y terapistas físicos.

Ello se plantea para las cuatro fases de la deglución: de preparación oral, oral, faríngea y esofágica; siempre entendiendo la deglución atípica no como una enfermedad, sino como una sintomatología que puede encontrarse en diversas patologías (neurogénicas, estructurales y/o respiratorias).

Respecto de la hipótesis de trabajo, que enunciaba, La deglución atípica incide en la clase molar, la misma fue corroborada, dada la ya reiteradamente mencionada relación significativa entre tal sintomatología y la Clase II molar.

Finalmente, como lineamientos de investigación futura, se plantean las siguientes proposiciones: 
- Realizar estudios sobre la prevalencia de la deglución atípica en poblaciones específicas determinadas principalmente por la edad, incluyendo adultos además de niños y adolescentes.

- Realizar estudios epidemiológicos con consideren la incidencia de comorbilidades en casos de deglución atípica, como ser neumonía aspirativa, desnutrición, deshidratación, obstrucción de la vía aérea y trastornos del habla.

- Realizar estudios prospectivos orientados a evaluar los efectos de estrategias de diagnóstico temprano de la deglución atípica considerando factores de riesgo epidemiológicos.

- Realizar estudios prospectivos orientados a evaluar los efectos de estrategias de tratamiento integral de la deglución atípica, considerando un abordaje multidisciplinario y factores de riesgo epidemiológicos. 


\section{BIBLIOGRAFÍA}

(1). Thibodeau GA, Patton KT. Estructura y función del cuerpo humano. $13^{a}$ ed. Barcelona: Elsevier; 2008.

(2). Silverthorn DU. Fisiología Humana. Un enfoque integrado. $4^{a}$ ed. Buenos Aires: Médica Panamericana; 2009.

(3). Serra S. Fonoaudiología. Aproximaciones logopédicas y audiológicas. Córdoba, Argentina: Brujas; 2007.

(4). Actis AB. Sistema estomatognático. Bases morfofuncionales aplicadas a La clínica. Buenos Aires: Médica Panamericana; 2014.

(5). Barrancos Mooney J, Barrancos PJ. Operatoria Dental. Integración clínica. 4ª ed. Buenos Aires: Médica Panamericana; 2006.

(6). Espinosa de la Sierra R. Diagnóstico Práctico de Oclusión. Atlas color. Ciudad de México: Médica Panamericana; 1995.

(7). BorrásSanchis S, Clari VR, coordinadores. Guía para la reeducación de la deglución atípica y trastornos asociados. Barcelona: Nau Libres; 2005.

(8). Hernández Sampieri R, Fernández-Collado C, Baptista Lucio P. Metodología de la investigación. $6^{a}$ ed. Ciudad de México: McGrawHill; 2010. 
(9). López Soto OP, López Soto LM, Osorio-Forero A, Restrepo F. Relación molar, actividad y fuerza muscular en escolares entre 7 y 12 años con deglución atípica. RevCienc Salud;15(3):373-85.

(10). Monaco A, Cattaneo R, Spadaro A, Marchetti E, Barone A. Prevalence of atypicalswallowing: a kinesiographicstudy. Eur J PaediatrDent. 2006;7(4):187-91.

(11). Störmer K, Pancherz H. Electromyography of theperioral and masticatorymuscles in orthodonticpatientswithatypicalswallowing. J OrofacOrthop. 1999;60(1):13-23.

(12). Monaco A, Cattaneo R, Spadaro A, Giannoni M. Surface electromyographypattern of human swallowing. BMC Oral Health. 2008;8:6.

(13). Carranza King MC. La ortopedia y su importancia en la prevención de maloclusiones. 2004; [1 página]. Disponible en: URL: http://www.icsmx.com/mundo-

dental/Editoriales/Editorial 05/editorial 05.html. Consultado Febrero 05, 2018.

(14). Queiroz IM. Deglución, diagnóstico y posibilidades terapéuticas. 1999; $[12$ páginas].

Disponible en: URL: http://www.sld.cu/galerias/pdf/sitios/rehabilitacion-logo/deglucion.pdf. Consultado Enero 18, 2018.

(15). Logemann JA. Evaluation and treatment of swallowingdisorders. $2^{a}$ ed. Austin: Pro-Ed; 1999.

(16). Moyers RE. Manual de Ortodoncia. $4^{\mathrm{a}}$ ed. Buenos Aires Médica Panamericana; 1992. 
(17). Elorza MP. Evaluación e incidencia de las alteraciones masticatoriodeglutorias en los trastornos instrumentales del habla. 1997; [20 páginas]. Disponible en: URL: http://www.sld.cu/galerias/pdf/sitios/rehabilitacionlogo/evaluacion de las alteraciones masticatorio.pdf. Consultado Febrero 05, 2018.

(18). Segovia ML. Interrelaciones entre la odontoestomatología y la fonoaudiología: la deglución atípica. $2^{\mathrm{a}}$ ed. Buenos Aires: Médica Panamericana, 1988.

(19). Rojas G, Brito H, Díaz J, Soto S, Alcedo C, Quirós O, et al. Tipo de Maloclusiones dentales más frecuentes en los pacientes del Diplomado de Ortodoncia Interceptiva de la Universidad Gran Mariscal de Ayacucho 2007-2008. RevLatinOrtodOdontoped[En línea] 2010: [1 página]. Disponible en: URL: https://www.ortodoncia.ws/publicaciones/2010/art-4/. Consultado Enero 11, 2018.

(20). Angle EH. Classification of themalocclusion. Dental Cosmos. 1899;41(3):248-264.

(21). Almandoz Calero AR. Clasificación de maloclusiones. [Trabajo Final de Grado]. Lima, Perú: Universidad Peruana Cayetano Heredia; 2011.

(22). Figún ME, Garino RR. Anatomía odontológica funcional y Aplicada. Buenos Aires: El Ateneo; 1992.

(23). Berkovitz BKB, Holland GR, Moxham BJ. Atlas en color y texto de anatomía oral: histología y embriología. $2^{\mathrm{a}}$ ed. Madrid: Mosby-Doyma Libros; 1995. 
(24). Suárez C, Gil-Carcedo LM, Marco J, Medina JE, Ortega P, Trinidad J. Tratado de Otorrinolaringología y Cirugía de Cabeza y Cuello. Enfermedades no oncológicas de la cavidad oral, glándulas salivales, faringe y laringe. Cirugía plástica y reconstrucción facial. Traumatología facial. $2^{\text {a }}$ ed. Tomo III. Buenos Aires: Médica Panamericana; 2008.

(25). Gregoret J. Ortodoncia y Cirugía Ortognática. Diagnóstico y planificación. Barcelona: Espaxs; 1997.

(26). Echarri Lobiondo P. Diagnóstico en Ortodoncia. Estudio multidisciplinario. Barcelona: Quintessence; 1992.

(27). Guardo AJ, Guardo CR. Ortodoncia. Buenos Aires: Mundi; 1981.

(28). Rakosi T, Jonas I. Atlas de ortopedia maxilar: diagnóstico. Barcelona: Ediciones Científicas y Técnicas; 1992.

(29). Quiros Álvarez OJ. Bases biomecánicas y aplicaciones clínicas en Ortodoncia Interceptiva. $4^{\mathrm{a}}$ ed. Bogotá: Amolca; 2006.

(30). Dawson PE. Centricrelation. Itseffect onoccluso-muscleharmony. DentClin North Am. 1979;23(2):169-80.

(31). Seoane Lorenzo M. Tratamiento y estabilidad en la mordida abierta. Revisión bibliográfica. [Trabajo Fin de Máster]. Oviedo, España: Universidad de Oviedo; 2014.

(32). Proffit WR, Fields HW. Ortodoncia: teoría y práctica. $2^{\mathrm{a}}$ ed. Barcelona: Mosby-Doyma Libros; 1996.

(33). McLaughlin RP, Bennett JC, Trevisi HJ. Mecánica sistematizada del tratamiento ortodóncico. Madrid: Elsevier; 2002. 
(34). Nie Q, Lin J. A comparison of dental archformsbetweenClass II Division 1 and normal occlusionassessedby Euclidean distancematrixanalysis. Am J OrthodDentofacialOrthop. 2006;129(4):528-35.

(35). Guisande González C, Barreiro Felpeto A, ManeiroEstraviz I, Riveiro Alarcón I, Vergara Castaño AR, Vaamonde Liste A. Tratamiento de datos. Madrid: Díaz de Santos; 2006.

(36). Organización Mundial de la Salud (OMS). Desarrollo en la adolescencia. 2018; [1 página]. Disponible en: URL: http://www.who.int/maternal child adolescent/topics/adolescence/dev/ es/. Consultado Abril 10, 2018.

(37). Camblor A, Cogorno V, Gutiérrez H, Veitia J, Jiménez Palacios C. Estudio retrospectivo de Maloclusiones frecuentes en infantes de 2 a 16 años de edad en el Centro Odontopediátrico de Carapa ubicado en la Parroquia Antímano - Caracas en el período 2000-2007. 2008; [1 página]. Disponible en: URL: https://www.ortodoncia.ws/publicaciones/2008/art-14/. Consultado Mayo 06, 2018.

(38). Mendoza Oropeza L, Meléndez Ocampo AF, Ortiz Sánchez R, Fernández López A. Prevalencia de las maloclusiones asociada con hábitos bucales nocivos en una muestra de mexicanos. RevMexOrtod. 2014;2(4):220-7.

(39). Elorza MP. Evaluación e incidencia de las alteraciones masticatoriodeglutorias en los trastornos instrumentales del habla. 1997; [15 páginas]. Disponible en: URL: 
http://www.sld.cu/galerias/pdf/sitios/rehabilitacion-

logo/evaluacion de las alteraciones masticatorio.pdf. Consultado Abril 17, 2018.

(40). Nazar G, Ortega A, Fuentealba I. Evaluación y manejo integral de la disfagia orofaríngea. RevMedClin Condes. 2009;20(4):449-57.

(41). Cámpora H, Falduti A. Evaluación y tratamiento de las alteraciones de la deglución. Rev Am MedResp. 2012;12(3):98-107. 


\section{ANEXOS DOCUMENTALES}

\section{A. Formulario del consentimiento informado}

\section{CONSENTIMIENTO INFORMADO PARA DATOS PERSONALES Y DE EXÁMENES FUNCIONAL}

Y DE CLASE MOLAR EN NIÑOS Y ADOLESCENTES CON DEGLUCIÓN ATÍPICA

Autorizo la realización a mi hijo/a, tutorado/a de exámenes funcionales para determinar la presencia de interposición labial, interposición lingual o interposición labial y lingual, y larelación/ clase molar (Clases I, II y III)y así determinar asociaciones entre la deglución atípica y los resultados de tales exámenes, así como con los datos demográficos (sexo y edad).

Se me ha explicado y he comprendido que esta actividad es no invasiva y totalmente inocua para el paciente, no representando una intervención experimental, sino como parte diagnóstica de la asistencia odontológica brindada en el consultorio. 
Fecha: A los días de de 2017.

Padre, Madre, Tutor/a:

Nombre y Apellido/s:

Firma:

Niño:

Nombre y Apellidos:

B. Ficha clínica

\section{DATOS GENERALES}

Nombre:

Edad: años.

Sexo:

Femenino 
Masculino

\section{EXAMEN FUNCIONAL}

Con interposición lingual

Con interposición labial

Con interposición labial y lingual

\section{EXAMEN DE LA CLASE MOLAR}

Anomalías en sentido sagital:

Clase I

Clase II $\square$

Clase III 


\section{Matriz de datos}

Tabla 30. Matriz de datos.

\begin{tabular}{llllll}
\hline Edad & $\begin{array}{l}\text { Categoría } \\
\text { etaria }\end{array}$ & $\begin{array}{l}\text { Categoría } \\
\text { adolescentes }\end{array}$ & Sexo & $\begin{array}{l}\text { Examen } \\
\text { funcional }\end{array}$ & Clase \\
molar
\end{tabular}




\begin{tabular}{|c|c|c|c|c|c|}
\hline Edad & $\begin{array}{l}\text { Categoría } \\
\text { etaria }\end{array}$ & $\begin{array}{l}\text { Categoría } \\
\text { adolescentes }\end{array}$ & Sexo & $\begin{array}{l}\text { Examen } \\
\text { funcional }\end{array}$ & $\begin{array}{l}\text { Clase } \\
\text { molar }\end{array}$ \\
\hline 9 & 4 & 1 & 1 & 1 & 2 \\
\hline 11 & 6 & 2 & 1 & 1 & 1 \\
\hline 10 & 5 & 2 & 1 & 1 & 2 \\
\hline 8 & 3 & 1 & 1 & 1 & 1 \\
\hline 11 & 6 & 2 & 2 & 1 & 1 \\
\hline 7 & 2 & 1 & 2 & 3 & 2 \\
\hline 10 & 5 & 2 & 2 & 1 & 2 \\
\hline 8 & 3 & 1 & 2 & 1 & 2 \\
\hline 7 & 2 & 1 & 1 & 1 & 2 \\
\hline 6 & 1 & 1 & 1 & 3 & 2 \\
\hline 9 & 4 & 1 & 1 & 2 & 2 \\
\hline 8 & 3 & 1 & 2 & 1 & 1 \\
\hline 6 & 1 & 1 & 1 & 2 & 2 \\
\hline 9 & 4 & 1 & 1 & 3 & 2 \\
\hline 8 & 3 & 1 & 2 & 1 & 2 \\
\hline 7 & 2 & 1 & 1 & 1 & 2 \\
\hline 7 & 2 & 1 & 1 & 2 & 2 \\
\hline 9 & 4 & 1 & 2 & 1 & 3 \\
\hline 7 & 2 & 1 & 1 & 1 & 2 \\
\hline 8 & 3 & 1 & 2 & 1 & 2 \\
\hline 8 & 3 & 1 & 2 & 1 & 1 \\
\hline 10 & 5 & 2 & 2 & 1 & 3 \\
\hline
\end{tabular}




\begin{tabular}{|c|c|c|c|c|c|}
\hline Edad & $\begin{array}{l}\text { Categoría } \\
\text { etaria }\end{array}$ & $\begin{array}{l}\text { Categoría } \\
\text { adolescentes }\end{array}$ & Sexo & $\begin{array}{l}\text { Examen } \\
\text { funcional }\end{array}$ & $\begin{array}{l}\text { Clase } \\
\text { molar }\end{array}$ \\
\hline 8 & 3 & 1 & 2 & 1 & 2 \\
\hline 7 & 2 & 1 & 1 & 1 & 2 \\
\hline 7 & 2 & 1 & 2 & 1 & 1 \\
\hline 8 & 3 & 1 & 1 & 1 & 2 \\
\hline 9 & 4 & 1 & 1 & 1 & 2 \\
\hline 9 & 4 & 1 & 2 & 1 & 1 \\
\hline 6 & 1 & 1 & 1 & 1 & 1 \\
\hline 9 & 4 & 1 & 1 & 1 & 2 \\
\hline 6 & 1 & 1 & 1 & 1 & 1 \\
\hline 6 & 1 & 1 & 2 & 1 & 2 \\
\hline 7 & 2 & 1 & 2 & 2 & 2 \\
\hline 7 & 2 & 1 & 1 & 1 & 2 \\
\hline 6 & 1 & 1 & 2 & 1 & 2 \\
\hline 9 & 4 & 1 & 1 & 1 & 1 \\
\hline 6 & 1 & 1 & 1 & 1 & 1 \\
\hline 9 & 4 & 1 & 2 & 3 & 2 \\
\hline 8 & 3 & 1 & 2 & 1 & 3 \\
\hline 8 & 3 & 1 & 2 & 1 & 1 \\
\hline 7 & 2 & 1 & 1 & 1 & 2 \\
\hline 9 & 4 & 1 & 2 & 1 & 3 \\
\hline 6 & 1 & 1 & 1 & 1 & 1 \\
\hline 8 & 3 & 1 & 2 & 1 & 2 \\
\hline
\end{tabular}




\begin{tabular}{|c|c|c|c|c|c|}
\hline Edad & $\begin{array}{l}\text { Categoría } \\
\text { etaria }\end{array}$ & $\begin{array}{l}\text { Categoría } \\
\text { adolescentes }\end{array}$ & Sexo & $\begin{array}{l}\text { Examen } \\
\text { funcional }\end{array}$ & $\begin{array}{l}\text { Clase } \\
\text { molar }\end{array}$ \\
\hline 7 & 2 & 1 & 1 & 1 & 2 \\
\hline 6 & 1 & 1 & 2 & 1 & 2 \\
\hline 7 & 2 & 1 & 2 & 1 & 2 \\
\hline 6 & 1 & 1 & 1 & 1 & 1 \\
\hline 8 & 3 & 1 & 1 & 1 & 2 \\
\hline 9 & 4 & 1 & 1 & 1 & 2 \\
\hline 7 & 2 & 1 & 1 & 1 & 2 \\
\hline 9 & 4 & 1 & 2 & 1 & 2 \\
\hline 7 & 2 & 1 & 2 & 1 & 1 \\
\hline 9 & 4 & 1 & 1 & 1 & 2 \\
\hline 11 & 6 & 2 & 1 & 1 & 2 \\
\hline 12 & 7 & 2 & 1 & 3 & 2 \\
\hline 14 & 9 & 2 & 2 & 1 & 2 \\
\hline 14 & 9 & 2 & 1 & 1 & 2 \\
\hline 13 & 8 & 2 & 2 & 1 & 2 \\
\hline 12 & 7 & 2 & 1 & 1 & 2 \\
\hline 15 & 10 & 2 & 2 & 1 & 2 \\
\hline 14 & 9 & 2 & 1 & 1 & 2 \\
\hline 15 & 10 & 2 & 1 & 1 & 1 \\
\hline 14 & 9 & 2 & 1 & 1 & 2 \\
\hline 14 & 9 & 2 & 1 & 3 & 2 \\
\hline 13 & 8 & 2 & 2 & 1 & 1 \\
\hline
\end{tabular}




\begin{tabular}{llllll}
\hline Edad & $\begin{array}{l}\text { Categoría } \\
\text { etaria }\end{array}$ & $\begin{array}{l}\text { Categoría } \\
\text { adolescentes }\end{array}$ & Sexo & $\begin{array}{l}\text { Examen } \\
\text { funcional }\end{array}$ & $\begin{array}{l}\text { Clase } \\
\text { molar }\end{array}$ \\
\hline 12 & 7 & 2 & 1 & 1 & 2 \\
\hline 12 & 7 & 2 & 2 & 1 & 2 \\
\hline 14 & 9 & 2 & 2 & 3 & 2 \\
\hline 12 & 7 & 2 & 1 & 1 & 2 \\
\hline 11 & 6 & 2 & 1 & 1 & 2 \\
\hline 11 & 6 & 2 & 2 & 1 & 1 \\
\hline 12 & 7 & 2 & 1 & 1 & 2 \\
\hline 15 & 10 & 2 & 1 & 1 & 1 \\
\hline 13 & 8 & 2 & 1 & 1 & 2 \\
\hline 8 & 3 & 1 & 2 & 1 & 2 \\
\hline 12 & 7 & 2 & 1 & 1 & 3 \\
\hline 14 & 9 & 2 & 2 & 1 & 2 \\
\hline 11 & 6 & 2 & 1 & 1 & 2 \\
\hline 12 & 7 & 2 & 2 & 1 & 2 \\
\hline 13 & 8 & 2 & 1 & 1 & 2 \\
\hline 15 & 10 & 2 & 2 & & 1 \\
\hline 14 & 9 & 2 & & & 1 \\
\hline
\end{tabular}

Fuente: Elaboración propia.

Categorías: Etaria: $1=6$ años, $2=7$ años, $3=8$ años, $4=9$ años, $5=10$ años, $6=11$ años, $7=12$ años, 8=13 años, 9=14 años, 10=15 años; Adolescentes: 1=Niñez, 2=Adolescencia; Sexo: 1=Femenino, 2=Masculino; Examen funcional: 1=Interposición lingual, 2=Interposición labial, $3=$ Interposición lingual y labial; Clase molar: 1=Clase I, 2=Clase II, 3=Clase III. 